\title{
The Propagation of Neurodegenerative Diseases by Inflammation and Exosomes
}

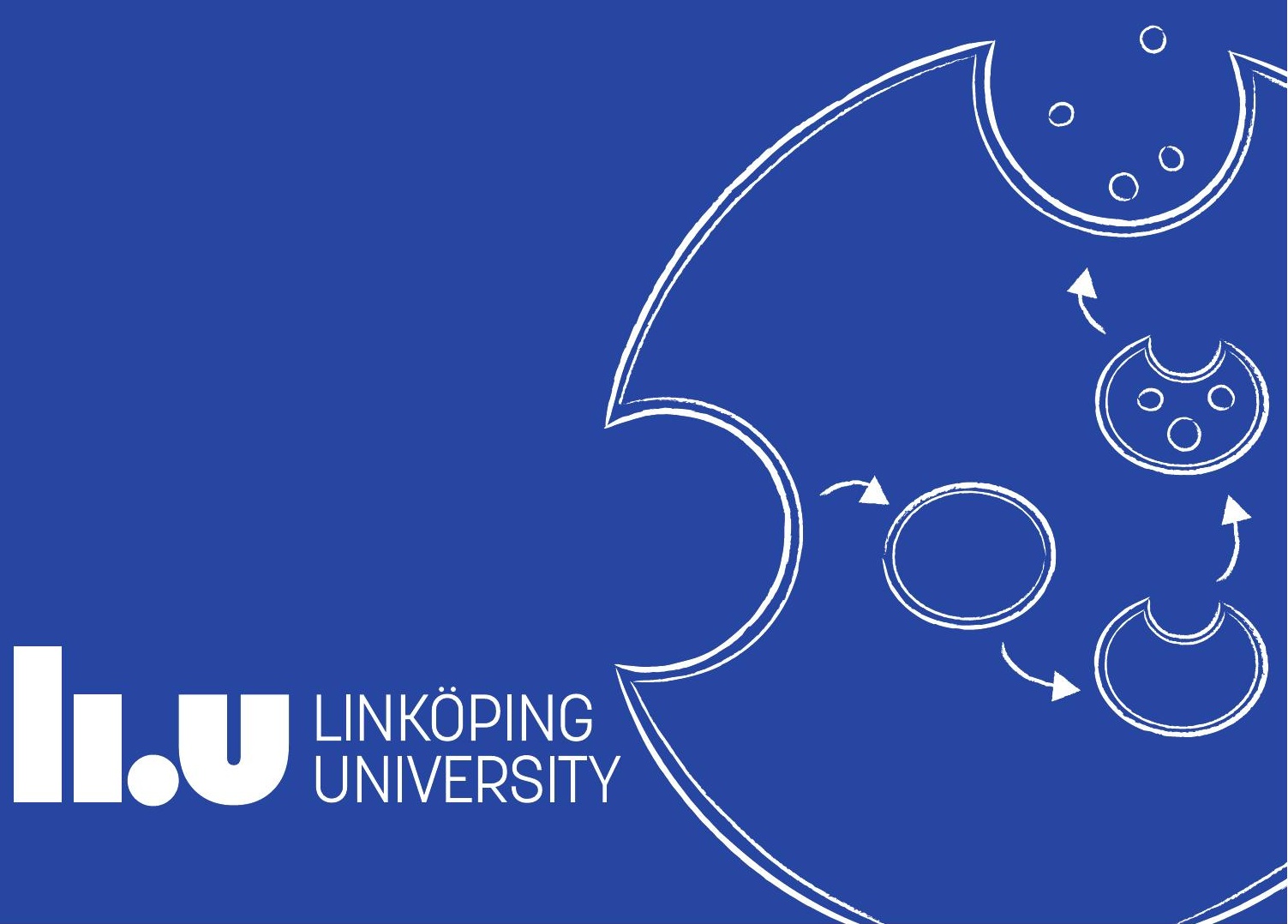




\title{
The Propagation of Neurodegenerative Diseases by Inflammation and Exosomes
}

\author{
Valerie Sackmann
}

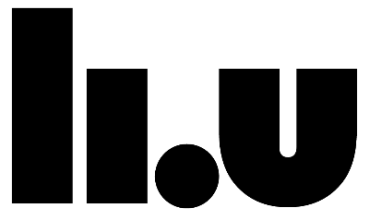

LINKÖPING UNIVERSITY

\author{
Division of Neurobiology \\ Department of Clinical and Experimental Medicine \\ Faculty of Medicine and Health Sciences, Linköping University \\ Linköping, Sweden
}

Linköping, 2019 
Copyright @ 2019 by Valerie L. Sackmann

Published papers I and II are open access articles and the authors retain the copyright ownership for their articles.

Figure 7 was adapted with permission from IOS Press.

ISBN: 978-91-7519-012-9

ISSN: 0345-0082

Printed in Linköping, Sweden by LiU-Tryck, October 2019 
"If the human brain were so simple that we could understand it, we would be so simple that we couldn't." -Emerson Pugh 


\section{MAIN SUPERVISOR}

Martin Hallbeck, Associate Professor, MD, PhD

Division of Neurobiology, Department of Clinical and Experimental Medicine, Linköping University, Linköping, Sweden

\section{CO-SUPERVISORS}

Camilla Nilsberth, Associate Professor, $\mathrm{MD}, \mathrm{PhD}$

Division of Neurobiology, Department of Clinical and Experimental Medicine, Linköping University, Linköping, Sweden

Anna Ansell-Schultz, $\mathrm{PhD}$

*Division of Neurobiology, Department of Clinical and Experimental Medicine, Linköping University, Linköping, Sweden

Maitrayee Sardar Sinha, $\mathrm{PhD}$

*Division of Neurobiology, Department of Clinical and Experimental Medicine, Linköping University, Linköping, Sweden

*previous affiliations

\section{FACULTY OPPONENT}

Tomas Deierborg, Associate Professor, $\mathrm{PhD}$

Division of Experimental Neuroinflammation, Department of Experimental Medical Science, Lund University, Sweden

\section{COMMITTEE BOARD}

Erik Portelius, Associate Professor, $\mathrm{PhD}$

Department of Neuroscience and Physiology, Sahlgrenska Academy at Gothenburg University, Gothenburg, Sweden

Simin Mohseni, Assistant Professor, $\mathrm{PhD}$

Division of Neurobiology, Department of Clinical and Experimental Medicine, Linköping University, Linköping, Sweden

Ioannis Spyrou, Professor, $\mathrm{PhD}$

Division of Neurobiology, Department of Clinical and Experimental Medicine, Linköping University, Linköping, Sweden 


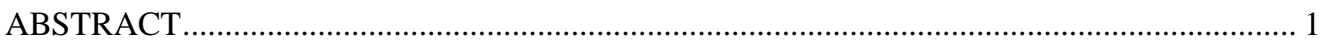

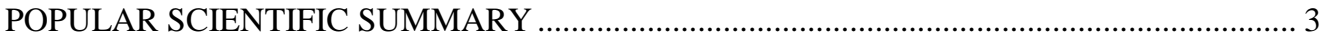

POPULÄRVETENSKAPLIG SAMMANFATTNING ............................................................ 5

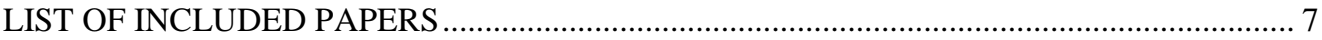

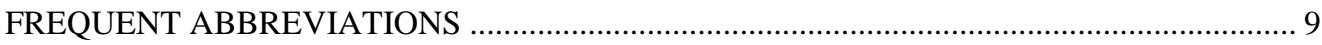

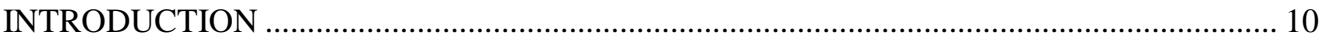

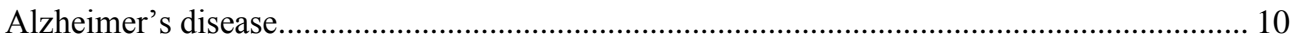

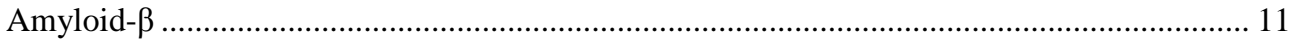

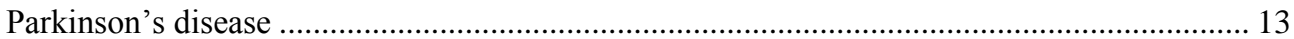

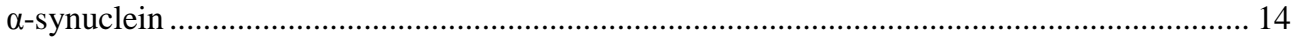

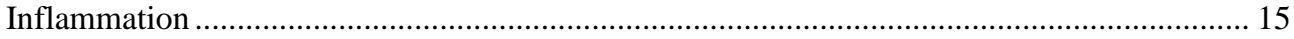

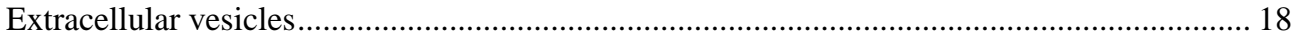

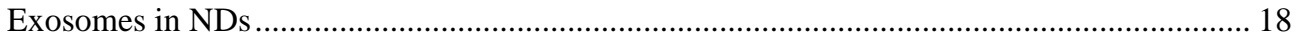

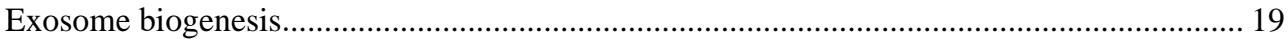

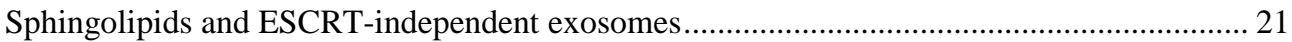

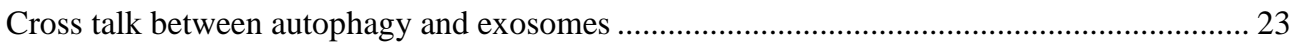

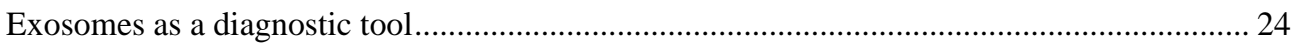

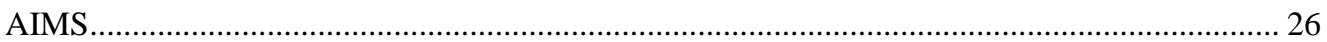

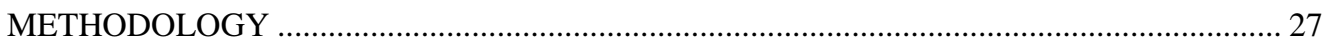

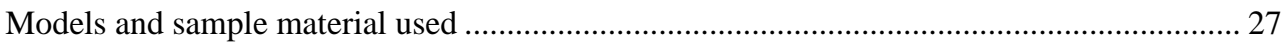

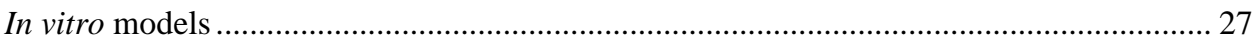

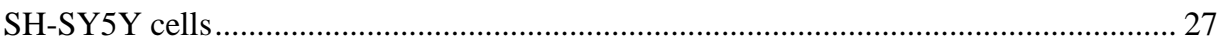

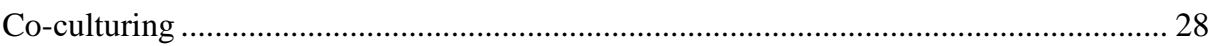

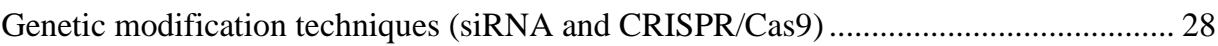

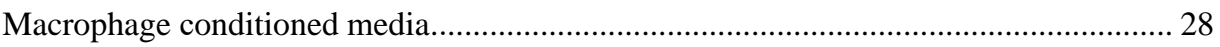

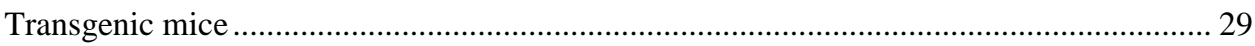

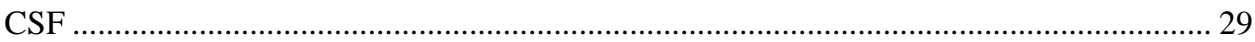

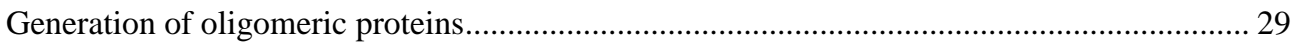

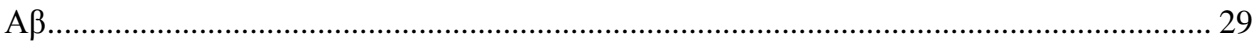

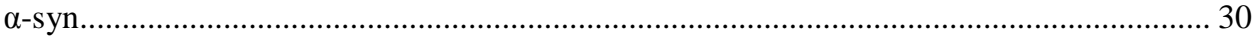

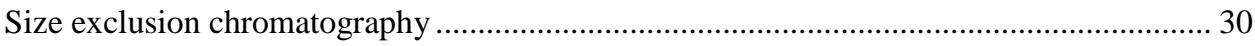

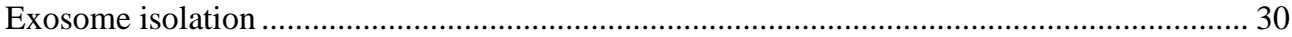




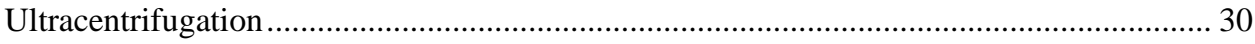

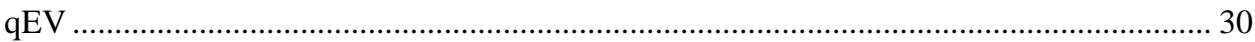

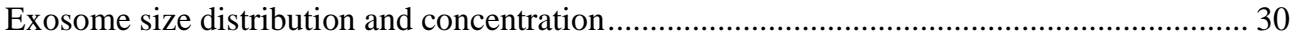

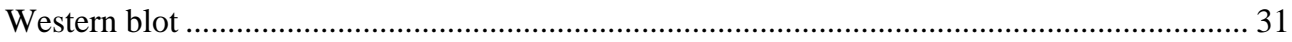

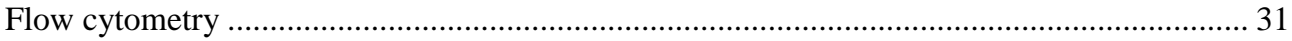

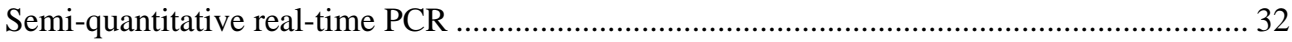

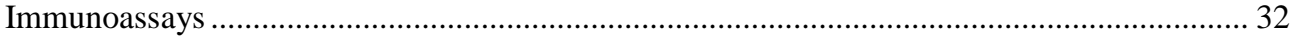

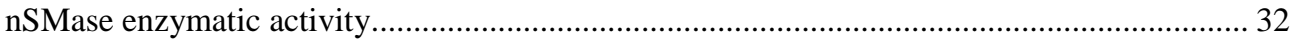

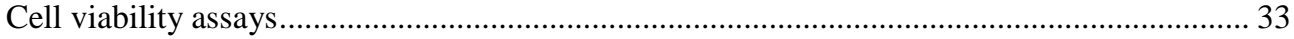

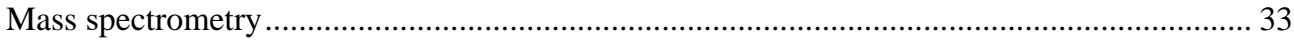

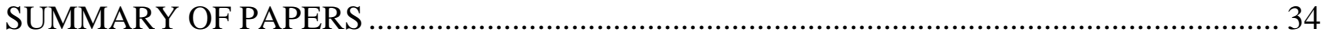

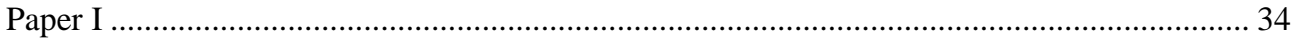

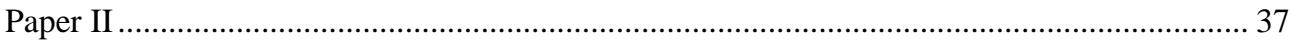

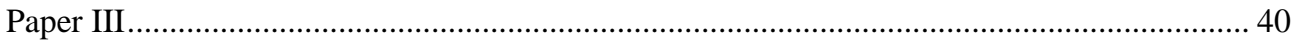

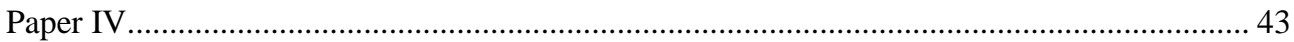

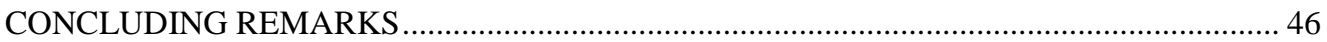

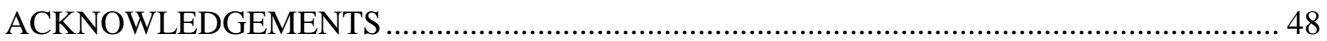

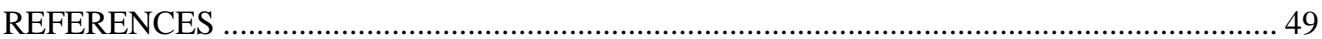


Alzheimer's disease (AD) and Parkinson's disease (PD) are the two most common neurodegenerative diseases with rates increasing along with the ageing global population. Despite best efforts, we still do not understand the etiopathogenesis of these diseases and there are no effective disease-modifying treatments. Cognitive deficiencies or motor complications that emerge during $\mathrm{AD}$ and $\mathrm{PD}$ are thought to be the result of the accumulation of misfolded, aggregate-prone proteins, such as amyloid- $\beta(\mathrm{A} \beta)$ and tau or $\alpha$-synuclein $(\alpha$-syn), respectively. Growing evidence suggests that prefibrillar oligomers of $\mathrm{A} \beta$ and $\alpha$-syn (oA $\beta$ and o $\alpha$-syn) are key contributors to the progression of these diseases. The progressive accumulation of these proteins leads to a gradual spread of pathology throughout interconnected brain regions, but the mechanisms by which this spreading occurs are still largely unknown.

Neuroinflammation has been recognised as an important contributor to neurodegenerative disease. It is hypothesised that a pro-inflammatory environment initiated by the innate immune system, either through activation from $A \beta$ itself or indirectly through neuronal injury signals in $A D$. These phenomena are thought to either cause or accelerate $\mathrm{AD}$, such that an anti-inflammatory approach may be neuroprotective. In paper I, we investigated whether different inflammatory environments affected the transfer of oA $\beta$ between neuron-like cells, in addition to investigating inter- and intracellular protein changes. This study demonstrated that an anti-inflammatory environment reduces the transfer of oA $\beta$ between cells. We also provide evidence that these cells begin to take on the "phenotype" of the inflammatory milieu, while also demonstrating that the expression profile of endosomal/lysosomal and protein trafficking proteins is altered during these conditions.

Small extracellular vesicles called exosomes, which are key players in cell to cell communication, have been proposed to play an influential role in spreading neurodegenerative proteins between cells. Exosomes are small membranous vesicles that are formed by the inward budding of multivesicular bodies (MVBs). These MVBs can then merge with the plasma membrane to be released into the extracellular environment as vesicles, which serve as vehicles for transferring proteins, lipids, and mRNAs between cells.

The ESCRT-dependent pathway is the most understood mechanism underlying exosome biogenesis. However, exosomes can also be formed through ESCRT-independent pathways, including through the hydrolysis of sphingomyelin by neutral sphingomyelinase 2 (nSMase2), which produces ceramide. Paper II investigated whether exosomes formed through an ESCRTindependent pathway plays a significant role in the transfer of o $\alpha$-syn between neuron-like cells. As oxidative stress is a common feature in PD brains, which in turn dysregulates nSMase 2 activity, we also tested our model under hypoxic conditions. Inhibition of nSMase 2 significantly reduced the transfer of o $\alpha$-syn between cells but also resulted in decreased $\alpha$-syn aggregation. Hypoxia did not influence $o \alpha$-syn transfer, however, it significantly dysregulated the sphingolipid composition, which may be important for $\alpha$-syn binding to exosomes and exosome communication.

During AD and PD, there is a noted reduction in the effectiveness of autophagy, a process critical to cellular proteostasis. Recent studies have uncovered shared regulatory mechanisms of exosome 
biogenesis and autophagy, suggesting that they are closely linked. Previous findings have shown that inhibition of autophagy in $\mathrm{AD}$ mice mediates $\mathrm{A} \beta$ trafficking through altering the secretion of $\mathrm{A} \beta$ in MVBs. To further study this effect, we investigated the interplay between autophagy and exosome secretion using $A T G 7$ knock-out x $A P P^{N L-F}$ knock-in $\mathrm{AD}$ mice in paper III. These autophagy-deficient $\mathrm{AD}$ mice had a reduced extracellular $\mathrm{A} \beta$ plaque load, but increased intracellular $A \beta$, which was found to be assembled into higher-ordered assemblies. While exosomal secretion was dysregulated in these mice, the amount of $\mathrm{A} \beta$ packaged into the exosomes was unchanged.

Lastly, one of the biggest challenges in developing effective treatments for AD is the lack of early diagnosis of living patients. As the connection between exosomes and the spread of neurodegenerative proteins is still relatively new, there remains a diagnostic potential to be explored with exosomes. Paper IV aimed to develop a new diagnostic assay to detect oA $\beta$ in exosomes isolated from human cerebrospinal fluid. Although exosomal oA $\beta$ was readily detected in some of these samples, the assay's sensitivity requires additional optimisation before it can be further validated for the clinic.

In summary, the studies presented in this thesis have furthered our understanding of how inflammation, autophagy, and exosomes contribute to the intercellular transmission of AD and PD associated proteins. We have shown that an anti-inflammatory approach may slow down the progression of $\mathrm{AD}$ through reducing the transfer of oA $\beta$ between cells. We also provide novel findings relating to the biogenesis of exosomes, which in turn affected the ability of exosomes to transmit neurodegenerative proteins between cells, and their association with autophagic processes. Finally, we have investigated the feasibility of exosomes as an early AD diagnostic marker. This work has helped to elucidate some of the mechanisms underlying the progression of neurodegenerative diseases, which may be useful targets for the investigation of new therapeutic avenues. 


\section{POPULAR SCIENTIFIC SUMMARY}

Neurodegenerative diseases are characterised by the progressive death of brain cells, such as neurons. The region experiencing the death of brain cells gives rise to different symptoms in the patients, such as memory loss in Alzheimer's disease (AD) and abnormal motor function in Parkinson's disease (PD). There is a gradual progression of disease, which eventually leads to patients being incapable of performing everyday tasks and ultimately causes premature death. AD and PD are the two most common neurodegenerative diseases with incidences increasing along with the ageing global population. Despite the prevalence of these diseases, we still do not understand the causes of these diseases. To date, there are no effective disease-modifying treatments, leading to a significant financial and emotional burden to society.

The symptoms in AD and PD are likely the result of the build-up of misfolded proteins that group together, such as amyloid- $\beta$ and tau in $\mathrm{AD}$, and $\alpha$-synuclein in PD. Growing evidence suggests that smaller clusters, called oligomers, of amyloid- $\beta$ and $\alpha$-synuclein are the key players in the progression of these diseases. The progressive accumulation of these proteins leads to a gradual spread of the disease to connected brain areas, but it is still largely unknown how this spreading occurs.

Inflammation is the body's defence against infection and injury. However, inflammation in the brain has been recognised as an important component of $\mathrm{AD}$ and PD. The innate immune system, which is the initial line of defense, can be activated directly by amyloid- $\beta$, but may also be activated through signals from injured neurons. Regardless of the activating signal, this inflammation may cause or accelerate $\mathrm{AD}$ pathology. During $\mathrm{AD}$, the brain is thought to be in a chronically pro-inflammatory state, leading to speculation that an anti-inflammatory environment may protect against $\mathrm{AD}$ progression. We investigated whether different inflammatory environments affected the spreading of oligomeric amyloid- $\beta$ between neuron-like cells, observing that an anti-inflammatory environment reduced the spreading of oligomeric amyloid- $\beta$ between cells. This work strengthens the hypothesis that anti-inflammatory mediators could be beneficial to $\mathrm{AD}$ patients in slowing disease progression.

Small vesicles, called exosomes, have been proposed to play a significant role in the spreading of amyloid- $\beta$ and $\alpha$-synuclein in AD and PD, respectively. Exosomes are formed by the inward budding of cellular compartments known as multivesicular bodies, which merge with the cell membrane to release these vesicles. Exosomes serve as vehicles for transferring proteins, lipids, and other small molecules between cells and are crucial for the communication between one another. During the generation of exosomes, an enzyme called neutral sphingomyelinase 2 (nSMase2) converts membrane lipids which causes multivesicular bodies to bud inwards. We genetically inhibited the nSMase 2 enzyme to examine whether exosomes formed through this pathway influenced the spreading of oligomeric $\alpha$-synuclein between neuron-like cells. Inhibiting nSMase 2 significantly reduced the spreading of oligomeric $\alpha$-synuclein between cells, while also reducing the accumulation of $\alpha$-synuclein over time. Inhibiting nSMase 2 should be investigated as a therapeutic target for PD, but additional research is required to reveal how lipid mechanisms are dysregulated in PD. 
Another hallmark of neurodegenerative diseases is the reduced effectiveness of autophagy. Autophagy is the cell's way to remove unnecessary or broken components or proteins within the cell by sectioning off these components into "autophagosomes", which are then degraded. Recent studies have shown that exosomes and autophagy pathways are closely linked; autophagosomes can fuse with multivesicular bodies. Using autophagy-deficient AD mice, we investigated the relationship between autophagy and exosome secretion. These mice had increased levels of amyloid- $\beta$ inside neurons, however, the amount of amyloid- $\beta$ within exosomes was not affected even though exosomal secretion was altered. This suggests that diminished secretion of neuronal exosomes may influence amyloid- $\beta$ accumulation, and ultimately the development of $\mathrm{AD}$ pathology, but further investigations are required.

Lastly, one of the biggest challenges in developing effective treatments for AD is the lack of early diagnosis of living patients. As the connection between exosomes and the spread of neurodegenerative proteins is still relatively new, there remains a diagnostic potential to be explored with exosomes. We aimed to develop a new diagnostic assay to detect oligomeric amyloid- $\beta$ in exosomes isolated from cerebrospinal fluid from patients. We were able to detect exosomal oligomeric amyloid- $\beta$ in some of the samples but the assay's sensitivity requires further optimisation for it to be used in a clinical setting.

In summary, the studies presented in this thesis have furthered our understanding of several systems that are dysregulated in AD and PD. We have shown that an anti-inflammatory approach may slow down the progression of $\mathrm{AD}$ by reducing the spreading of oligomeric amyloid- $\beta$. We also provide novel findings relating to the generation of exosomes influencing the transfer of oligomeric $\alpha$-synuclein. Furthermore, we have provided insight into whether the dysregulation of autophagy affects the secretion of amyloid- $\beta$ through exosomes. We have also explored the potential of using exosomes as an early marker of $\mathrm{AD}$, which may be useful in the development of novel diagnostic methods. Taken together, this work has shown new opportunity for therapeutic avenues to be explored for AD and PD. 


\section{POPULÄRVETENSKAPLIG SAMMANFATTNING}

Vid neurodegenerativa sjukdomar ses en progressiv nedbrytning av hjärnans nervceller. De symtom som uppkommer till följd av nervcellsdöden speglas av var i hjärnan förlusten sker. Till exempel kan patienter drabbas av minnessvikt som vid Alzheimers sjukdom (AS) eller motorisk dysfunktion som vid Parkinsons sjukdom (PS). De neurodegenerativa sjukdomarna försämrar den drabbade långsamt tills vardagsfunktioner helt försvunnit och leder slutligen till döden. De vanligaste neurodegenerativa sjukdomarna är AS och PS och eftersom de är starkt kopplade till ålder beräknas antalet som insjuknar öka kraftigt i framtiden parallellt med att befolkningens livslängd ökar. Vi förstår fortfarande inte fullt ut orsaken till dessa sjukdomar och det finns ännu ingen sjukdomsmodifierande behandling. Samhället står för stora utmaningar i att ta hand om de som drabbas men detta är också sjukdomar som leder till stort lidande för både patient och familj.

Forskning har påvisat en gemensam sjukdomsmekanism vid AS och PS även om grundstenarna, proteinerna, är olika: ansamling av amyloid- $\beta$ i AS och $\alpha$-synuclein i PS. Dessa proteiner, ändrar sin form till att bli mer benägen att bilda svårlösliga aggregat och allt mer forskning har visat att små aggregat, oligomerer, kan vara det som initierar sjukdomarna och bidrar till det progressiva förloppet. Oligomererna sprids mellan närliggande områden i hjärnan vilket leder till att sjukdomen sprids inom hjärnan, vi vet fortfarande inte i detalj hur denna spridning sker men forskning har visat att små membraninbundna vesikler utanför cellerna, så kallade exosomer kan ha en viktig roll.

Vid AS och PS har forskning även visat att inflammation i hjärnan påverkar förloppet. Inflammation är kroppens försvarsreaktion mot skada. Vi har ett medfött, ospecifikt immunförsvar som är en första linjens försvar mot främmande ämnen som kan aktiveras av amyloid- $\beta$ men även av signaler från skadade nervceller. Den inflammation som det ospecifika immunförsvaret startar kan accelerera sjukdomsprogressen av AS och hjärnan försätts i en kronisk pro-inflammatorisk miljö. En hypotes är att man kan skydda hjärnan genom att förskjuta jämvikten mot en antiinflammatorisk omgivning. Vi har undersökt hur olika inflammatoriska omgivningar påverkar hur amyloid- $\beta$ sprids mellan nervcellslika celler. Vi har påvisat minskad spridning av amyloid- $\beta$ mellan celler vid en anti-inflammatorisk miljö och detta arbete styrker hypotesen att antiinflammatoriska mediatorer kan göra sjukdomsprogressen långsammare vid AS.

Vi har också undersökt exosomernas roll vid neurodegenerativa sjukdomar. Exosomerna är bärare av proteiner, lipider och andra små molekyler och överför dessa mellan cellerna. Exosomerna är nödvändiga för cell-till-cell kommunikationen. Ett enzym som är viktigt för att bilda exosomer är sphingomyelinase 2 (nSMase2), det omvandlar membrankomponenter så att exosomerna kan knoppas av. Vi ändrade nSMase 2 genetiskt och undersökte om spridningen av $\alpha$-synuclein mellan neuronlika celler påverkas. Hämning av nSMase 2 minskade signifikant spridning av $\alpha$-synuclein mellan celler samtidigt som ackumulering av $\alpha$-synuclein över tid minskade. Hämning av nSMase2 kan vara ett nytt mål för PS läkemedel, men ytterligare forskning krävs för att klargöra dessa mekanismer. 
Autofagi är ett sätt för celler att göra sig av med överflödiga eller dysfunktionella komponenter i cellen. Avfallet kapslas bort i "autofagosomer" som sedan degraderas. Gemensamt för neurodegenerativa sjukdomar är att dessa processer blir mindre effektiva. Vi har studerat genetiskt modifierade möss, sk transgena möss, för att undersöka sambandet mellan autofagi och exosomutsöndring Vi har visat att möss vars celler inte kan nyttja autofagi hade minskad mängd plack i hjärnan men vi såg ökad mängd amyloid- $\beta$ inuti nervcellerna. Trots förändrad exosomal utsöddring var mängden amyloid- $\beta$ i exosomerna oförändrad. Dessa resultat tyder på att minskad utsöndring av neuronala exosomer kan påverka amyloid- $\beta$ ackumulering och i förlängningen utveckling av AS-patologi men ytterligare forskning krävs för att klargöra dessa mekanismer.

En av de största utmaningarna för att hitta effektiv behandling mot AS är att det saknas pålitliga metoder för tidig diagnos i patienter. Kunskapen om kopplingen mellan exosomer och spridning av neurodegenerativa proteiner är fortfarande ny. $\mathrm{Vi}$ ser en diagnostisk potential i exosomutsöndring. Vi har som målsättning att utveckla en ny diagnostisk metod för att detektera amyloid- $\beta$ i exosomer isolerade från likvor från AS patiener. Vi har arbetat fram en metod för att isolera amyloid- $\beta$ i exosomer men metodens känslighet behöver ytterligare optimeras innan den kan användas kliniskt.

Sammantaget har dessa studier ökat vår förståelse av flera system som blir defekta i AS och PS. Vi har visat att antiinflammatorisk miljö kan göra progressen av AS mer långsam genom att minska spridning av amyloid- $\beta$. Vi har också presenterat nya fynd avseende biogenes av exosomer som påverkar överföring av $\alpha$-synuclein. Vidare har vi ökat kunskapen om hur dysregulering av autofagi påverkar utsöndring av amyloid- $\beta$ via exosomer. Vi har även undersökt möjligheten att använda exosomer som en tidig markör för AS vid diagnostik. Detta arbete har visat nya möjligheter för flera terapeutiska mål att utforskas vid AS och PS i framtiden. 


\section{LIST OF INCLUDED PAPERS}

\section{Paper I}

Valerie Sackmann, Anna Ansell, Christopher Sackmann, Harald Lund, Robert A Harris, Martin Hallbeck, Camilla Nilsberth (2017). Anti-inflammatory (M2) macrophage media reduce transmission of oligomeric amyloid-beta in SH-SY5Y cells. Neurobiology of Aging. doi:10.1016/j.neurobiolaging.2017.08.022

\section{Paper II}

Valerie Sackmann, Maitrayee Sardar Sinha, Christopher Sackmann, Anna Ansell-Schultz, Livia Civitelli, Joakim Bergström, Martin Hallbeck (2019). Inhibition of nSMase2 reduces the transfer of oligomeric $\alpha$-synuclein irrespective of hypoxia. Frontiers in Molecular Neuroscience. doi:10.3389/fnmol.2019.00200

\section{Paper III}

Richeng Jiang, Simone Tambaro, Valerie Sackmann, Misaki Sekiguchi, Takashi Saito, Bengt Winblad, Takaomi C. Saido, Martin Hallbeck, Per Nilsson. Autophagy deficiency in excitatory neurons leads to intracellular $A \beta$ fibrillization, reduction in exosome secretion and decreased extracellular $\mathrm{A} \beta$ plaques. Manuscript.

\section{Paper IV}

Valerie Sackmann, Lovisa Johansson, Anna Ansell-Schultz, Lars Lannfelt, Martin Ingelsson, Martin Hallbeck. Exosomal oligomeric amyloid- $\beta$ in cerebrospinal fluid as a potential biomarker for Alzheimer's disease. Manuscript. 


\section{LIST OF PAPERS NOT INCLUDED}

Christopher Sackmann, Valerie Sackmann, Martin Hallbeck. Full length TPD-43, and N- and Ctruncated fragments are reliably transferred between neuron-like cells (2019). Currently under review.

Nilsberth et al. mPGES-1 generated PGE2 in Alzheimer mice attenuates $\beta$-amyloid load in the brain. Manuscript.

Nilsberth et al. Pro-inflammatory cytokines are associated to symptom clusters in palliative cancer patients. Manuscript. 


\section{FREQUENT ABBREVIATIONS}

\begin{tabular}{|c|c|}
\hline$\alpha$-syn & $\alpha$-synuclein \\
\hline $\mathrm{AChE}$ & acetylcholinesterase \\
\hline $\mathrm{AD}$ & Alzheimer's disease \\
\hline ATG7 & autophagy-related gene 7 \\
\hline $\mathrm{A} \beta$ & amyloid- $\beta$ \\
\hline APP & amyloid precursor protein \\
\hline CSF & cerebrospinal fluid \\
\hline CNS & central nervous system \\
\hline $\mathrm{CM}$ & conditioned media \\
\hline ESCRT & endosomal sorting complexes required for transport \\
\hline ELISA & enzyme-linked immunosorbent assay \\
\hline EV & extracellular vesicle \\
\hline GCase & glucocerebrosidase \\
\hline GFP & green fluorescent protein \\
\hline $\mathrm{KO}$ & knockout \\
\hline o $\alpha$-syn & oligomeric $\alpha$-synuclein \\
\hline $\mathrm{oA} \beta$ & oligomeric amyloid- $\beta$ \\
\hline MSD & Meso Scale Discovery \\
\hline MVB & multivesicular body \\
\hline NIAAA & National Institute on Aging and Alzheimer's Association \\
\hline ND & neurodegenerative disease \\
\hline nSMase2 & neutral sphingomyelinase 2 \\
\hline PD & Parkinson's disease \\
\hline siRNA & small interfering RNA \\
\hline RT-PCR & real-time polymerase chain reaction \\
\hline
\end{tabular}




\section{INTRODUCTION}

\section{Neurodegenerative diseases}

The number of people affected by neurodegenerative diseases (NDs) is expected to steadily rise along with the increasing global population. These diseases cause great suffering to those affected and their families, but also encompass an enormous financial burden to health care costs. It is therefore of great importance to better understand the pathological mechanisms causing NDs such as Alzheimer's and Parkinson's disease, in order to develop effective treatments, which are currently unavailable for NDs.

\section{Alzheimer's disease}

Alzheimer's disease (AD) is the most common dementia-causing ND, with an estimated 50 million people affected by AD worldwide as of 2017 [1]. AD severely affects the quality of life of the patient and family, eventually leading to premature death. AD was first described over 100 years ago when Alois Alzheimer described the characteristic pathological hallmarks of AD [2]. In his work, he identified protein deposits in the cerebral cortex during the autopsy of a patient with profound memory loss and abnormal confusion. The proteinaceous deposits described in this work were later identified as amyloid plaques, consisting of amyloid- $\beta(\mathrm{A} \beta)$ peptides, and neurofibrillary tangles (NFTs) that are used to diagnose AD to this day.

Cognitive deficits occur through neuronal death and the loss of synapses among affected brain regions. During mid- to late-stage AD, these lesions can be found in the hippocampus and entorhinal cortex, areas involved in memory formation and executive functions, respectively. Currently, the clinical diagnosis of AD is based on a series of clinical assessments (cognitive function, biomarkers, and brain imaging) in living patients, with definitive diagnosis only possible during autopsy. The neuropathology of AD includes macroscopic brain atrophy due to the loss of neuritic processes, synapses, and neurons, which eventually contributes to the death of the patient. Other AD hallmarks include neurovascular dysfunction, chronic inflammation, mitochondrial dysfunction, oxidative stress, alongside the primary pathologies of widespread A $\beta$ aggregates and intracellular NFTs consisting of hyperphosphorylated tau (reviewed in [3]). A $\beta$ plaques were once considered the cause of neuronal death, but it is now understood that smaller soluble aggregates (oligomers) of $A \beta$ are likely the most toxic species [4], and that the deposition of $A \beta$ plaques may serve as a "reservoir" for toxic soluble A $\beta$ aggregates, sequestering them from the extracellular space and thereby preventing their toxicity during early stages of pathology [5]. Cognitive decline has also been shown to correlate better with NFTs than A $\beta$ plaques [6], although accumulation of soluble $A \beta$ is suggested to precede the formation of NFTs $[7,8]$. However, these pathological changes are gradual, and it is now believed that the initial pathology develops decades before any clinical symptoms are apparent. This is further exemplified through the hypothesis that the numerous failed clinical trials targeting $\mathrm{A} \beta$ are related to the delay in diagnosis, such that anti-A $\beta$ therapeutics are given to patients too far into the disease process to be effective [9]. Current 
interventions rely on acetylcholinesterase inhibitors and glutamate antagonists, however, these accomplish only a very minor delay in the cognitive decline for the patient (reviewed in [10]).

$\mathrm{A} \beta$ is strongly linked to $\mathrm{AD}$ pathology, as the familial forms of $\mathrm{AD}$ are caused by mutations linked to A $\beta$ 's upstream peptide (APP) and its processing enzymes (Presenilin 1/2) [11]. With the same pathological hallmarks, familial $\mathrm{AD}$ develops an aggressive progressive form of $\mathrm{AD}$, with an early age of onset ( $<65$ years of age) compared to sporadic AD ( $>65$ years of age), however, familial $\mathrm{AD}$ only accounts for $1-2 \%$ of cases [12]. Ageing is the greatest risk factor for developing sporadic $\mathrm{AD}$, but a combination of genetic (e.g. carrying the apolipoprotein E4 allele) and environmental risk factors (e.g. type II diabetes, smoking, severe head trauma) are thought to contribute to AD etiology [11].

\section{Amyloid- $\beta$}

$\mathrm{A} \beta$ is produced by the cleavage of the amyloid precursor protein (APP). APP is a transmembrane glycoprotein expressed as multiple isoforms throughout the body [13]. The normal physiological role of APP is unclear, however, in the central nervous system (CNS) it is known to contribute to synaptic plasticity, neurite outgrowth, adhesion, and regulation of neuronal excitation [14]. The processing of APP can occur either by the non-amyloidogenic pathway or the amyloidogenic pathway, where $A \beta$ is produced (Figure 1). In the non-amyloidogenic pathway, $\alpha$-secretase cleaves APP within the A $\beta$-region, creating soluble APP $\alpha$ and carboxy-terminal fragment (CTF)$\alpha(\mathrm{CTF} \alpha)$, which are subsequently cleaved by $\gamma$-secretase into P3 and APP intracellular domain (AICD). In the amyloidogenic pathway, $\beta$-secretase cleaves APP into soluble APP $\beta$ and CTF $\beta$. $\mathrm{CTF} \beta$ is then further cleaved by $\gamma$-secretase to release A $\beta$ and the AICD.

The normal physiological function of $\mathrm{A} \beta$ is not yet fully understood, but it has been shown to promote synaptic plasticity and long-term potentiation $[15,16]$. During amyloid pathology, there is an imbalance in $A \beta$ metabolism. Depending on where the $\gamma$-secretase cleaves, different lengths of $\mathrm{A} \beta$ are produced, where $\mathrm{A} \beta 38, \mathrm{~A} \beta 40$, and $\mathrm{A} \beta 42$ are the most abundant forms found in $\mathrm{AD}$ plaques [17]. Low levels of $A \beta 42$ or $A \beta 42 / A \beta 40$ ratio in cerebrospinal fluid (CSF) are commonly used as biomarkers as of today, as well as amyloid positron-emission tomography (PET) imagining being recommended by the National Institute on Aging and Alzheimer's Association (NIAAA) for diagnosis [18]. The pathogenesis of $\mathrm{AD}$ is often attributed to the increased production and/or decreased clearance of $A \beta$, especially $A \beta 42$ [19]. 


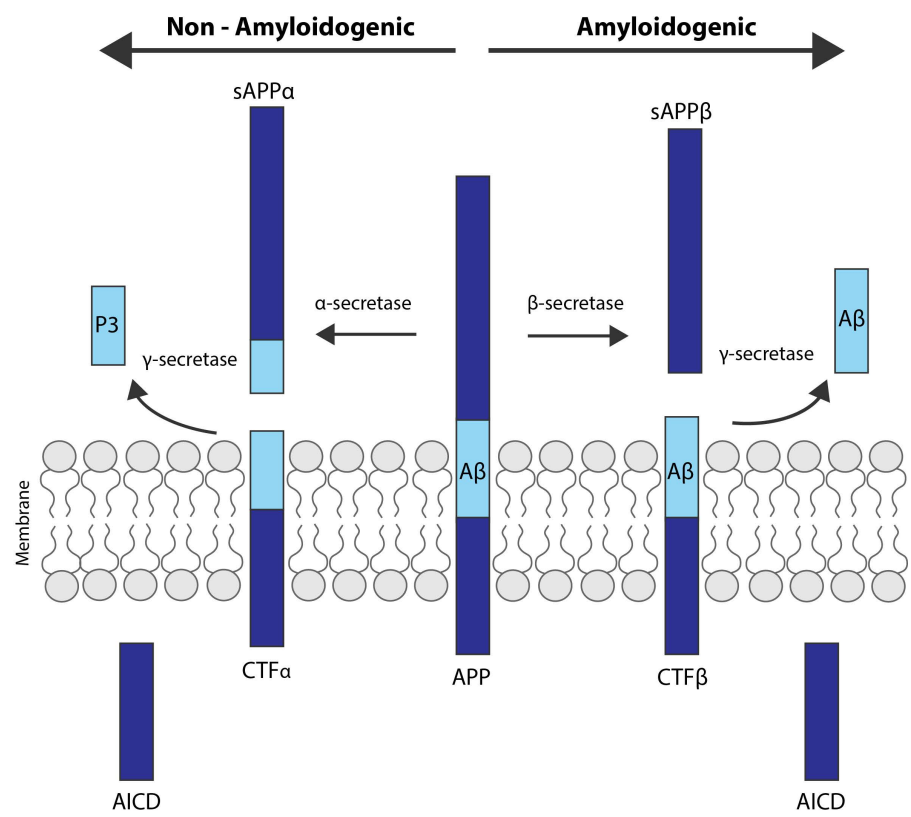

Figure 1. Overview of APP processing. In the non-amyloidogenic pathway, $\alpha$-secretase cleaves APP creating $s A P P \alpha$ and $C T F \alpha$, which is subsequently cleaved by $\gamma$-secretase into P3 and AICD. In the amyloidogenic pathway, APP is first processed by $\beta$-secretase, where $s A P P \beta$ is released, followed by cleavage of the CTF $\beta$ by $\gamma$-secretase to release $A \beta$.

A $\beta$ can also exist as $\alpha$-helical or $\beta$-sheet in secondary protein structure confirmations. The $\beta$-sheet conformation is more hydrophobic and aggregation-prone and is believed to confer the assembly of dimers, trimers, and small oligomers. This aggregation cascade contributes to the formation of larger oligomers, protofibrils, and large fibrils that are ultimately deposited into plaques (Figure 2A). The mechanisms of $A \beta$ aggregation can be due to destabilising mutations, changes in $\mathrm{pH}$ or temperature, post-translational modifications or interactions with cellular components, although this is still poorly understood (A $\beta$ aggregation reviewed in [20]). It is generally accepted that $A \beta$ toxicity requires the aggregation of monomers [20], but due to the vast number of possible $A \beta$ conformations, it has been difficult to characterise. However, it is proposed that the amount of soluble oligomeric $A \beta(o A \beta)$ correlates with early synaptic loss and cognitive decline [21,22]. In addition to this extracellular $A \beta$, intracellular $A \beta$ has been shown to localise in the ER, Golgi, mitochondria, endosomes, lysosomes, multivesicular bodies (MVB), and cytosol (reviewed in [8]). $\mathrm{A} \beta$ can be degraded through several pathways (reviewed in [23]) or it can be passed on to other cells [24-27], involving mechanisms including the endosome recycling pathway/exocytosis, extracellular vesicles/exosomes, and possibly tunnelling nanotubes (Figure 2B). The propagation of oA $\beta$ between cells according to this paradigm is thought to underlie the spread of pathology among interconnected brain regions. 


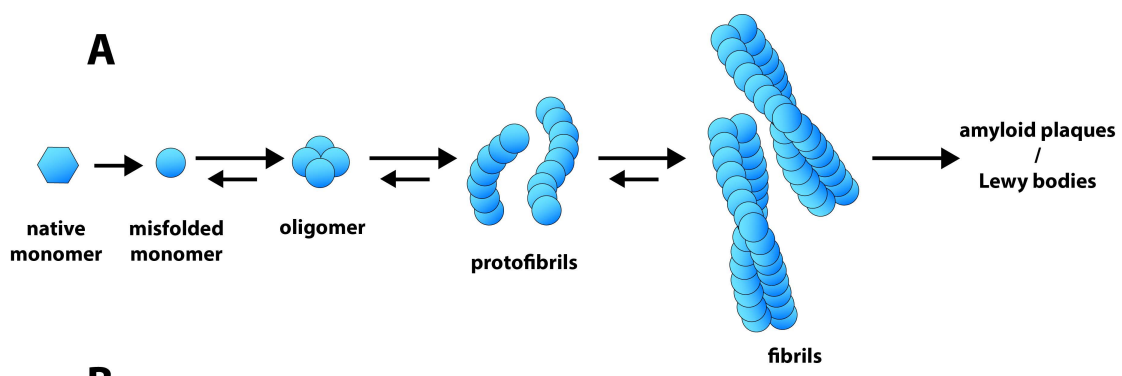

B

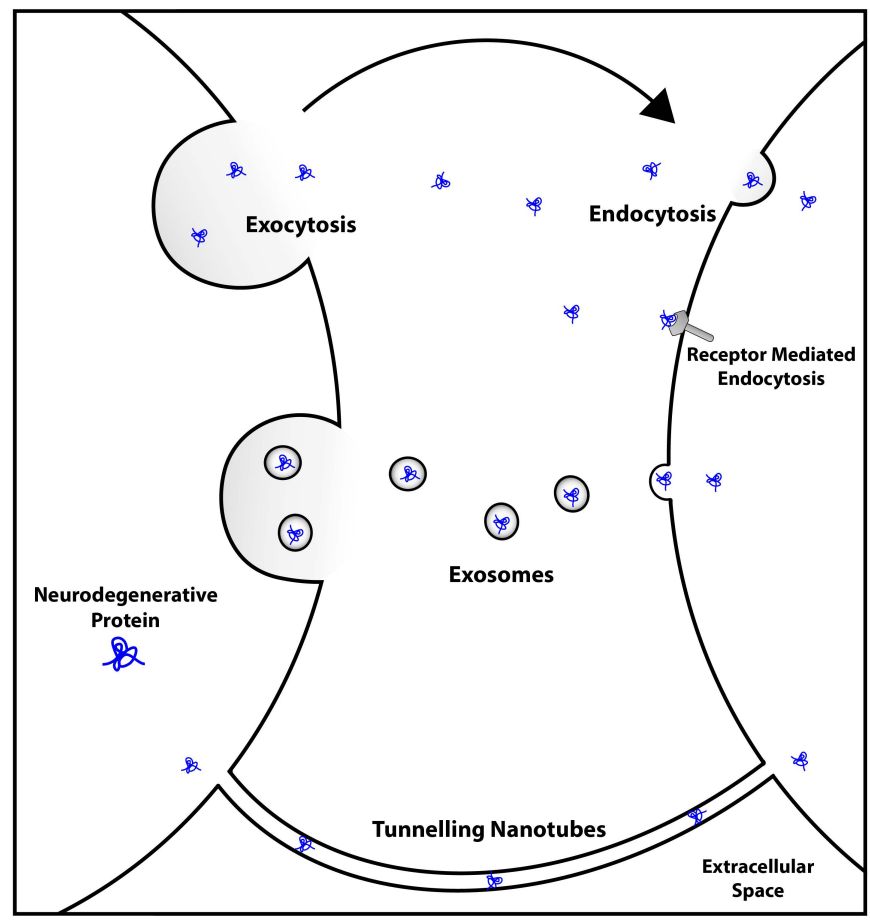

Figure 2: Protein aggregation and proposals of mechanisms of transfer. (A) Misfolding of native monomeric $A \beta$ and $\alpha$-synuclein into $\beta$-sheet rich structures contributes to their aggregation into oligomers and protofibrils that eventually lead to amyloid plaques/Lewy bodies. (B) Depiction of how $A \beta$ and $\alpha$-syn are transferred between nearby cells according to several possible mechanisms including exosomes, exocytosis/endocytosis, receptor-mediated endocytosis, or possibly through tunnelling nanotubes.

\section{Parkinson's disease}

Parkinson's disease (PD) is the second most common ND after AD. It is estimated that 2-3\% of the population over the age of 65 years are affected by this disease [28]. Over 200 years ago James Parkinson described patients with common characteristics of PD, such as resting tremor, abnormal 
posture and gait, and paralysis. However, it took another century until Frederic Lewy described microscopic particles in the brain, which were later named "Lewy bodies" [29].

On top of motor dysfunction, advanced-stage PD patients may also experience cognitive impairment and other neurological symptoms. In early-stage disease, loss of dopaminergic neurons is restricted to the ventrolateral substantia nigra with relative sparing of other midbrain dopaminergic neurons but becomes more widespread by the end-stage of the disease [30,31]. During PD, widespread neurodegeneration is attributed to the neuronal deposition of inclusions into Lewy bodies and Lewy neurites consisting of $\alpha$-synuclein ( $\alpha$-syn). The Lewy pathology initially occurs in cholinergic and monoaminergic brainstem neurons and neurons in the olfactory system but is also found in limbic and neocortical brain regions with disease progression [32]. There is also systemic mitochondrial dysfunction, oxidative stress, and neuroinflammation found in PD brains [33]. Similarly to AD, research indicates that smaller soluble aggregates (oligomers) of $\alpha$-syn are the most toxic species and the driver of the disease (reviewed in [34]).

PD onset usually occurs between ages 50 to 70 and follows a gradual deterioration that can last for approximately 20 years. The majority of PD cases are also sporadic in origin, with less than $10 \%$ having family history. The list of mutations contributing to familial PD continues to grow, with 23 genes currently assigned the PARK moniker, denoting PD-associated genes (e.g. SNCA, LRRK2, VPS35, PINK1, ATP13A2, FBXO7) (reviewed in [33]). Several other genes have been identified that contribute to an increased risk for the sporadic form of the disease, of which the most prevalent are mutations in $G B A$ [35,36], which affect lysosomal functions and $\alpha$-syn clearance [37]. As with $\mathrm{AD}$, age is the biggest risk factor in $\mathrm{PD}$, but there are also environmental risk factors, such as pesticides and traumatic brain injury (reviewed in [38]). Highly efficacious therapies have become available, such as pharmacological dopamine substitution (L-DOPA treatment), monoamine oxidase type B inhibitors, or deep brain stimulation [39,40]. However, none of these treatments are curative and the disease progresses, eventually contributing to premature death to the patient.

\section{a-synuclein}

The SNCA gene encodes $\alpha$-syn, a 140 amino acid protein, and is highly expressed in the nervous system and mainly localises to synaptic terminals [41]. The physiological functions of $\alpha$-syn include vesicle transport, synaptic plasticity, and chaperone activity [41]. The protein can be divided into three regions, with each region having distinct structural characteristics. The highly conserved $\mathrm{N}$-terminal region binds to phospholipids and adopts an $\alpha$-helical conformation suggesting that the biological function of $\alpha$-syn may involve binding to lipid membranes [42]. The central region is referred to as the non-amyloid-like component but contains the amino acid sequences essential for $\beta$-sheet amyloid fibril formation [43]. The acidic C-terminal region of $\alpha$ syn contains mostly negatively charged residues and is largely unfolded, but can be targeted for various disease-causing post-translational modifications [44]. Point mutations of SNCA, which cause aggressive, heritable forms of PD, strongly support the notion that $\alpha$-syn is the key player in PD. 
Similar to $A \beta$, the native structure of $\alpha$-syn can misfold into $\beta$-sheet rich conformations, which makes it prone to aggregation. $\alpha$-syn monomers initially form oligomers, then progressively combine to form small protofibrils and eventually large, insoluble $\alpha$-synuclein fibrils, which ultimately result in the accumulation of Lewy pathology (Figure 2A) [45]. Various factors can induce conformational changes within the $\alpha$-syn monomer and modulate the aggregation of $\alpha$-syn, such as changes in $\mathrm{pH}$, temperature, and presence of metal ions [46,47]. Different posttranslational modifications can formulate stable soluble oligomers that do not elongate into fibrils [48], while others can promote $\alpha$-syn oligomerization, aggregation, and cytotoxicity [49]. It is strongly suggested that species of oligomeric $\alpha$-syn (o $\alpha$-syn) are the neurotoxic species in PD and that the mature fibrils within the Lewy bodies are neuroprotective, sequestering toxic species away from the internal cellular environment [50]. The transfer of o $\alpha$-syn occurs between cells and likely accounts for the pathological progression of PD [51-53]. This intercellular transmission of $\alpha$-syn can occur through exosomes [54-56] and exocytosis/endocytosis [51], however, additional mechanisms may also be implicated (Figure 2B).

\section{Inflammation}

Inflammation is the body's response to external threats, such as viral and bacterial infections, and internal threats like bleeding. There are two major defence systems in the body: the innate and the adaptive immune system. The adaptive immune system is based on immunological memory whereas the innate immunity is an older evolutionary strategy, activating and recruiting immune cells through cytokine production. Innate immunity plays a key role in tissue repair, clearance of apoptotic cells and cellular debris, as well as the response to tumours. While key players of innate immunity in the CNS are microglia, other cells such as astrocytes, macrophages, oligodendrocytes, and neurons also contribute to innate immune responses. Despite their different aetiologies, a common feature of NDs is the chronic activation of innate immune cells within the CNS.

Microglia, the principal resident immune cells of the CNS, have diverse functions. During development they shape neural circuits by pruning synapses as well as regulating cell death and elimination of waste products during inflammation or CNS damage. Microglia reside in a resting state (M0) and are differentially activated to either classical/pro-inflammatory (M1) or alternative/anti-inflammatory (M2) states. In general, the M1 phenotype responds to immune challenge by producing oxidative metabolites and the release of pro-inflammatory cytokines, such as interleukin (IL) $-1 \beta$, IL-6, tumour necrosis factor- $\alpha$ (TNF $\alpha$ ), and reactive oxygen species (ROS). The M2 phenotype facilitates phagocytosis and tissue repair, in part through the release of antiinflammatory cytokines such as IL-4, IL-10, transforming growth factor- $\beta$ (TGF $\beta$ ) and other neurotrophic factors. However, the M1/M2 phenotype does not reflect the different phenotypic subsets of microglia. Depending on the activating stimulus received, M2 microglia can be further divided into three different subsets consisting of M2a, M2b, and M2c. A summary of the activation and secretion profiles is provided in Figure 3A (reviewed in [57]). Although it is convenient to classify microglia into subcategories, it is physiologically appropriate to consider the phenotypes as points along a spectrum. 


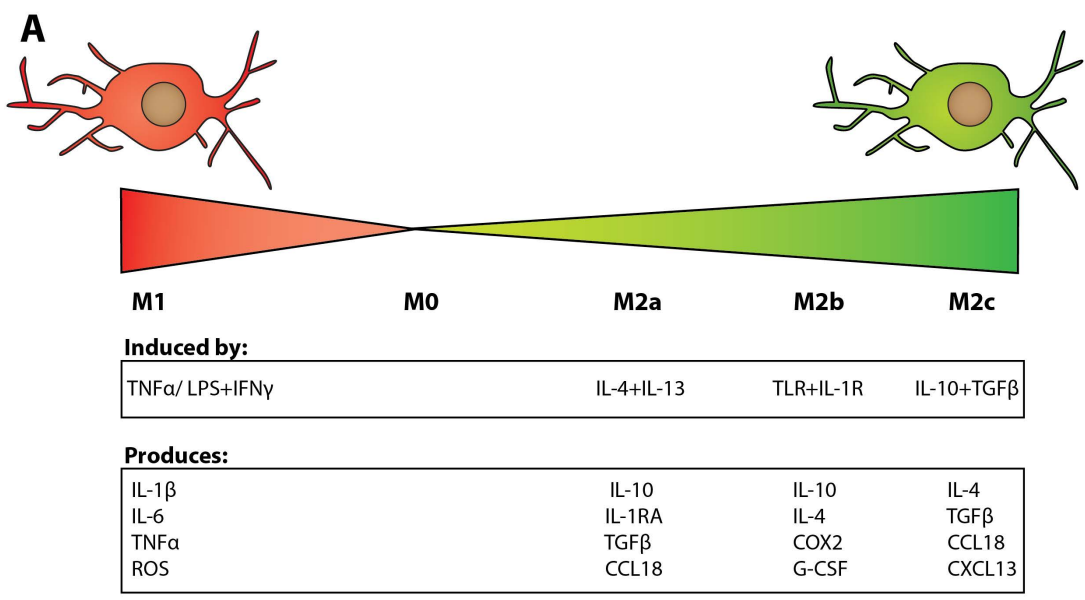

B

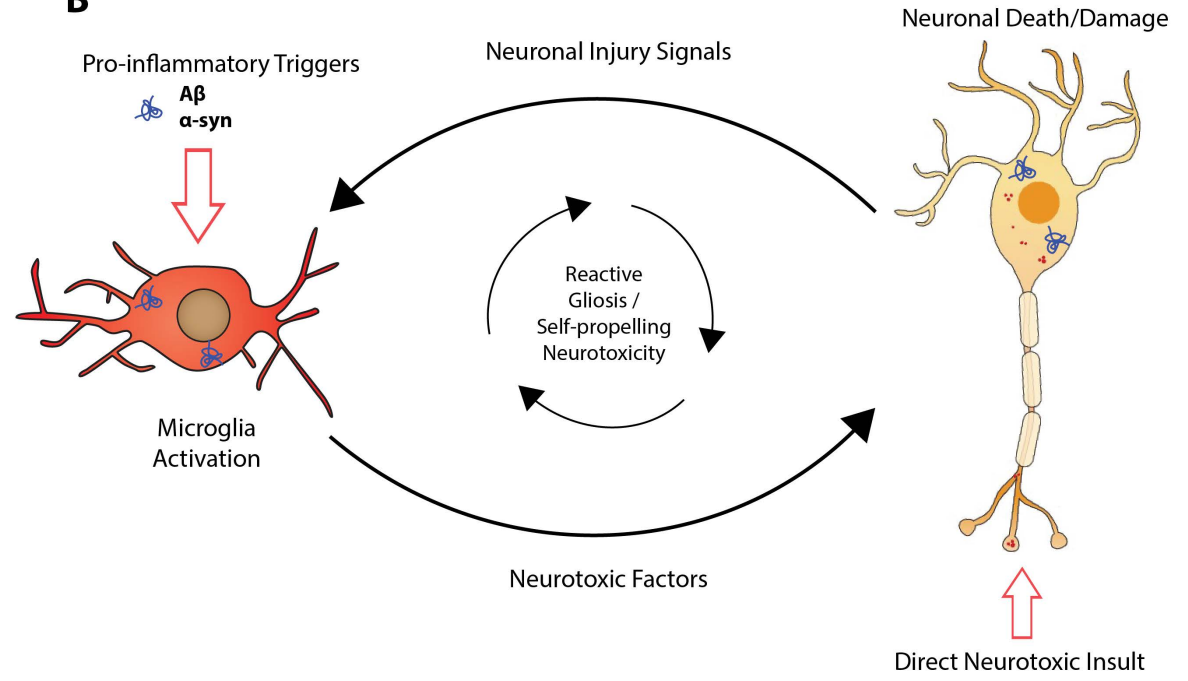

Figure 3. Neuroinflammation in NDs. (A) Spectrum of activation states of microglia. The molecules that induce the pro-inflammatory $(M 1)$ or the anti-inflammatory $(M 2)$ activation pathways are indicated in the upper box for each of the phenotypes, with some examples of molecules expressed by the different states in the lower box. (B) Reactive microglia drive a feedback loop of neuronal damage in NDs. Stimulation of microglia with pro-inflammatory triggers (including $A \beta$ and $\alpha$-syn), or through direct neuronal damage, results in microglial activation that initiates the release of neurotoxic factors. These microglial activators stimulate additional microglia, which in turn release proinflammatory mediators in a positive-feedback mechanism. This self-perpetuating cycle of neurotoxicity is known as reactive microgliosis. CCL18, chemokine (C-C motif) ligand 18; COX2, cyclooxygenase 2; CXCL13, chemokine (C$X-C$ motif) ligand 13; G-CSF, granulocyte colony-stimulating factor; IFN $\gamma$, Interferon- $\gamma ;$ IL, interleukin; LPS, lipopolysaccharide; TGF $\beta$, transforming growth factor- $\beta$; TLR, toll-like receptor; TNF $\alpha$, tumor necrosis factor- $\alpha$; $R O S$, reactive oxygen species. 
During chronic neuroinflammation in NDs, it is hypothesised that the pro-inflammatory environment initiated by the innate immune system enhances aggregated protein accumulation, which either causes or accelerates pathological cascades (Figure 3B). For example, A $\beta$ peptides induce the activation of primary microglia and stimulate nitric oxide production in vitro [58,59], and amyloid plaques attract and stimulate microglia cells in vivo [60]. Neurons also stimulate the production of pro-inflammatory cytokines, which may start or accelerate local inflammation and neurodegeneration in $\mathrm{AD}[61,62]$. Prolonged activation of the immune system, likely due to sustained exposure of microglia to $A \beta$, initiates a positive feedback loop, referred to as reactive microgliosis. However, it appears that microglia in $\mathrm{AD}$ patients exhibit mixed activation phenotypes, as probed cortical tissue from tg-2575 and tg-SwDi mice and AD patients demonstrated a mixed profile of pro- and anti-inflammatory activation genes [63]. This indicates that there is a failure in the resolution of neuroinflammation (i.e. microglia failing to return to a resting state), that there a deficiency in the repair process (i.e. microglia losing phagocytic efficiency), or both. This could be attributed to the age-dependent increase in the prevalence and prominence of $\mathrm{A} \beta$ plaques in $\mathrm{AD}$, combined with the age-related reduction in microglial phagocytic capability [64,65]. In PS1M146L/APP751SL mice, microglia confer an antiinflammatory phenotype around $A \beta$ plaques during the first 6 months, when $A \beta$ load is relatively low, but switch into a pro-inflammatory phenotype at 18 months of age, coincident with accumulated levels of $A \beta$ [64]. This is likely due to the phagocytic activity of microglia being attenuated by pro-inflammatory cytokines [66], which most likely continuously shifts microglia into the pro-inflammatory state from the steady accumulation of $\mathrm{A} \beta$.

Interestingly, different forms of $A \beta$ peptides may induce different inflammatory profiles of microglia. oA $\beta$ appears to be a stronger pro-inflammatory inductor than the fibrillar forms and an anti-inflammatory environment reduces microglial reactivity towards oA $\beta$ [67]. Aged PS1M146L/APP751SL mice exhibited activated microglia in the hippocampus prior to the formation of hippocampal $A \beta$ plaques, whereby the pro-inflammatory microglia were found to induce cellular damage to the hippocampal neurons [64]. This was associated with the accumulating levels of oA $\beta$ switching the microglia phenotype into a pro-inflammatory state [64], further implicating $\mathrm{oA} \beta$ as the driving force of $\mathrm{AD}$ pathology before the formation of plaques. As microglia are able to transition between phenotypes, there is the possibility that phenotype switching may provide neuroprotection. How this contributes to AD pathology is not well understood, as the induction of an anti-inflammatory environment has been shown by some authors to decrease $\mathrm{A} \beta$ accumulation and alleviate $\mathrm{AD}$ symptoms [68-70], while others demonstrate that this promotes $A \beta$ accumulation and worsening of $A D$ symptoms [71,72]. However, to be clinically effective, targeting the pro- and anti-inflammatory balance will likely require patient-specific adaptations since the temporality and severity of the disease are critically associated with the changing of microglial activation states (further reviewed in [73]).

In PD, microglial activation may be initiated either directly or indirectly by misfolded $\alpha$-syn or other environmental toxins (Figure 3B). Pro-inflammatory microglia are shown to surround dopaminergic neurons, whereby microglial activation is inversely correlated with the dopaminergic neuron survival in PD patients [74]. Numerous studies have shown that aggregated $\alpha$-syn released into the extracellular space can directly induce microglia towards the pro- 
inflammatory phenotype, thereby increasing production of ROS and pro-inflammatory cytokines [75-77]. In addition, the suppression of anti-inflammatory activation leads to an enhancement of pro-inflammation cytokines and nitric oxide, causing increased dopaminergic neuron death [78]. The role of microglia and neuroinflammation in PD is still largely unknown, however, the general hypothesis and approaches from AD could be applied to future studies.

\section{Extracellular vesicles}

Extracellular vesicles (EVs) are small membranous vesicles that are critical for intercellular communication and transporting cargo. They were first observed over 50 years ago in the plasma [79]. Since then, all biological fluids and in vitro cell lines have shown to contain or release vesicles [80]. EVs are currently characterised according to their mechanism of release and size. EVs are lipid-bilayer enclosed vesicles that are released into the extracellular environment following the fusion of MVBs with the plasma membrane or through the direct budding of the plasma membrane itself. However, due to the lack of specific markers for EV subtypes, it is often encouraged to categorise EVs based on their size, density, or biochemical composition. For this thesis, small EVs of vesicle size less than $200 \mathrm{~nm}$ are referred to as "exosomes" and assumed to have endosomal origins (Figure 4). Other EVs, often referred to as "microvesicles", "ectosomes" or "apoptotic bodies", usually range from 100-1000 nm and are plasma membrane-derived but will not be further discussed in this work.

\section{Exosomes in NDs}

Exosomes are released into the extracellular environment and play an important role in intercellular communication by transferring proteins, lipids, mRNA, and miRNA between cells. In the CNS, exosomes can mediate neuronal and glial communication, as well as promoting neuronal repair and growth (reviewed in [81]). Exosomes also function as a mechanism for the disposal of unwanted intracellular material, especially under cellular stress or impaired degradation mechanisms [82]. In NDs, cell to cell contact and passive spreading of aggregated proteins were initially thought to be the means at which these proteins spread, therefore propagating disease to interconnected brain regions. However, exosomes have since been shown to propagate proteinopathy between cells (Figure 2B). Studies have shown A $\beta, \alpha$-syn and tau can be found within exosomes and that these protein-containing exosomes can facilitate the transmission of these misfolded proteins between cells (described below). In patients, exosomes containing these ND-associated proteins have been found in the CSF and blood of individuals afflicted with their respective disorders (reviewed in [83]).

The full-length APP protein and many of its metabolites have been found in exosomes isolated from in vitro cell cultures as well as the CSF and blood of AD patients. APP and its C-terminal fragments have been consistently identified in exosomes, and importantly, many of the proteases involved in APP processing have also been found in exosomes [84,85]. This suggests that proteolytic processing of APP may occur in situ in the exosome microenvironment. It has been reported that exosomes can enhance the aggregation of $A \beta 42$ [86], but also that exosomes from 
AD brains contain an elevated amount of oA $\beta$ [26]. This may lead to the spreading of AD pathology as exosomes isolated from $\mathrm{AD}$ patients act as a vehicle for spreading toxic species in vitro [26] and in vivo [87]. Conversely, expulsion of $A \beta$ through exosomes may be a cellular protective mechanism, such that cells overburdened with $\mathrm{A} \beta$ attempt to rid themselves of the excessive protein load [88,89]. In addition to $A \beta$, exosomes isolated from PD patients induce synucleinopathy in vivo [90], possibly due to toxic species of $\alpha$-syn accelerating exosomal production [91] and exosomal $\alpha$-syn preferential uptake compared to free $\alpha$-syn [54]. In vitro investigations also demonstrated that tau secretion is mediated by exosomes and contributes to the progression of tauopathy [92-95]. Given the increasing understanding that exosomes may play a major role in NDs and can be found in plasma and CSF, it is possible that exosomes and their molecular cargoes could be used as biomarkers for NDs.

\section{Exosome biogenesis}

Exosome biogenesis begins with early endosomes maturing into late endosomes or MVBs, during which the endosomal membrane invaginates to generate intraluminal vesicles (ILVs) [96]. MVBs then either fuse with lysosomes (which degrades their content) or with the plasma membrane to shed off the vesicles into the extracellular space (Figure 4). The ILVs are formed by the fission of the membrane inwards by sorting complexes of proteins and/or lipids, encapsulating surrounding cytosol and other molecules. The most understood pathway for formation of MVBs and ILVs is the endosomal sorting complex required for transport (ESCRT)-dependent mechanism. The ESCRT-dependent pathway requires the assembly of four complexes (ESCRT-0, -I, -II, -III), made up of approximately thirty proteins (e.g. VPS4, ALIX, VTA1) (Figure 4A) (reviewed in [97]). However, MVBs and ILVs can also be formed via ESCRT-independent pathways, including regulation by tetraspanins such as CD63 and CD81 (Figure 4B) [98]. Formation of ILVs can also be produced through lipid metabolism enzymes such as neutral sphingomyelinase (nSMase), which hydrolyse sphingomyelin into ceramide [99], or phospholipase D2, which hydrolyses phosphatidylcholine into phosphatidic acid (Figure 4C) [100]. However, whether these different machinery pathways act on specific MVB populations, or if they simultaneously act on the same $\mathrm{MVB}$, is still being elucidated. It is also of key importance to understand that exosomes from a single cell type, tissue, or biological fluid can differ greatly in composition, although the complexity of exosomes is only beginning to be illuminated (Figure 5) [101,102]. 


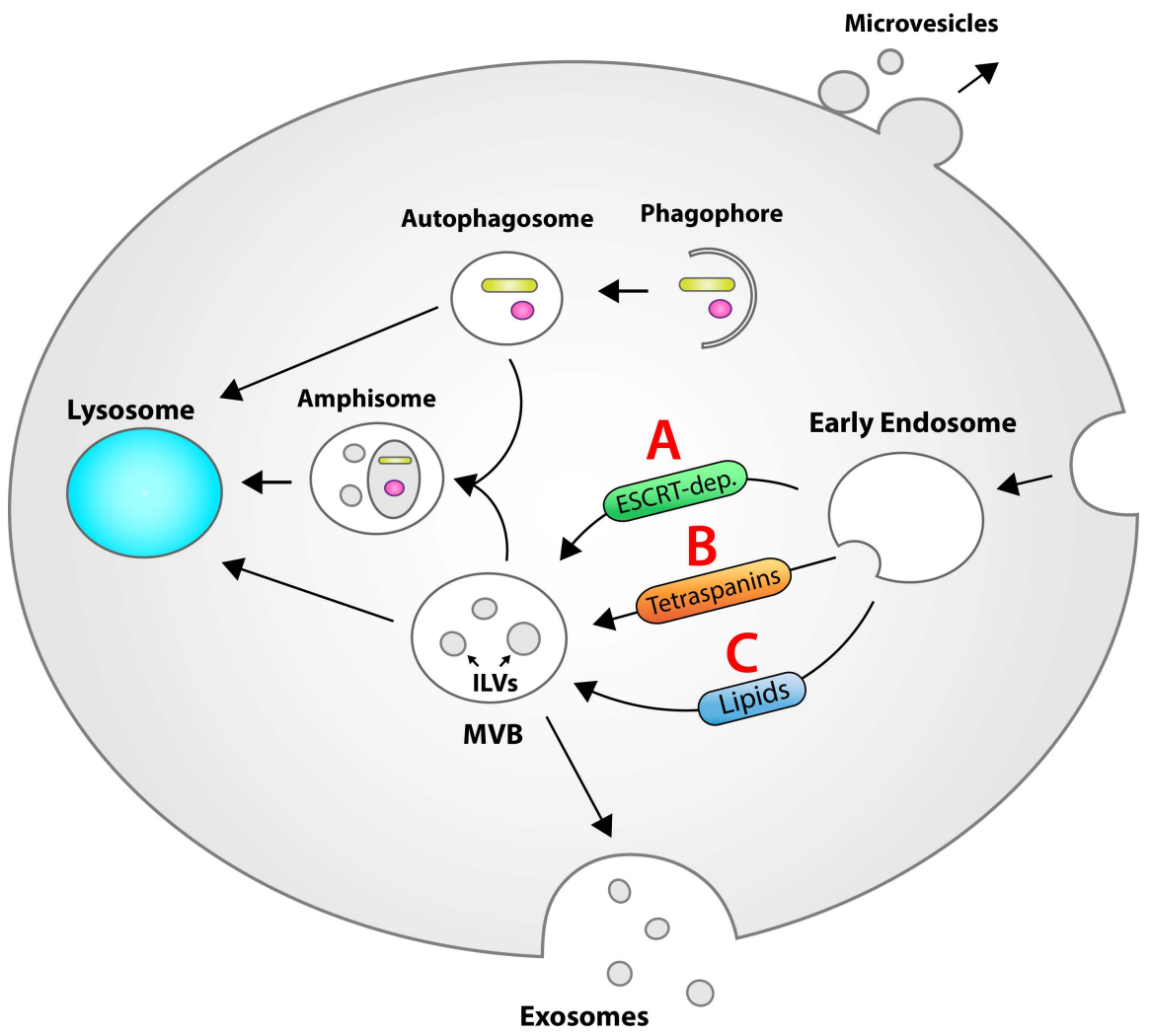

Figure 4. Biogenesis of exosomes. The maturation of early endosomes gives rise to multivesicular bodies (MVBs), late endocytic compartments containing many intraluminal vesicles (ILVS). Fusion of MVBs with the plasma membrane results in the release of ILVs into the extracellular space as exosomes. Other vesicles can be shed from the cell by direct budding from the plasma membrane (e.g. microvesicles). Multiple machineries are involved in the biogenesis of ILVs, and thus of exosomes, such as (A) ESCRT components, (B) tetraspanins, and (C) lipids. Autophagy also starts with the nucleation and expansion of phagophores, which engulf cytoplasmic proteins and organelles. Sealing of the phagophores results in the formation of autophagosomes, which fuse with lysosomes to degrade engulfed contents. Alternatively, autophagosomes can fuse with MVBs to form hybrid organelles termed amphisomes, which are also believed to fuse with lysosomes. ESCRT-dep.; ESCRT-dependent. 


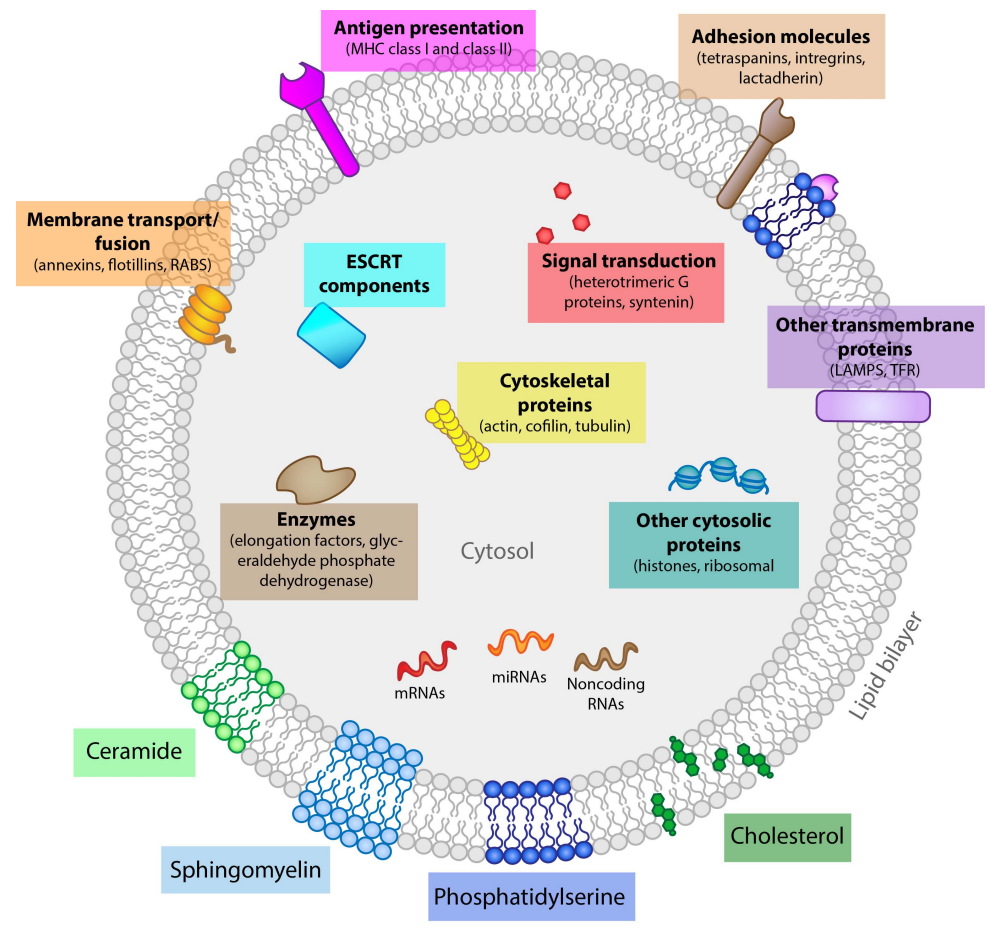

Figure 5. Composition of exosomes. Composition and components of exosomes vary greatly and may be present in some subtypes while absent in others. The schematic depicted here shows commonly found exosome components.

\section{Sphingolipids and ESCRT-independent exosomes}

Sphingolipids have long been viewed as ubiquitous components of the cell membrane, having a critical role in regulating vital cell functions, but also in the formation of membrane microdomain "lipid rafts", important for integrating cell signalling. Sphingolipids are particularly abundant in the brain and are essential for the development and maintenance of the functional integrity of the nervous system, but are also heavy regulators of apoptosis (reviewed in [103]). Ceramide constitutes the fundamental building block for which more complex sphingolipids assemble, consisting of a long-chain sphingosine base with an amide linkage to a fatty acid (Figure 6A) [104]. Sphingolipids constitute a very diverse group of lipids, which account for several hundred different lipid species due to their structural diversity and combinations within fatty acids chains (N-acyl chains), along with the multitude of variant head groups (shown as the "R" group in Figure 6A) [105-108]. Sphingolipid synthesis can occur via the de novo biosynthetic pathway which starts with the condensation of serine and palmitoyl-CoA, the hydrolysis of sphingomyelin, or by the "salvage pathway" which recovers sphingosine by the recycling of other complex sphingolipids through the action of enzymes (Figure 6B) [109]. 
A

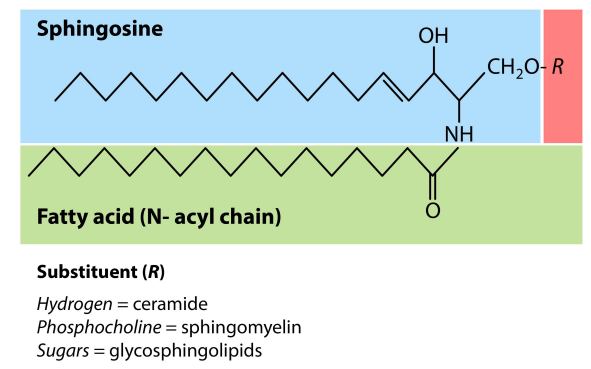

B

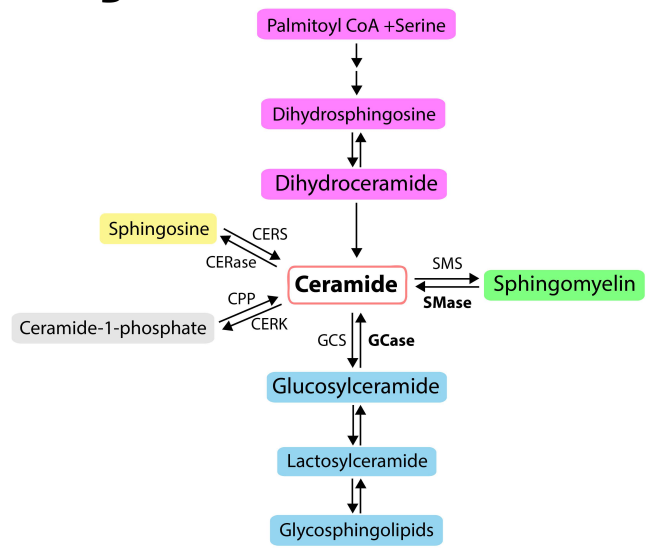

Figure 6. General sphingolipid structure and synthesis pathways. (A) Basic sphingolipid structure. Sphingolipids are composed of a sphingosine backbone linked to a fatty acid, which can vary in length $(N)$, via an amide bond. There are three main types of sphingolipids, which differ in their hydrophilic attachments $(R)$ : ceramides, sphingomyelins, and glycosphingolipids. (B) Overview of sphingolipid metabolism and related enzymes. CERase, ceramidase; CERK, ceramide kinase; CerS, ceramide synthase; CPP, ceramide-1-phosphate phosphatase; CoA, coenzyme-A; CERS, ceramide synthase; GCS, glucosylceramide synthase; GCase, glucosylceramidase; SMase, sphingomyelinase; SMS, sphingomyelin synthase.

Defects in sphingolipid metabolism have been linked to numerous neurological diseases, including AD, PD, epilepsy, Huntington's disease, Krabbe's disease and Gaucher's disease. Ceramides are elevated in the AD brain [110-112] and have been shown to correlate with $A \beta$ generation and tau phosphorylation [113,114]. Additionally, elevated serum ceramide may be a risk factor for both $\mathrm{AD}$ and PD and has been suggested as a biomarker for people with dementia [115-118]. A number of studies have reported that mutations in the ceramide-producing enzyme glucocerebrosidase (GCase) gene $G B A$, increases susceptibility to developing sporadic PD [35,36], and reduced activity of GCase has been documented in the brain of PD patients $[119,120]$. These findings are supported by in vitro data, where GCase knockdown was found to promote the accumulation of $\alpha$ syn in neurons [121]. Alterations in the expression of ceramide synthase genes and their related ceramide species have been reported in brain tissues from sporadic PD patients, although it has been speculated that lipid dysregulation may be region specific [120,122-125]. Consistently, LRRK2 (a familial PD gene) knockout (KO) mice showed a significant increase in brain ceramide that also correlated with decreased GCase activity [126], tying a commonality of sphingolipid dysregulation in familial and sporadic PD. It has also been suggested that specific acid SMase (aSMase) variants are associated with PD and that reductions in the activity of these specific aSMases were associated with an earlier age of onset [127], possibly as a result of reduced lysosomal localisation of aSMase, influencing accumulation of $\alpha$-syn. 
During the generation of exosomes, sphingolipid-enriched lipid rafts from the originating cell are incorporated into the exosome structure $[99,128,129]$. The formation of exosomes in the MVB can arise through the ESCRT-independent pathway, wherein sphingomyelin is hydrolysed by nSMase to produce ceramide, causing the plasma membrane to bud inwards (Figure 4C). There are four different nSMase isoforms, with nSMase 2 being predominantly expressed in the brain relative to other the isoforms [130]. nSMase 2 has been shown to mediate pro-inflammatory cytokine signalling [131,132] and is activated during oxidative stress [133,134], implicating it having an important role in NDs. It has been suggested that under normal conditions, nSMase 2 primarily exists as an inactive enzyme, while oxidative stress initiates its movement to the plasma membrane where it can generate ceramide and its downstream effects [135]. Moreover, nSMase 2 is activated in response to $A \beta$ peptides [136,137], which may be linked to exosomal acceleration of $A \beta$ aggregation and spreading $[88,138,139]$. Exosomes are reduced through the inhibition of nSMase2 in vitro $[88,95,99,138]$ and in vivo, where the inhibition of nSMase 2 in 5XFAD mice led to the reduction of $A \beta$ plaques and decreased serum levels of most ceramide species [114]. nSMase 2 derived exosomes may represent a common mechanism for the transfer of misfolded proteins, as this pathway has also been implicated in the packaging and transmission of the prion protein [140]. This phenomenon of packing misfolded proteins into exosomes might also provide a more efficient means of cellular uptake during NDs, as exosomal o $\alpha$-syn has been shown to be taken up more readily than free o $\alpha$-syn [54]. Lipid rafts in PD brains have reduced total sphingomyelin levels [123], which may affect not only the binding behaviour of $\alpha$-syn to the plasma membrane [141143] but also the structural properties of exosomes themselves. These alterations to the composition and binding kinetics likely influence the exosome's ability to propagate $\alpha$-syn to neighbouring cells.

\section{Cross talk between autophagy and exosomes}

Macroautophagy (hereafter referred to as autophagy) is a degradative pathway critical in the maintenance of proteostasis, as well as the preservation of proper organelle function through the selective removal of proteins and damaged organelles. In autophagy, whole cytosolic regions are sequestered inside double-membraned vesicles (autophagosomes) that are then able to fuse with either lysosomes, which provide the hydrolytic enzymes for the degradation of autophagosomal content, or MVBs (Figure 4). Autophagy-related genes (ATG), the genes necessary for autophagy, comprise of more than 30 genes [144]. The rate of autophagy turnover, or autophagy flux, is regulated by many different signalling pathways and is heavily influenced by stressors such as starvation, reactive oxygen species, and hypoxia. The most understood regulator of autophagy is nutrient availability, which is mediated through the mechanistic target of the rapamycin (mTOR) pathway (reviewed in [145]).

In the AD brain, autophagosomes accumulate in the dystrophic neurites, an indicator of impaired autophagy [146]. During AD, both the autophagy-inhibiting mTOR signalling and lysosomal hydrolases are increased [147], possibly due to interactions with A $\beta$ itself [148]. Autophagosomes also generate and contain $A \beta$ [149] and oxidative stress-induced autophagy increases $A \beta$ generation [150]. In sporadic PD, impaired autophagy and endolysosomal activity are thought to 
contribute to the reduced clearance of $\alpha$-syn, which then leads to $\alpha$-syn accumulation and aggregation [151,152]. This is supported by an in vitro study showing that the presence of $\alpha$-syn inclusions specifically inhibits transport of endocytic and autophagic vesicles [153]. Additionally, overexpression of $\alpha$-syn in vitro and in vivo leads to compromised autophagosome biogenesis [154], which may act as a driving force for PD pathology by preventing sufficient $\alpha$-syn degradation.

It was recently reported that human CSF-derived exosomes have an autophagosome-exosome-like profile (having autophagy markers SQSTM1 and LC3-II) [155], emphasising that exosomes can be used as vehicles for material disposal from autophagy pathways. Other studies have also uncovered some of the molecular machinery and regulatory mechanisms shared between exosome biogenesis and autophagy, suggesting that the two processes are intimately linked. Studies on ESCRT-pathway protein mutants CHMP2B and VPS25/28/32 revealed that cells harbouring these mutations were unable to complete autophagic maturation due to the lack of autophagosome fusion with the endolysosomal system and exhibited an increased number of autophagosomes [156,157]. Induction of autophagy through starvation or rapamycin treatment causes inhibition of exosome release, suggesting that the failure to release exosomes leads to the redirection of MVBs to autophagic degradation, perhaps as cells attempt to recycle MVBs for energy instead [158]. Accordingly, KO of ATG5 or ATG16L1 caused significantly reduced exosome release [159]. In addition, the loss of the ATG12-ATG3 complex altered MVB morphology, impeded late endosome trafficking and reduced exosome biogenesis [160]. Alterations in the exosome protein composition may affect intercellular communication during pathology. For example, ATG7 knockdown decreases extracellular exosome-associated Hepatitis C virus [161], suggesting that the core autophagy machinery plays a role in the packaging of virus particles into exosomes. It is speculated that a similar mechanism occurs with ND-associated proteins, as AGT7 KO x APP23 mice led to the altered vesicle-mediated trafficking of $A \beta$ through a decrease in the number of $A \beta$-containing vesicles in MVBs upon disruption of autophagy [162].

\section{Exosomes as a diagnostic tool}

$\mathrm{AD}$ diagnosis is typically made long after the first signs of illness, as the early symptoms can overlap with other diseases and can be quite varied [163]. According to the criteria outlined by the NIAAA, definitive diagnosis is only possible after post-mortem determination of the essential neuropathological hallmarks of A $\beta$ plaques and NFTs, although there is a movement towards the possibility of definitive molecular diagnosis in the latest suggestions for research diagnostic criteria [18,164]. Clinical diagnosis is still largely dependent on the clinical assessment of neuropsychiatric function but also supported with CSF biomarkers targeting A $\beta$ and tau, and PET imaging of metabolic activity [165]. PET has shown high sensitivity and specificity of detecting A $\beta$ plaques and NFTs in the living brain [166], however, they are currently only used in research. Reduced levels of $A \beta 42, A \beta 42 / A \beta 40$ ratio, and increased levels of tau and phosphorylated tau in CSF increase the accuracy of clinical diagnosis of cognitive impairment, however, there is still a significant error rate [18]. It is also highly speculated that the pathophysiological process of AD begins decades before diagnosis and the buildup of $A \beta$ peaks at the beginning of the mild cognitive 
impairment stage [9]. It has been hypothesised that clinical trials such as anti-A $\beta$ immunotherapies have failed due to being administrated too late in disease progression, where there is irreversible damage to the cells [9]. In the future, it may be possible to revisit these therapeutics in earlier, more accurately diagnosed individuals, who may see cognitive improvements from these therapies.

Exosomes can travel substantial distances once released from cells before being absorbed by another cell, potentially able to circulate the whole body [167]. The CNS is protected from invading pathogens and molecules by the blood-brain barrier (BBB); however, exosomes readily pass through the BBB from the brain to the periphery and vice versa. This feature of exosomes indicates that CNS-derived exosomes and peripheral exosomes could serve as an important material for ND biomarkers $[168,169]$. In fact, late-onset AD patients have been shown to express an increased $A \beta 42 / A \beta 40$ ratio in the CSF [170]. Elevated levels of oA $\beta$ have also been measured in brain-derived exosomes of AD patients, which were shown to transfer oA $\beta$ between cells, subsequently eliciting neurotoxic effects in vitro [26]. Since oA $\beta$ correlates with the synaptic loss and cognitive decline [21,22] and may be an early event in $A D$ pathology, detection of $\mathrm{OA} \beta$ in exosomes may be a useful early biomarker. Currently, oA $\beta$ has not been measured in plasma exosomes and $\mathrm{oA} \beta$ in total plasma has not shown any differences between $\mathrm{AD}$ patients and controls $[171,172]$. However, a limitation of using plasma for this purpose is that the majority of the exosomes in plasma originate from erythrocytes and platelets, making the detection of the relatively few neuronal exosomes challenging. However, the adaptation of exosomes from different sources may be used in concert with the detection of other ND proteins and are a promising avenue to explore for the early diagnosis of NDs. 


\section{AIMS}

The general aims of the studies in this thesis were to investigate how the aggregate prone proteins $A \beta$ and $\alpha$-syn propagate between cells in models of AD and PD.

\section{Specific Aims}

Paper I: What are the effects of the different inflammatory phenotypes (M1/M2) on the transfer of oA $\beta$ between cells?

Paper II: Is the exosomal ESCRT-independent pathway implicated in the transfer of a significant portion of o $\alpha$-syn between cells and does hypoxia influence this pathway?

Paper III: Does the inhibition of autophagy affect the degradation of A $\beta$ through alternations in autophagosome fusing with the endolysosomal system and does this modify exosome secretion?

Paper IV: Can the CSF from AD patients detect exosomal oA $\beta 42$ and can this be used as an early biomarker? 


\section{METHODOLOGY}

\section{Models and sample material used}

\section{In vitro models}

\section{SH-SY5Y cells}

The SH-SY5Y cell line was used for Papers I and II. The SH-SY5Y neuroblastoma cell line originates from SK-N-SH cells, which were taken from a bone marrow biopsy from a 4-year-old girl in the 1970s. The SK-N-SH cells were subcloned to generate the SH-SY5Y cells, which express better neuronal characteristics. The Hallbeck lab has previously developed a differentiation protocol where the SH-SY5Y cells are treated with retinoic acid for 7 days, followed by a 10-day differentiation in extracellular matrix gel with a growth factor cocktail containing brain-derived neurotropic factor, neuregulin $\beta 1$, nerve growth factor, and vitamin $\mathrm{D}_{3}[24,173]$. This differentiation process results in cells with a neuron-like morphology that form extensive neuritic networks and express neuronal markers (Figure 7).

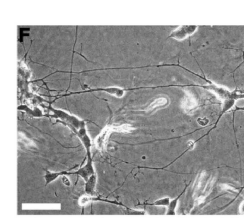

7d RA differentiated + $10 \mathrm{~d}$ in gel with Vit D3, NGF, NRG $\beta 1$, and BDNF
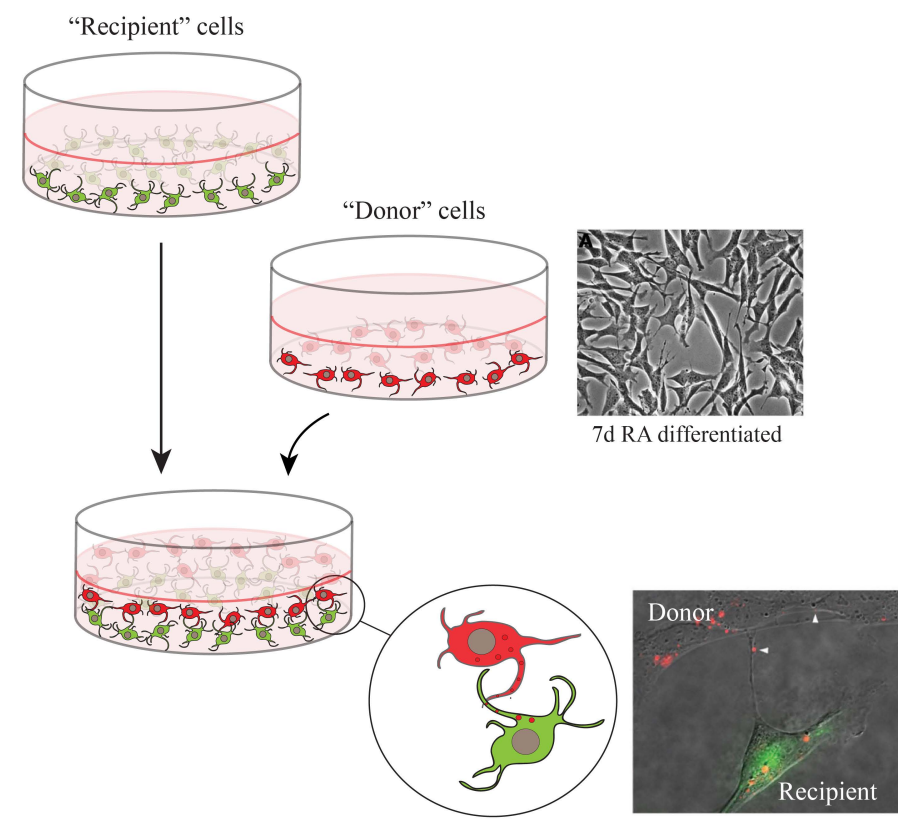

Figure 7. Donor and recipient co-culture model of SH-SY5Y cells. "Donor" cells are differentiated for 7 days with $R A$ and loaded with exogenous $A \beta$ or $\alpha$-syn labelled with AlexaFluor700 (red). "Recipient" cells are further differentiated for 10 days in gel with a growth factor cocktail. Recipient cells express GFP, either through transient or stable expression of GFP-containing constructs (green). Donor cells are placed on top of recipient cells for 24 hours to study the transfer of the labelled proteins. BDNF, brain-derived neurotropic factor; NRG $\beta 1$, neuregulin- $\beta 1$; $N G F$, nerve growth factor; RA, retinoic acid; Vit D3, vitamin D3. Images adapted from Agholme et al. J Alzheimers Dis 2010 and Nath et al. JNeurosci 2012 [24,173]. 


\section{Co-culturing}

Prior to the co-culturing of SH-SY5Y cells, the "recipient" cells are differentiated for 7 days in retinoic acid, followed by a further 10-day differentiation in extracellular matrix gel supplemented with growth factors as described above. "Donor" cells are differentiated for 7 days in retinoic acid and fed with either oA $\beta$ or o $\alpha$-syn tagged with AlexaFluor700 (AF700). Recipient cells in Paper I were transfected with BacMam baculoviral agent in order to express green fluorescent protein (GFP), while recipient cells in Paper II utilised stably expressing $\beta$-Actin-GFP SH-SY5Y cells to allow us to distinguish the donor and recipient cell populations (Figure 7). The stably expressing GFP cells allowed us to quantify the rate of transfer more accurately, as BacMam transfection is relatively inefficient, allowing for possible false negatives.

\section{Genetic modification techniques (siRNA and CRISPR/Cas9)}

Cells in Paper II reduced the SMPD3 gene by two different methods. Oneof the techniques was small interfering RNA (siRNA), which interferes with the expression of the gene by introducing complementary nucleotide sequences against a gene of interest, which causes the inability of the messenger RNA to be translated, where it is then degraded. siRNA is a common and easy to use method to downregulate genes but suffers the pitfall that its effectiveness is tied to the turnover rate of the gene of interest. This technique is well suited to studying the acute effects of gene knockdown. In order to study this system with a more robust gene reduction, we elected to use clustered regularly interspaced short palindromic repeat (CRISPR)/Cas9 to generate an SMPD3 KOcell line. The CRISPR/Cas9 system functions as the RNA-based adaptive immune system in bacteria and archaea. Complexed with a synthetic guide RNA, the Cas9 nuclease containing construct enters the nucleus of the cell, where it opens both strands of the targeted sequence of DNA. KOof the gene occurs through errors in the cellular repair machinery after an induced double-strand break, resulting in random deletions or insertions at the repair site. These insertions and/or deletions cause changes to the reading frame of the DNA (e.g. frameshift, missense or nonsense mutations), ideally leading to premature stop codons that result in dysfunctional proteins. siRNA transfection was carried out according to the manufacturer's instructions and CRISPR/Cas9 plasmid design and assembly were performed according to the protocol of Ran et al. [174].

\section{Macrophage conditioned media}

Until recently, immortalised human microglia were unavailable, making them difficult and costly to culture from post-mortem tissue. Therefore, we opted to use human monocyte-derived macrophages as a comparative myeloid analogue to study the effects of inflammatory factors on the SH-SY5Y cells in Paper I. Human monocytes were isolated and purified from peripheral blood mononuclear cells (PBMC) of buffy coats obtained from healthy volunteers (Clinical Immunology and Transfusion Medicine Department of Karolinska Institute, Sweden). Ethical permission for the experiments was obtained from the Regional Ethical Review Board in Stockholm, Sweden (approval number: 2013/1458-31/1). In short, isolated monocytes were left unstimulated (M0) or stimulated with lipopolysaccharide and interferon- $\gamma$ (M1: pro-inflammatory) or IL-4, IL-10 and TGF $\beta$ (M2: anti-inflammatory). The conditioned media (CM) collected from the macrophages was 
cultured with SH-SY5Y cells to mimic different inflammatory environments. Using this approach, we were able to gain insight as to how surrounding inflammatory milieu affects the transfer of oA $\beta$ without interference of phagocytosis by the macrophages.

\section{Transgenic mice}

In Paper III, Atg $7^{\text {floxflox }} x$ CamKII-Cre $x A p p^{N L-F}$ mice were used, which are referred to as ATG7 cKO $x$ APP KI in this thesis. Neuron-specific KO of the autophagy-related gene Atg7 was

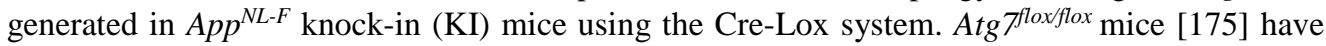
two loxP sites which compose of short target sequences flanking Atg7. Cre recombinase catalyses recombination between the two loxP sites. CamKII-Cre mice [176] express Cre only in the excitatory neurons in the forebrain, the neurons canonically associated with the CamKII promotor. These mice were then crossed with $A p p^{N L-F} \mathrm{KI}$ mice [177]. The targeted APP KI construct contains humanised APP expressing two pathogenic mutations, KM670/671NL (Swedish) and I716F (Iberian). These mice contain an endogenous mouse App promoter, so the construct is expressed with appropriate cell-type and temporal specificity. Around six months of age, marked elevation of $A \beta 42$ is observed, relating to the combined effects on the APP proteolysis of NL-F mutant APP, which increases total $A \beta$ and $A \beta 42$. All animal experiments were carried out according to the guidelines of the RIKEN Brain Science Institute.

\section{CSF}

Paper IV used exosomes isolated from CSF (see the Exosome isolation section below) from healthy control and AD patients (characterised by clinical evaluation), to try to identify an early biomarker within the CSF itself. CSF samples from patients suffering from normal pressure hydrocephalus were used for method development. All fresh-frozen CSF samples were provided by the brain bank at Uppsala University, Sweden. None of the healthy control nor the normal pressure hydrocephalus patients suffered from dementia or any cognitive deficiency at the time of sample collection. All subjects were anonymized, and ethical permits were obtained by the upholder of the biobank for biochemical diagnostics of dementia (nr 2005/244 and Ö 48/2005).

\section{Generation of oligomeric proteins}

\section{A $\beta$}

Paper I and Paper IV used oligomeric A $\beta 42$, the preparation of which has been well described in the Hallbeck lab [24-27,178]. In brief, A $\beta 42$ peptides are dissolved in hexafluoroisopropanol, lyophilised, and re-suspended in $\mathrm{Na}_{2} \mathrm{CO}_{3}$ with AF700. The sample was then vortexed, sonicated, and incubated overnight at $4{ }^{\circ} \mathrm{C}$ to generate oligomers. 
$\alpha-\operatorname{syn}$

Paper II used oligomeric $\alpha$-syn that was prepared as previously described $[51,179,180]$. Monomeric $\alpha$-syn was incubated with an excess of 4-hydroxy-2-nonenal (HNE) during the formation of oligomers, which was performed by shaking for 7 days at $37^{\circ} \mathrm{C}$. $\mathrm{HNE}$ is an end product of lipid peroxidation, which promotes $\alpha$-syn oligomerization by inducing $\beta$-sheet formation and covalently linking monomers. Afterwards, the sample was equilibrated with $\mathrm{Na}_{2} \mathrm{CO}_{3}$ and incubated with AF700.

\section{Size exclusion chromatography}

Size exclusion chromatography (SEC) was used to collect separate fractions of A $\beta$ and $\alpha$-syn aggregates according to their size, as well as to ensure that unbound AF700 and unlabelled A $\beta$ and $\alpha$-syn were removed from the preparation. SEC separates aqueous molecules based on their size by processing them through a porous, gel-filtration column. In this system, small molecules enter the pores while traversing the column, therefore eluting slower than large molecules, which take a direct route through the column. This allows the user to collect different fractions from a solution according to their size.

\section{Exosome isolation \\ Ultracentrifugation}

Exosomes isolated from cell culture supernatant (Paper II) or mouse brain tissue (Paper III) were isolated by differential ultracentrifugation. In brief, brain tissue was digested in papain and spun down at 300x g to remove undigested tissue. The supernatant from the tissue or cells were then spun at 2000x $\mathrm{g}$ to remove cells and cell debris. The supernatant was subsequently spun at $10000 \mathrm{x}$ $\mathrm{g}$ and $100000 \mathrm{x} \mathrm{g}$ to pellet the exosomes.

\section{qEV}

To isolate exosomes from CSF in Paper IV, qEV columns were used. qEV columns are specifically designed for the isolation of EVs, doing so by SEC in a manner similar to that described above in a proprietary resin. Whole CSF is added to the top of the column and collected in fractions. The exosome-enriched fractions are pooled together for the downstream applications. This method removes a significant proportion of contaminating proteins which is critical in the use of exosomes as a potential diagnostic tool to remove any compounding factors.

\section{Exosome size distribution and concentration}

The size distribution of our exosomes was determined by nanoparticle tracking analysis (NTA) in Paper II and Paper III and tunable resistive pulse sensing (TRSP) in Paper IV. NTA visually tracks and analyses particles in solution by relating the rate of Brownian motion of particles in solution to particle size. In this process, the particles are visualised by the amount of light that they 
scatter when illuminated by a laser. The motion of each particle is tracked by a digital camera to determine its size, using the Stokes-Einstein equation. TRSP uses a transient current pulse caused by a particle traversing a pore that is directly proportional to particle volume. The particles measured are compared to a set of calibration particles of a known size.

Although both the instruments are capable of determining particle concentration, NTA analysis was not available in our Core Facility and TRSP is limited to only particles in the size range of the pore. To make sure we included all isolated exosomes for quantification, we used the FluoroCet quantitation kit to determine exosome concentration in Papers II and III. FluoroCet is a fast and sensitive method that uses a fluorescence-based, enzymatic assay that measures acetylcholinesterase (AChE), a protein known to be present inside of exosomes.

\section{Western blot}

Western blot is a widely used technique to measure the relative protein content of a given sample. In Paper II, this method was used to determine the effectiveness of the disruption of nSMase 2 and intracellular $\alpha$-syn. Papers II, III, and IV used Western blot to characterise our exosome isolations, by examining the presence of exosome markers such as Flotillin-1, Alix, CD63, and CD81, along with the absence of the cellular marker Calnexin and synaptic vesicle marker Synaptophysin. Proteins are lysed in an SDS and DTT-containing solution, denatured, and loaded into a gel, where a current is applied to separate them by molecular weight through electrophoresis. Once the proteins are sufficiently separated, they are transferred onto a nitrocellulose membrane. This is followed by detection of the protein of interest with a protein specific antibody, which is followed by incubation with a secondary antibody conjugated to horseradish peroxidase (HRP). The HRP converts a reporter substrate into a chemiluminescent product which can be visualised with a photo imaging system.

\section{Flow cytometry}

Flow cytometry is based on the light scattering and fluorescence emission of single cells contained in moving droplets. Light scattering is directly related to the morphological properties of the cell while the fluorescence emission is derived from fluorescence probes and is proportional to the amount of fluorescent protein bound to, or expressed by, the cell. In Papers I and II, flow cytometry was used to quantify oA $\beta$-AF700 and o $\alpha$-syn-AF700 uptake in SH-SY5Y cells, but also to quantify intercellular transfer (detection of GFP and AF700 double-positive cells), which allowed for the fast and reliable quantification of thousands of individual data points. In addition to traditional flow cytometry, Paper II utilised fluorescence-activated cell sorting (FACS) to sort out potential hits for further screening during the development of the CRISPR/Cas9 cell line. FACS is similar to conventional flow cytometry, except when the cell-containing droplets are separated, an electric charge is applied to the droplets, allowing individual cells to be sorted by charged deflection plates. 


\section{Semi-quantitative real-time PCR}

Gene analysis by semi-quantitative real-time polymerase chain reaction (RT-PCR) was used in Papers I and II. RNA was converted to cDNA through reverse transcription and quantified using specific TaqMan probes. In brief, semi-quantitative RT-PCR uses an increase in the intensity of a fluorescent signal generated by the breakdown of a probe during amplification of a target sequence to detect nucleic acids. The PCR cycle number where the fluorescent signal becomes discernable above background noise is called the $\mathrm{Ct}$ value. Relative expression of the genes was calculated using the comparative $\Delta \Delta \mathrm{Ct}$ method, which normalises the gene of interest against a reference gene.

\section{Immunoassays}

Papers I and IV utilised the Meso Scale Discovery (MSD) platform to quantify pro-inflammatory cytokines and oA $\beta$, respectively. MSD is similar to a sandwich enzyme-linked immunosorbent assay (ELISA), using coated capture antibodies and detection antibodies. The detection antibodies are conjugated with an electrochemiluminescent label, called SULFO-TAG, that generates a light emission after an electric current is applied to the plate. The light intensity is then measured to quantify the analytes in the sample.

Paper I used a commercially available MSD assay to detect pro-inflammatory cytokines from CM. This was a 10-spot multi-array that can distinguish the location of the emitted light of 10 different detection antibodies within the same well. This approach has the advantage of removing inter-plate variability, as all the analytes are measured within the same well.

A traditional ELISA was not sensitive enough to detect oA $\beta$ in exosomes isolated from CSF (data not shown). Therefore, Paper IV involved the development of a new assay, which adapted the previously established, oA $\beta$-specific antibody mAb158 from an ELISA into the MSD platform. Plates were coated with the capture antibody mAb158, which has been shown to be selective for $\mathrm{A} \beta$ protofibrils over monomers [181], while 82E1 was used for the detection antibody, which detects both soluble A $\beta$ as well as fibrils [182]. For detection, the SULFO-TAG was conjugated to streptavidin, which binds to biotin. This antibody combination provides specificity and a suitable dynamic range for the detection of oA $\beta$.

\section{nSMase enzymatic activity}

To quantify nSMase enzymatic activity in Paper II, a commercially available kit was used. The nSMase assay involves the hydrolysis of sphingomyelin into ceramide and phosphorylcholine, which through a series of reactions can be detected with a spectrophotometer. For the purposes of Paper II, it is important to consider that this assay detects multiple isoforms of nSMase and is not specific for nSMase2. 


\section{Cell viability assays}

Two methods were used to determine cell viability. Cytotoxicity was determined by the release of lactate dehydrogenase (LDH) in Papers I and II. LDH is an enzyme present in the cytosol. When the plasma membrane is damaged, LDH is released into the media. This can then be quantified by a coupled enzymatic reaction in which $\mathrm{LDH}$ is proportionally converted into a red formazan product that is measured at a specific wavelength. Paper I also used a cell proliferation kit (XTT) to assess cell viability. This assay is based on the ability of viable cells to facilitate the reduction of XTT to a formazan product, which is thought to be done by mitochondrial dehydrogenases within viable cells. This reaction directly correlates to the number of viable cells within a well and can be measured by spectral absorbance.

\section{Mass spectrometry}

Liquid chromatography tandem-mass spectrometry (LC-MS/MS) is a synergistic technique that combines the separating power of liquid chromatography (LC) with the resolution of mass spectrometry (MS). Prior to analysis in the instrument, proteins are denatured, reduced, alkylated, and subsequently digested with trypsin. The peptides are then lyophilised and reconstituted in an acidic solution, which aids in ionisation. The samples are then loaded into a reverse-phase LC column, which separates the peptide samples by size and hydrophobicity. The peptides are then introduced to the MS system by electrospray ionisation, causing the droplets containing charged ions to break apart in the air from solvent evaporation, releasing the charged ions into the instrument. For example, the instrument used in Paper I (LTQ Orbitrap Velos Pro) comprises of two different ion traps; the linear ion trap and the orbitrap. First, the most intense ions are selected for fragmentation by collision-induced dissociation. Next, the fragmented ions enter the orbitrap, where their rotation and migration are measured as the mass-to-charge ratio $(\mathrm{m} / \mathrm{z})$. Paper I used a discovery approach for identification of proteins and samples where they are matched against a publicly available protein database. Sphingolipid analysis in Paper II used internal standards during the extraction phase to be able to quantify sphingolipids. 


\section{SUMMARY OF PAPERS}

\section{Paper I \\ Anti-inflammatory (M2) macrophage media reduce transmission of oAß in SH-SY5Y cells}

Neuroinflammation has been recognised as an important component of AD pathology, although it is not clear whether inflammation is a cause, contributor, or secondary phenomenon in the disease [183,184]. Microglia are known as key players of the innate immune system in the CNS and can exhibit both pro-inflammatory and anti-inflammatory responses, depending on the signals they receive. The pro-inflammatory phenotype (M1) is usually associated with the release of pro-inflammatory cytokines, such as IL- $1 \beta$, and TNF $\alpha$, while the anti-inflammatory phenotype (M2) is associated with the release of anti-inflammatory cytokines such as IL-10 and TGF $\beta$ [57]. Increases in pro-inflammatory cytokines have been detected in $\mathrm{AD}$ brains, indicating that inflammatory processes are activated in AD patients [185], and it is hypothesised that $\mathrm{A} \beta$ elicits an initial immune response by activating microglia. These activated microglia then either initiate or accelerate $\mathrm{AD}$, leading to the speculation that an anti-inflammatory environment may be neuroprotective (Figure 3B).

In Paper I, we investigated the effects of M1 and M2 CM (derived from macrophages as a peripheral analogue to microglia) upon the uptake and transfer of oA $\beta$ between neuron-like cells in a 3D co-culture cell model (Figure 7). We also investigated how the different inflammatory states, with or without $\mathrm{oA} \beta$, related to inter- and intracellular protein changes.

We demonstrated that M2 CM significantly reduced the transmission of oA $\beta$ between neuronal cells when the media was present during the transfer process (Figure 8A), whereas M0 and M1 $\mathrm{CM}$ had no effect. This was determined by the detection of fluorescently labelled oA $\beta$ in GFPtransfected "recipient" SH-SY5Y cells by flow cytometry. This is in concordance with the hypothesis that an anti-inflammatory approach might reduce $\mathrm{A} \beta$ accumulation and spreading, and could, therefore, be neuroprotective. As we only saw a decrease in transfer when the CM was present during the co-culture, we concluded that the mediators needed to be present during the transfer process in order to have an inhibitory effect. Contrarily, when we treated the co-culture with classical anti-inflammatory cytokines (IL-4, IL-10, and/or IL-13), we saw that the combination of anti-inflammatory cytokines increased the rate of transfer (Figure 8B). Aside from cytokines, the M2 CM media contains other trophic factors, antioxidants and metabolites that could contribute to the observed reduction in oA $\beta$ transfer, although this was not further investigated in this study. 

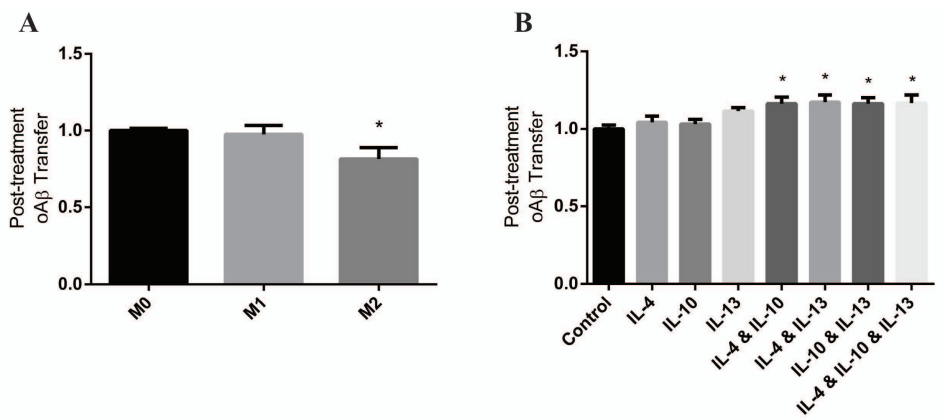

Figure 8. M2 CM reduces the transfer of $\boldsymbol{o A \beta}$. Flow cytometry analysis of (A) transfer of oA $\beta$ with post-treatment of $C M$ and $(\boldsymbol{B})$ transfer of oA $\beta$ with post-treatment of $I L-4, I L-10$, and/or IL-13.

Using a multiplexed MSD assay, cytokines were measured in the (naïve) CM, control co-culture supernatant and co-culture supernatant after the addition of oA $\beta$ (Figure 9A-D). Surprisingly, we determined that there were no changes in cytokine levels in the oA $\beta$ treated co-cultures, however, the gene expression of many cytokines in the neuronal-like cells were altered from the CM, as determined by RT-PCR (Figure 9E-H). For example, IL-1 $\beta$ and IL-10 expression were both decreased from the addition of M2 media (Figure 9E and 9H). Conversely, IL-1 $\beta$ and IL-6 expression were increased as a result of M1 media (Figure 9E and 9G), both of which have been shown to be elevated in post-mortem AD tissue [186]. This implies that neurons are able to "take on" the phenotype of the local microenvironment, which may induce neuronal factors that further influence surrounding cells in a positive mechanism, contributing to neuroinflammation.
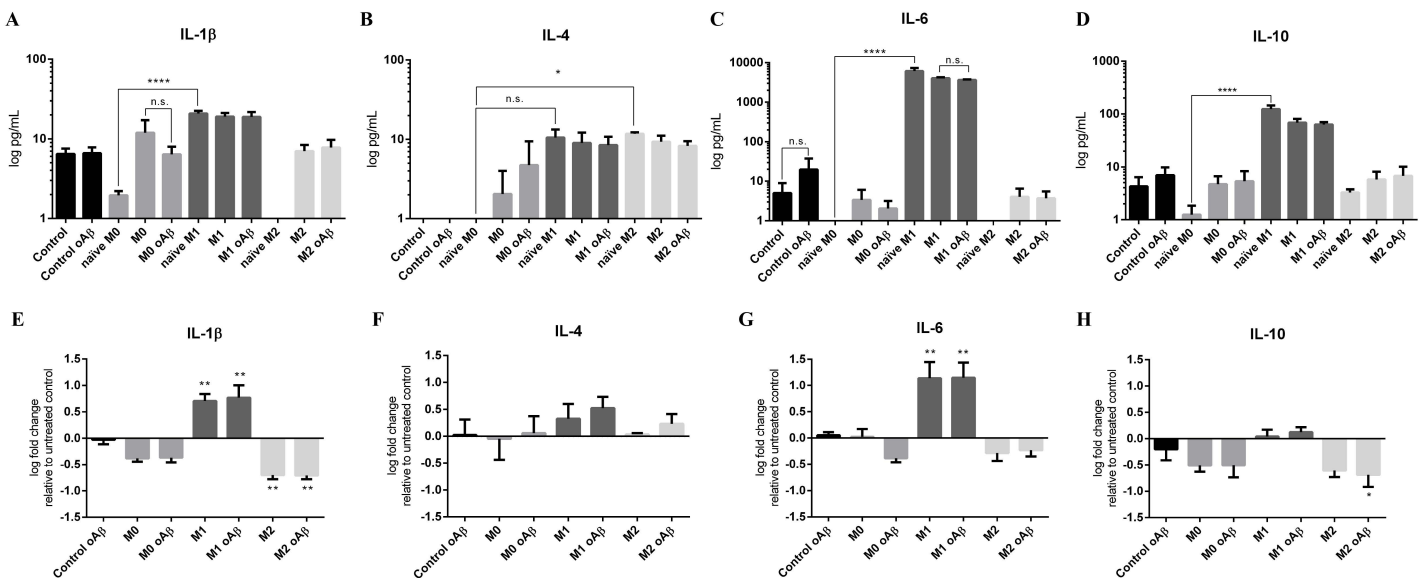

H

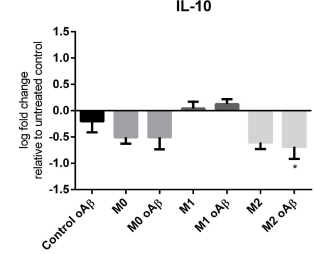

Figure 9. Cytokine profile after treatment with $C M$ and $\boldsymbol{o A \beta}$. (A-D) Quantification of cytokine protein in supernatant of CM treatment during co-culture with or without $O A \beta$ and $(\boldsymbol{E}-\boldsymbol{H})$ RNA expression of neuron-like cells. Measurement of cytokine concentrations also contains nä̈ve CM concentrations. 
In order to examine additional changes elicited by the $\mathrm{CM}$ and $\mathrm{oA} \beta$, we analysed the cell preparations with LC-MS/MS. This approach indicated alterations to immune, endosomal/lysosomal, protein trafficking and apoptosis systems in response to the $\mathrm{CM}$ and oA $\beta$ treatments. The proteins that were highlighted in Paper $\mathbf{I}$ are provided in Table 1. For example, SURF4 and SEC61A1, proteins that have been shown to interact with one another and are important for endoplasmic reticulum (ER) to Golgi transportation [187], were both absent in M0 oA $\beta$ cells, but present in M2 oA $\beta$ cells. The absence of SURF4 has been shown to contribute to the accumulation of misfolded proteins in the ER, leading to persistent ER stress and subsequent cell death [188]. AD is also associated with progressive abnormalities of the endosomal-lysosomal system and there have been links to vacuolar ATPase deficiencies in early-onset cases [189]. ATP6V1H, a component of vacuolar ATPase, was present in M2 oA $\beta$ cells while absent in M0 oA $\beta$ cells. However, the involvement of these proteins in altering oA $\beta$ transfer was beyond the scope of this study.

Table 1. Proteomic changes due to inflammatory environments and $o A \beta$.

\begin{tabular}{|c|c|c|c|c|c|c|c|}
\hline Gene Name & M0 & $\begin{array}{l}\text { M0 } \\
\mathrm{oA} \beta\end{array}$ & M1 & $\begin{array}{l}\mathrm{M} 1 \\
\mathrm{oA} \beta\end{array}$ & M2 & $\begin{array}{l}\mathrm{M} 2 \\
\mathrm{oA} \beta\end{array}$ & Function \\
\hline ATP6V1H & - & - & + & + & - & + & $\begin{array}{l}\text { Component of vacuolar ATPase. Necessary for protein sorting, } \\
\text { receptor-mediated endocytosis and synaptic vesicle proton gradient } \\
\text { generation. ATPase deficiencies found in early-onset AD [189]. }\end{array}$ \\
\hline$B A X$ & - & - & + & - & - & + & An apoptotic activator. BAX is increased in AD brains [190]. \\
\hline$P D C D 6 I P$ & - & + & - & + & - & + & $\begin{array}{l}\text { Functions within ESCRT pathway forming intraluminal endosomal } \\
\text { vesicles. Found to be decreased in AD [191]. }\end{array}$ \\
\hline$R A B 3 G A P 2$ & - & + & - & - & + & - & $\begin{array}{l}\text { Part of Rab3GTPase-activating complex for synaptic vesicle } \\
\text { exocytosis. Inhibition reduces vesicle frequency [192]. }\end{array}$ \\
\hline SEC61A1 & + & - & + & + & - & + & $\begin{array}{l}\text { A crucial role in the insertion of secretory and membrane } \\
\text { polypeptides into the endoplasmic reticulum. Silencing can decrease } \\
\text { calcium leakage from the ER [193]. Calcium irregularities are found } \\
\text { in AD [194]. }\end{array}$ \\
\hline SURF4 & + & - & + & + & + & + & $\begin{array}{l}\text { Membrane protein that interacts with ER-Golgi intermediate } \\
\text { compartment proteins. Silencing can accumulate misfolded proteins } \\
\text { in the ER, leading to ER stress and cell death [188]. }\end{array}$ \\
\hline STAT1 & - & - & + & + & - & - & $\begin{array}{l}\text { Transcription factor inducing pro-inflammatory and anti-viral genes. } \\
\text { Upregulated in AD [195]. }\end{array}$ \\
\hline STAT2 & - & - & + & + & - & - & $\begin{array}{l}\text { Transcription factor anti-viral response. Implicated that A } \beta \text { insult } \\
\text { activates SGK1-STAT1/STAT2 signalling to protect cell survival } \\
\text { [196]. }\end{array}$ \\
\hline STAT3 & - & - & - & + & - & - & $\begin{array}{l}\text { Transcription factor that can suppress pro-inflammatory genes. } \\
\text { Increased phosphorylation in } \mathrm{AD} \text { and may mediate } \mathrm{A} \beta \text { induced cell } \\
\text { death }[186,197] \text {. }\end{array}$ \\
\hline
\end{tabular}

Paper I demonstrated that an anti-inflammatory environment reduced the transfer of oA $\beta$ between neuron-like cells. This study also demonstrates the complexity of the inflammatory cascade, yet provides further support for the anti-inflammatory hypothesis to neuroinflammation and AD, in that an anti-inflammatory approach causes reduced oA $\beta$ transfer and could, therefore, be 
neuroprotective and/or slow the progression of AD. However, exactly how this anti-inflammatory environment reduces transmission, be it through modulation of the endosomal/lysosomal pathway or another, unknown mechanism, needs further investigation.

\section{Paper II}

\section{Inhibition of nSMase 2 reduces the transfer of oa-syn irrespective of hypoxia}

Extracellular vesicles, such as exosomes, have been proposed to play an influential role in the cell to cell spread of neurodegenerative diseases, including the intercellular transmission of $\alpha$-syn [54]. However, the regulation of exosome biogenesis and its relation to PD is not well understood. The generation of exosomes can occur through the ESCRT-independent pathway in which sphingomyelin hydrolysed by nSMase 2 to produce ceramide, which causes the membrane of endosomal MVBs to bud inwards (Figure 4C) [99]. Transfer of exosomes between cells is an important pathway for intercellular communication, whereby exosomes shuttle biomolecular contents (miRNA, mRNA, proteins) between cells and might be a prominent method by which o $\alpha$ syn is transferred in PD.

Although it was originally reported nearly half a century ago that sphingomyelin accumulates in Lewy bodies [198], little is known about how sphingolipid metabolism relates to the pathogenesis of PD. The regulation of ceramide seems to vary depending on the brain region investigated, as increased ceramide has been reported in the visual cortex of PD patients [125], while ceramide decreases have been described the PD anterior cingulate cortex [120,122].

Reduced activity of GCase is reported in PD brains [119,120] and reduced aSMase activity is associated with earlier age of PD onset [127]. These observations indicate that there is sphingolipid dysregulation in PD (Figure 6B). However, these pathways are linked to the dysregulation of lysosomal clearance as both of these enzymes hydrolyse sphingolipids in lysosomes [199]. In the plasma membrane, nSMase hydrolyses sphingomyelin, which can lead to the generation of exosomes. However, the dysregulation of ceramide production likely affects the exosome generation as a whole, which may alter the amount of $\alpha$-syn transferring between cells. Additionally, the lipid rafts of exosomes are highly influenced by the cell's originating lipid composition $[128,129]$, which may affect how $\alpha$-syn binds to exosomes and their capacity to be transferred to other cells.

Paper II investigated nSMase 2 as an important contributing factor toward the progressive accumulation of o $\alpha$-syn. In this work, we investigated the effectiveness of o $\alpha$-syn transfer between neuron-like cells when nSMase2 was inhibited or KO'd, employing our well-established coculture cell model to carry out this study (Figure 7). As oxidative stress is a common feature in PD brains [200], which is associated with increased $\alpha$-syn aggregation [201] and influences nSMase2 expression [133,135], we also investigated the influence of hypoxia on the sphingolipid pathway with regard to promoting $\alpha$-syn aggregation and transfer.

First, we examined the effects of inhibition of nSMase 2 in the "donor" cells by using genetic inhibition (siRNA) or gene KO using CRISPR/Cas9. siRNA-based inhibition of nSMase2 and 
nSMase $2 \mathrm{KO}$ both resulted in significantly reduced total nSMase2 protein levels, as determined by immunoblotting (Figure 10A), but only the nSMase2 $\mathrm{KO}$ caused a significant reduction in nSMase enzymatic activity (Figure 10B). However, this could be related to the assay used in this scenario, which can detect other nSMase isoforms. Interestingly, hypoxia significantly reduced nSMase 2 protein expression, but only when o $\alpha$-syn was not present (Figure 10A). Most importantly, there was a significant reduction in high molecular weight (MW) $\alpha$-syn $(\sim 25-250$ $\mathrm{kDa}$ ), when nSMase2 was inhibited (Figure 10C), indicating that nSMase2 is either involved in promoting the fibrillization of $\alpha$-syn or preventing its clearance.
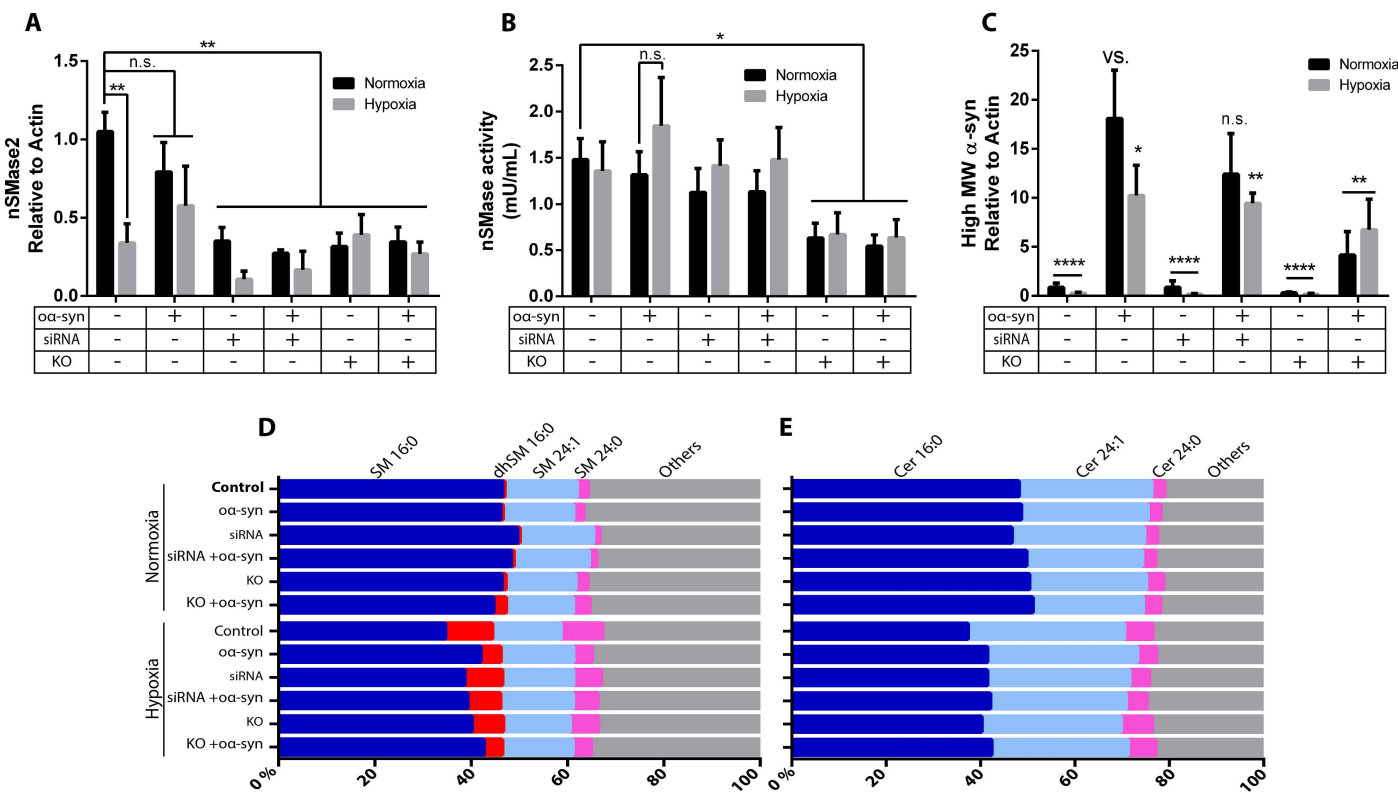

Figure 10. nSMase 2 inhibition reduces high $M W \alpha$-syn and hypoxia shifts lipid composition. Quantification of different nSMase 2 reducing cell models under hypoxia and normoxia of $(\boldsymbol{A})$ nSMase 2 expression and $(\boldsymbol{B})$ total $n S M a s e$

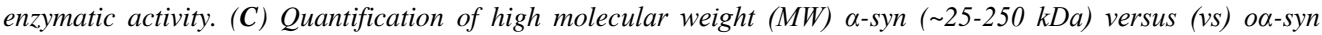
treatment. $(\boldsymbol{D}, \boldsymbol{E})$ Lipid extraction and UPLC-MS/MS analysis of $(\boldsymbol{D})$ sphingomyelin $(S M)$ and $(\boldsymbol{E})$ ceramide $($ Cer $)$ presented as the mole percentage of all acyl chain lengths.

We then investigated whether inhibiting nSMase2 affected the lipid composition of sphingolipids after the addition of o $\alpha$-syn in the absence or presence of hypoxia using UPLC-MS/MS. The most significant change was due to hypoxia, which induced the shift in acyl chain composition shifting towards a larger percentage of long-chained sphingomyelins (C21-C24) at the expense of shorter chain length sphingomyelins (C16-C20) (Figure 10D) and ceramide species (Figure 10E). Also, during hypoxia, nSMase $2 \mathrm{KO}$, siRNA treatment, and oo-syn treatment each contributed to a shift of acyl chain lengths toward shorter chains. It has been shown that ceramide acyl chain composition shifts toward shorter acyl chain lengths at the expense of longer chain lengths in PD 
brains [122] and that ceramide long chains are associated with mitochondrial damage and cell death [202]. However, additional research needs to be conducted to further elucidate which sphingolipids are dysregulated in PD and how these changes affect $\alpha$-syn binding.

Due to the importance of nSMase2 in generating exosomes through the ESCRT-independent pathway, we next investigated whether nSMase 2 inhibition or $\mathrm{KO}$ affected exosome production and whether this would affect the transmissibility of o $\alpha$-syn between neuron-like cells. Exosome abundance was determined with the FluoroCet kit, which directly measures the AChE activity inside of exosomes. We saw a statistically significant reduction in the number of exosomes in the nSMase2 KO and Cambinol (a pharmaceutical inhibitor) treated cells, whereas the siRNA treatment also saw a reduction but did not reach statistical significance $(\mathrm{p}=0.11)$ (Figure 11A). Hypoxia alone did not affect exosome production but did stimulate exosome production in the nSMase2 KO cells back to baseline, perhaps signifying a compensatory, widespread shift of exosome producing machinery to the ESCRT-dependent pathway as many ESCRT-dependent genes were dysregulated (shown in Paper II). Finally, we co-cultured nSMase2 inhibited (siRNA or Cambinol) or nSMase2 KO cells with o $\alpha$-syn on top of stably expressing GFP recipient cells and quantified the degree of o $\alpha$-syn transfer between the populations using flow cytometry. All nSMase2-reducing treatments significantly reduced the transfer of o $\alpha$-syn, while hypoxia had no detectable influence (Figure 11B). A previous study has shown that nSMase2 facilitates the intercellular transmission of specific proteins, including the Zika virus, which use exosomes to propagate throughout the brain and can be successfully inhibited through the inhibition of nSMase2 [203]. It has been suggested that, while other nSMase isoforms play an important role in exosome biogenesis, the packing of aggregated proteins into exosomes may be nSMase 2 dependent [140]. There is speculation that o $\alpha$-syn may be packed into larger microvesicles that are not as easily taken up by surrounding cells, as it has been reported that inhibiting nSMase2 increases the secretion of larger vesicles originating from the plasma membrane [204]. This provides strong evidence for the importance of the formation of exosomes by nSMase 2 as a critical pathway by which o $\alpha$-syn is propagated between cells. 
A

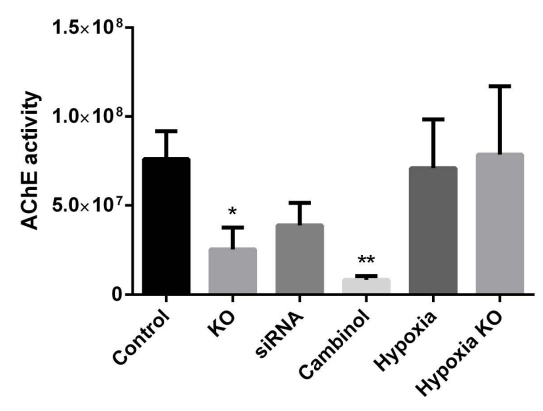

B

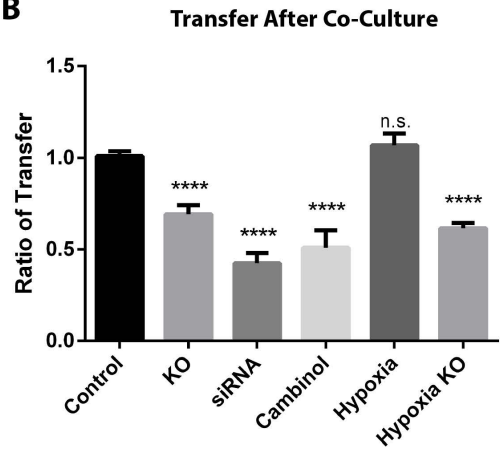

Figure 11. nSMase2 expression is a critical component for the transmission of oa-syn. (A) Exosome abundance, as measured by AChE activity, of exosomes isolated from cells treated with oo-syn. (B) Flow cytometry analysis of

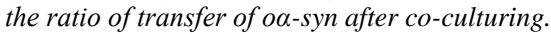

In conclusion, Paper II demonstrated that reducing nSMase2 significantly decreases the transfer of o $\alpha$-syn between neuron-like cells and reduces $\alpha$-syn aggregation, even under hypoxic conditions. Inhibiting nSMase 2 could be a beneficial strategy for reducing the progression of PD, however, the direct mechanism by which this is accomplished requires further investigation. Additionally, this study supports the need for a deeper investigation of sphingolipid metabolism in PD patients to further elucidate the lipid dysregulation and lipid-protein interactions observed in PD.

\section{Paper III}

\section{Autophagy deficiency in excitatory neurons leads to intracellular Aß fibrillization, reduction in exosome secretion, and decreased extracellular AB plaques}

Autophagy controls cellular proteostasis by sequestering and delivering potential toxic protein aggregates and impaired organelles to lysosomes for degradation. In dystrophic neurites in the AD brain, autophagosomes accumulate, which indicates impaired autophagy [146]. Additionally, both the autophagy-inhibitory mTOR signalling and the levels of lysosomal hydrolases are increased in $\mathrm{AD}$ [147], with the latter possibly reflecting impaired autophagosomal-lysosomal clearance [205]. Autophagy also plays a role in A $\beta$ metabolism [148,206,207], where autophagosomes generate and contain $A \beta$ [149] and oxidative stress-induced autophagy increases $A \beta$ generation [150].

The Per Nilsson group has previously demonstrated that in autophagy-deficient APP23 transgenic mice, autophagy mediates the secretion of $A \beta$ [208] and that MVBs are involved in A $\beta$ trafficking [162]. Paper III sought to further elucidate the role of autophagy in $A \beta$ metabolism in a model free from $A P P$ overexpression, using a new transgenic mouse model generated by the crossing of humanised APP KI mice with CAMKII-ATG7 conditional knockout (cKO) mice. As recent studies 
have uncovered some of the molecular machinery and regulatory mechanisms shared between exosome biogenesis and autophagy [209] (also see Figure 4), we aimed to investigate the interplay between autophagy and the secretion of A $\beta$-containing exosomes using this model.

We first investigated the effects of $\mathrm{A} \beta$ metabolism from the brain sections of $A T G 7 \mathrm{cKO} \times A P P$ $\mathrm{KI}$ and $A P P$ KI littermates. First, the cortex and hippocampus of 15-month-old mice were immunostained for $A \beta$. The deletion of autophagy significantly reduced the extracellular $A \beta$ deposits in $A T G 7 \mathrm{cKO} \times A P P$ KI mice (Figure 12A), which is in accordance with the previously obtained data from autophagy-deficient APP23 mice. However, where the extracellular A $\beta$ deposits decreased in the ATG7 cKO x APP KI mice, intracellular A $\beta 42$ accumulated in the autophagy-deficient neurons (Figure 12B). To further investigate the intracellular $A \beta$ deposition, we investigated 24-month-old $A T G 7 \mathrm{cKO} \times A P P$ KI CA1 neurons with immunoelectron microscopy. Interestingly, immunogold-labelled $A \beta$ detected in the autophagy-deficient neurons formed fibril-like structures in the perinuclear region, which was not observed in control APP KI mice (Figure 12C). This shows that lack of autophagy leads to intracellular A $\beta$ pathology. Memory capacity was also significantly decreased in autophagy-deficient mice, showing that functional autophagy is indispensable for memory.
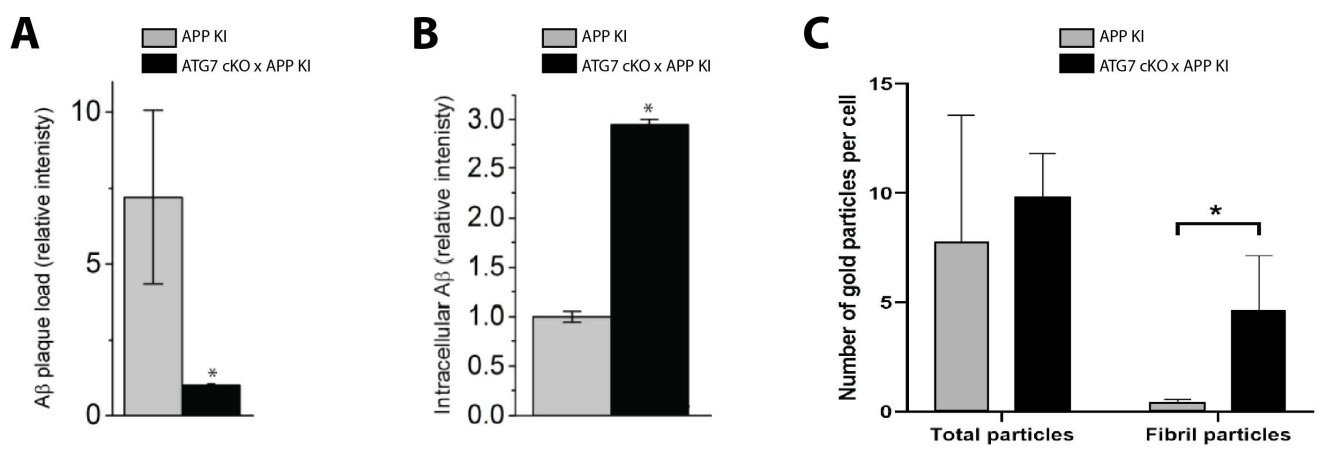

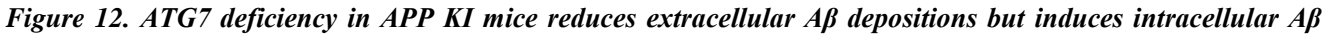
accumulation in fibril-like structures. $(\boldsymbol{A}, \boldsymbol{B})$ Quantification of immunohistochemistry of 15-month-old mice of $(\boldsymbol{A})$ extracellular A $\beta$ plaques in the cortex and hippocampus $(\boldsymbol{B})$ intracellular AB42 in the perinuclear region of the CA1 pyramidal neurons. $(\boldsymbol{C})$ Quantification of immunoelectron microscopy analysis of intracellular A $\beta$ deposits in the CA1 neurons of 24-month-old mice.

To understand the autophagy-mediated secretory pathway in relation to exosomes, we purified exosomes from the cortex and hippocampus of 7-8-month-old mice. Using NTA analysis, the purified exosomes showed a mode particle size of $89 \mathrm{~nm}$ (shown in Paper III). The exosomes were also characterised by immunoblotting, which confirmed the presence of exosomal markers CD63 and Flotillin-1, and the absence of cellular and synaptic vesicle markers (Figure 13A). We further examined the association between autophagy and exosome biogenesis through the detection of LC3 and p62 in exosomes, which showed a significant shift toward LC3-II relative to 
LC3-I in whole-brain lysate (Figure 13A), which further emphasises that exosomes can be used as a vehicle for material disposal from autophagy pathways.

The abundance of exosomes was determined by AChE activity normalised to the total protein content of the isolated exosomes. ATG7 cKO mice had significantly less exosomal abundance in the cortex compared to WT mice (Figure 13B), but not in the hippocampus (Figure 13C). However, $A T G 7 \mathrm{cKO}$ x APP KI had significantly fewer exosomes than WT or $A T G 7 \mathrm{cKO}$ mice in the hippocampus (Figure 13C). As exosome abundance can be dysregulated due to autophagy deficiency, we next investigated whether exosomal A $\beta 42$ was altered. However, there were no significant differences in exosomal $\mathrm{A} \beta 42$ in either the cortex or hippocampus of APP KI and ATG7 cKO x APP KI mice (Figure 13D, E). This may be due to the exosomes generated by non-neuronal cell types, whose autophagy has not been disrupted, diluting the total pool of exosomes. It is also possible that exosomes secreted through autophagy-independent pathways have also contributed and may be compensating in the other models. Interestingly, infusion of neuronal exosomes into the brain of APP transgenic mice decreased A $\beta$ generation and deposition, which was not observed with glial exosomes [89]. This finding highlights the role of neuronal exosomes in $A \beta$ clearance and suggests that diminished secretion of neuronal exosomes may relate to $A \beta$ accumulation and ultimately, development of AD pathology.

A
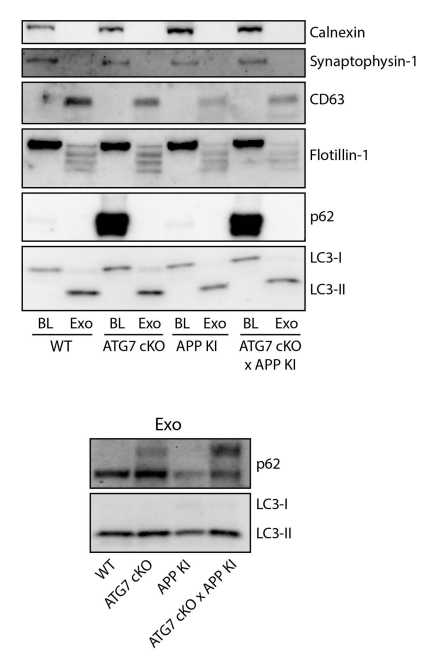

B

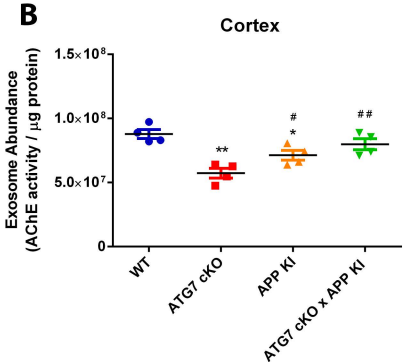

D

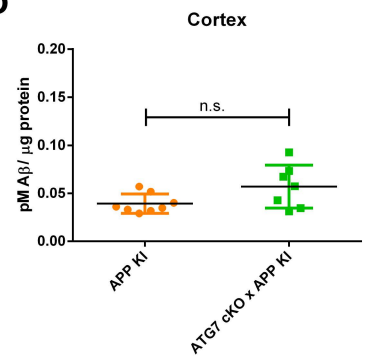

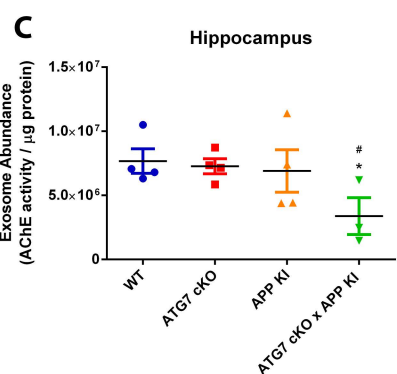

E

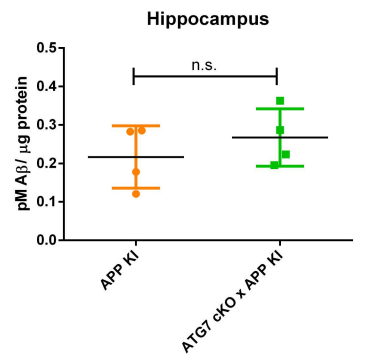

Figure 13. Autophagy inhibition impairs exosomal secretion but does not affect exosomal Aß levels. (A) Immunoblot showing presence of exosomal markers Flotillin-1 and CD63, while showing the absence of Calnexin and Synaptophysin, demonstrating no cellular or synapse vesicle contamination in the isolation. In addition, exosomes also contained autophagy markers LC3-II and p62. BL = Brain Lysate and Exo = exosomes. (B,C) Exosome abundance measured by acetylcholinesterase (AChE) activity of exosomes isolated from the $(B)$ cortex or $(C)$ hippocampus. * versus WT, \# versus ATG7 cKO. (D,E) ELISA quantification of exosomal A $\beta 42$ from the (D) cortex or (E) hippocampus. Mice in all experiments were 7-8 months in age. 
Paper III has highlighted the importance of autophagy in A $\beta$ metabolism. In this model, autophagy deficiency induced intracellular $A \beta$ accumulation, leading to $A \beta$ aggregation, while the extracellular $A \beta$ plaque load was drastically decreased. Autophagy can also impair exosome secretion but was dependent on the region investigated and whether or not $A P P$ was overexpressed. There were no differences in exosomal $\mathrm{A} \beta 42$ in autophagy-deficient mice, but analysis of neuronal cell cultures derived from $A T G 7 \mathrm{cKO}$ mice would clarify whether an autophagy-independent secretory pathway(s) of $\mathrm{A} \beta$ exists.

\section{Paper IV}

\section{Exosomal oA $\beta$ in CSF as a potential biomarker for $A D$}

A number of disease-modifying drugs have been developed for $\mathrm{AD}$, but have failed in clinical trials due to ineffectiveness and safety concerns [9]. One of the biggest challenges in developing effective treatments for $\mathrm{AD}$ is the accurate diagnosis of living patients. This leads to difficulty in meaningful stratification of treated and placebo patient groups, making interpretation of clinical trials uncertain. The current biomarkers for AD diagnosis have a significant error rate [18], where a 2015 meta-analysis indicated only 77\% effectiveness in diagnostic accuracy in living patients [210]. Due to these challenges, there is a great need for accurate biomarkers to aid clinicians in the early diagnosis of AD patients.

Exosomes harbouring neurodegenerative-associated proteins have been detected in blood, CSF, and urine of patients with NDs (reviewed in [81]). As the connection between exosomes and the spread of neurodegenerative proteins is still relatively new, there remains a diagnostic potential to be explored with exosomes. The A $\beta 42 / \mathrm{A} \beta 40$ ratio in CSF is increased in late-onset AD patients [170] and our lab recently showed that exosomal oA $\beta 42$ is elevated in the AD brain [26]. In addition, it is speculated that the accumulation of soluble oA $\beta 42$ may be an early event in disease progression. In Paper IV, we isolated exosomes from CSF and aimed to develop a sensitive oA $\beta 42$ assay as a potential early and specific biomarker for AD.

We first fully characterised the exosomes isolated from CSF using a SEC-based method, called $\mathrm{qEV}$. Exosomes were collected from the column in different fractions and the fractions with the greatest abundance exosomes were further characterised. Exosomes were immunoblotted to confirm an endosomal origin through the presence of exosomal markers CD81, Flotillin-1, and Alix, as well as the absence of the cellular marker Calnexin and the synaptic vesicle marker Synaptophysin (Figure 14A). This method also removed the immunoglobulin $G(\operatorname{IgG})$ found in total CSF, as well as significantly removed haemoglobin contamination. Furthermore, TEM analysis showed a mode vesicle size of $82 \mathrm{~nm}$ with classic spherical shapes (Figure 14B), and TRSP analysis showed a mode size of $95 \mathrm{~nm}$, corresponding to typical exosome characteristics. 

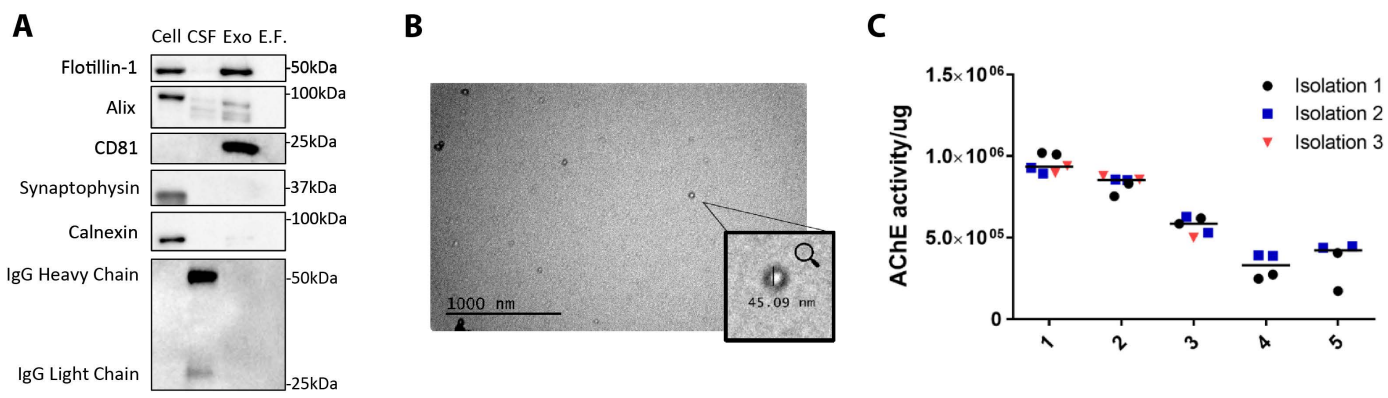

Figure 14. Exosomes isolated with qEV give pure and reproducible isolations. (A) Exosomes showed the presence of Flotillin-1, Alix, CD81 and the absence of the synaptic vesicle marker Synaptophysin and cellular marker Calnexin. IgG was used as a positive control for the CSF sample and an exosome-free sample was used as a negative control. (B) Transmission electron microscopy image of isolated exosomes. (C) Total CSF was divided into two or three aliquots and independently isolated into exosomes (Isolation 1-3) from five individuals (1-5) and quantified by AChE activity. Exo, exosomes; E.F., exosome-free fraction.

Total CSF was divided into two or three aliquots from five different individuals and exosome isolations were repeated on consecutive days to assess the reproducibility of this isolation method. Exosome abundance was quantified by measuring the AChE activity and normalising it to total exosomal protein. No significant differences in the number of isolated exosomes were observed across separate isolations from the same individual (Error! Reference source not found.C). Thus, based on exosome abundance, this suggests that the $\mathrm{qEV}$ isolation method is a reproducible method for the isolation of CSF exosomes.

Using reliably isolated exosomes from CSF, we first tried to detect oA $\beta 42$ using the mAb158 ELISA assay [26,181], however, this assay was not sensitive enough for our application (data not shown). Therefore, we elected to adapt the ELISA assay onto the MSD platform. The protofibrilspecific $\mathrm{oA} \beta 42$ antibody $\mathrm{mAb} 158$ and the $\mathrm{A} \beta \mathrm{N}$-terminal specific mAb $82 \mathrm{E} 1$ were used as capture and detection antibodies, respectively. This combination resulted in a limit of detection (LOD) and limit of quantification (LOQ) of $4.65 \mathrm{pg} / \mathrm{mL}$, and a coefficient of variance of 14.3. Exosomes isolated from cohort 1 had readily detectable oA $\beta 42$, while cohort 2 was undetectable or fell below the LOQ (Table 2). We also observed a ten-fold decrease in total exosomal protein compared to samples isolated from cohort 1 . This suggests that regardless of volume input, approximately 20 $\mu \mathrm{g}$ of total exosome protein is required to reliably detect $\mathrm{oA} \beta$ with this platform. 
Table 2. Detection of oA $\beta$ in exosomes isolated from two different cohorts of CSF collection.

\begin{tabular}{|c|c|c|c|c|c|c|c|c|}
\hline Cohort & Gender & Age & Diagnosis & $\begin{array}{c}\text { MMSE } \\
\text { score }\end{array}$ & $\mu l$ CSF & $\begin{array}{c}\mu g \text { exo } \\
\text { protein }\end{array}$ & $\begin{array}{c}\mathrm{pg} / \mathrm{mL} \\
\mathrm{oA} \boldsymbol{\beta}\end{array}$ & $\begin{array}{c}\mathbf{o A} \beta / \operatorname{exo} \\
\text { protein }\end{array}$ \\
\hline 1 & Female & 52 & $\mathrm{NPH}$ & & 2000 & 25.07 & 37.78 & 1.51 \\
\hline 1 & Female & 78 & $\mathrm{NPH}$ & & 2000 & 26.59 & 138.13 & 5.19 \\
\hline 1 & Male & 72 & $\mathrm{NPH}$ & & 2000 & 29.57 & 32.43 & 1.1 \\
\hline 1 & Male & 82 & $\mathrm{NPH}$ & & 2000 & 40.01 & 15.2 & 0.38 \\
\hline 2 & Female & 86 & Healthy & 29 & 740 & 3.75 & $0.57 *$ & $0.15^{*}$ \\
\hline 2 & Female & 85 & Healthy & 29 & 1000 & 4.09 & ND & \\
\hline 2 & Female & 82 & Healthy & 30 & 850 & 4.2 & $1.43^{*}$ & $0.34 *$ \\
\hline 2 & Female & 78 & Healthy & 29 & 320 & 3.95 & ND & \\
\hline 2 & Male & 45 & $\mathrm{AD}$ & 21 & 180 & 3.25 & $0.57 *$ & $0.18 *$ \\
\hline 2 & Female & 77 & $\mathrm{AD}$ & 26 & 380 & 3.55 & ND & \\
\hline 2 & Male & 59 & $\mathrm{AD}$ & 18 & 820 & 3.49 & ND & \\
\hline 2 & Female & 69 & $\mathrm{AD}$ & 13 & 320 & 3 & ND & \\
\hline
\end{tabular}

*Denotes an estimate of oA 42 concentration, as samples were under LOQ of the assay. exo, exosomes; MMSE, Mini-Mental State Exam; ND, not detected; NPH, normal pressure hydrocephalus.

Paper IV demonstrated a reproducible isolation method of exosomes from CSF and characterised them according to size, structure, and exosome-related markers. Exosomal oA $\beta 42$ was measured using an ELISA to MSD conversion, however, for this technique to be used as a standardised method in the clinic, further optimising the assay's sensitivity is needed. Additional consideration should also be taken to assess the specificity of the assay towards oligomers and against different $\mathrm{A} \beta$ species. 


\section{CONCLUDING REMARKS}

$\mathrm{AD}$ and $\mathrm{PD}$ are the two most prevalent NDs, yet we still do not understand the etiopathogenesis of these diseases and there are no effective disease-modifying treatments. With the rates of these diseases increasing every year as the global population ages, it is of utmost importance to understand the mechanisms behind disease propagation in order to be able to develop effective treatments.

Evidence suggests that $\mathrm{oA} \beta$ and o $\alpha$-syn are key contributors in the progression of $\mathrm{AD}$ and PD, respectively, and it is the progressive accumulation of these proteins that leads to a gradual spread of pathology. However, the mechanisms by which these proteins spread is still largely unknown.

Neuroinflammation is a common characteristic in NDs. However, it is still highly debated whether inflammation is the cause, contributor, or a secondary phenomenon to NDs. Paper I demonstrated that an anti-inflammatory environment reduces the transfer of oA $\beta$ between neuronal-like cells, providing further support that an anti-inflammatory approach may be neuroprotective and/or slow the progression of AD. Many proteins involved in endosomal and lysosomal pathways were altered in response to the different inflammatory environments, which should be further investigated to determine their roles in oA $\beta$ transfer. In addition, selective immunodepletion of the antiinflammatory $\mathrm{CM}$ would provide insight into which cytokines or chemokines may be important in regulating oA $\beta$ transfer.

The role of exosomes in spreading neurodegenerative proteins is becoming increasingly understood. The neurodegenerative proteins involved in many NDs have been found in the CSF and blood of patients, and these protein harbouring exosomes have been shown to be transferable between cells in vitro and in vivo. However, the significance of exosomes to the progression of $\mathrm{AD}$ and $\mathrm{PD}$ is still a matter of debate.

Defects in sphingolipid metabolism have been linked to numerous NDs. Reduced activity of GCase and aSMase have provided insight into the lysosomal dysfunction found in PD patients, however, the association between sphingolipid composition and exosomal production in PD was poorly understood. Paper II demonstrated that reducing exosomes through the inhibition or KO of nSMase2 significantly decreased the transfer of o $\alpha$-syn between neuron-like cells and reduced $\alpha$-syn aggregation, even under hypoxic conditions. Inhibiting nSMase 2 could be a beneficial strategy for reducing the progression of $\mathrm{PD}$, however, the mechanism in which this is accomplished is not known. As there are discrepancies of sphingolipid dysregulation in PD brains, this study also provides support for deeper investigation of sphingolipids. This could also provide further insight into critical lipid-protein interactions that may be driving PD pathology.

It has been shown that autophagy plays an important role in regulating extracellular A $\beta$ homeostasis. The interaction between autophagy and MVBs and their collective role in the release of A $\beta$ via exosomes (especially under impaired autophagy) is not known. Paper III has emphasised the importance of autophagy in $A \beta$ metabolism. Autophagy-deficient mice displayed increased intracellular $A \beta$ accumulation leading to $A \beta$ fibrillization, while the extracellular $A \beta$ plaque load was decreased. Autophagy inhibition also impaired exosome secretion but did not 
affect exosomal $A \beta$ levels. Changes to neuronal $A \beta$ exosomes may still be altered by the extracellular shuttling of MVB contents and may significantly alter the EV biochemical profile, which may lead to toxic effects in neighbouring cells. The analysis of neuronal cell cultures derived from autophagy-deficient mice would clarify whether autophagy inhibition affects the secretory pathway of $\mathrm{A} \beta$ that may be occluded from other cell types in the brain.

Due to the need for early and reliable diagnostics for AD, Paper IV aimed to develop a new diagnostic assay as a possible early detection method. This work verified a reproducible method for isolating exosomes from CSF and was able to detect exosomal oA $\beta 42$ in a portion of the patient samples. However, for it to be used in a clinical setting, further optimisation of the assay's sensitivity is required. In addition, the specificity of the assay towards oligomers and other $\mathrm{A} \beta$ species needs to be assessed. Using exosomes as a diagnostic tool has also opened up multiple avenues for diagnostic research, from the several bodily sources and seemingly limitless content within them. However, with improvements to our assay, we are optimistic about the diagnostic potential of exosomal oA $\beta 42$.

In summary, the studies presented in this thesis have contributed to the understanding of multiple systems that are dysregulated in AD and PD. These studies have also helped to identify new therapeutic avenues to be explored for delaying the progression of $\mathrm{AD}$ and $\mathrm{PD}$ and potential biomarkers for these diseases. 


\section{ACKNOWLEDGEMENTS}

I would like to thank many people who have helped me in many ways to be able to finish my thesis and during my time as a $\mathrm{PhD}$ student.

I would like to extend my gratitude to all my supervisors for their guidance throughout my time as a PhD student. First of all, to my supervisors, Martin Hallbeck and Camilla Nilsberth, for taking me on as a PhD student, providing support and advice, and allowing me to develop as an independent researcher. And to my other supervisors, Anna Ansell-Schultz and Maitrayee Sardar Sinha, for their valuable hands-on mentoring and always providing positive energy to the group.

To the Hallbeck lab group, old and new, for their valuable input in project meetings and support in the lab. And to all my collaborators for their hard work on each paper. Science is done as a team.

To all my friends in Linköping, especially the Ghostbusters group. Your years of friendship are invaluable and will forever be cherished. You are the ones that made living in Linköping enjoyable and fun.

To my family and friends back in Canada for all your support while I live abroad. And especially to my mother, Donna Koziski, for always encouraging my academic pursuits.

And most importantly, to my husband, Christopher Sackmann. Your pursuit of always wanting to improve yourself personally and academically has made me strive higher, alongside your loving support. Without you, I would not be the person I am today nor the scientist I have become. 


\section{REFERENCES}

1. Global action plan on the public health response to dementia $2017-2025$. World Heal Organ 2017; DOI: Licence: CC BY-NC-SA 3.0 IGO

2. Stelzmann RA, Norman Schnitzlein H, Reed Murtagh F: An english translation of Alzheimer's 1907 paper "Uber eine eigenartige Erlranliung der Hirnrinde." Clin Anat 1995;8:429-431.

3. Ahmed MQ, Alenazi FSH, Fazaludeen MF, Shahid SMA, Kausar MA: Pathology and management of Alzheimer's disease: A review [Internet]. . Int J Pharm Res Allied Sci 2018;7:30-42.

4. Sengupta U, Nilson AN, Kayed R: The Role of Amyloid-beta Oligomers in Toxicity, Propagation, and Immunotherapy. EBioMedicine 2016;6:42-49.

5. Brody DL, Jiang H, Wildburger N, Esparza TJ: Non-canonical soluble amyloid-beta aggregates and plaque buffering: Controversies and future directions for target discovery in Alzheimer's disease. Alzheimer's Res Ther 2017;9:1-13.

6. Braak H, Braak E: Neuropathological stageing of Alzheimer-related changes. Acta Neuropathol 1991;4:239-59.

7. Gouras GK, Tampellini D, Takahashi RH, Capetillo-Zarate E: Intraneuronal beta-amyloid accumulation and synapse pathology in Alzheimer's disease. Acta Neuropathol 2010;119:523-41.

8. LaFerla FM, Green KN, Oddo S: Intracellular amyloid-beta in Alzheimer's disease. Nat Rev Neurosci 2007;8:499-509.

9. Mehta D, Jackson R, Paul G, Shi J, Sabbagh M: Why do trials for Alzheimer's disease drugs keep failing? A discontinued drug perspective for 2010-2015. Expert Opin Investig Drugs 2017; DOI: 10.1080/13543784.2017.1323868

10. Folch J, Busquets O, Ettcheto M, Sánchez-López E, Castro-Torres RD, Verdaguer E, et al.: Memantine for the treatment of dementia: A review on its current and future applications. $\mathbf{J}$ Alzheimer's Dis 2018;62:1223-1240.

11. Ertekin-Taner N: Genetics of Alzheimer's Disease: A Centennial Review. Neurol Clin 2007;25:17.

12. Reitz C, Mayeux R: Alzheimer disease: Epidemiology, Diagnostic Criteria, Risk Factors and Biomarkers 2014;88:640-51.

13. Bayer TA, Cappai R, Masters CL, Beyreuther K, Multhaup G: It all sticks together - The APPrelated family of proteins and Alzheimer's disease. Mol Psychiatry 1999;4:524-528.

14. Müller UC, Zheng H: Physiological functions of APP family proteins. Cold Spring Harb Perspect Med 2012;2:1-18.

15. Puzzo D, Privitera L, Leznik E, Fa M, Staniszewski A, Palmeri A, et al.: Picomolar Amyloid- Positively Modulates Synaptic Plasticity and Memory in Hippocampus. J Neurosci 2008;28:14537-14545.

16. Morley JE, Farr SA, Banks WA, Johnson SN, Yamada KA, Xu L: A physiological role for amyloid$\beta$ protein: Enhancement of learning and memory. J Alzheimer's Dis 2010;19:441-449.

17. Matsumura N, Takami M, Okochi M, Wada-Kakuda S, Fujiwara H, Tagami S, et al.: $\gamma$-Secretase Associated with Lipid Rafts. J Biol Chem 2014;289:5109-5121.

18. Jack CR, Bennett DA, Blennow K, Carrillo MC, Dunn B, Haeberlein SB, et al.: NIA-AA Research Framework: Toward a biological definition of Alzheimer's disease. Alzheimer's Dement 2018;14:535-562.

19. Younkin SG: The role of Aß42 in Alzheimer's disease. J Physiol 1998;92:289-292.

20. Finder VH, Glockshuber R: Amyloid- $\beta$ aggregation. Neurodegener Dis 2007;4:13-27.

21. Mclean CA, RA C, Fraser FW, Fuller SJ, Smith MJ, Vbeyreuther K, et al.: Soluble Pool of Abeta Amyloid as a Determinant of Severity of Neurodegeneration in Alzheimer's Disease. Ann Neurol 1999;46:860-866.

22. Cleary JP, Walsh DM, Hofmeister JJ, Shankar GM, Kuskowski MA, Selkoe DJ, et al.: Natural oligomers of the amyloid- $\beta$ protein specifically disrupt cognitive function. Nat Neurosci 2005;8:7984 . 
23. Baranello RJ, Bharani KL, Padmaraju V, Chopra N, Lahiri DK, Greig NH, et al.: Amyloid-Beta Protein Clearance and Degradation (ABCD) Pathways and their Role in Alzheimer's Disease. Curr Alzhimer's Researcj 2015;12:32-46.

24. Nath S, Agholme L, Kurudenkandy FR, Granseth B, Marcusson J, Hallbeck M: Spreading of neurodegenerative pathology via neuron-to-neuron transmission of $\beta$-amyloid. J Neurosci 2012 Jun 27;32:8767-77.

25. Domert J, Rao SB, Agholme L, Brorsson A-C, Marcusson J, Hallbeck M, et al.: Spreading of amyloid- $\beta$ peptides via neuritic cell-to-cell transfer is dependent on insufficient cellular clearance. Neurobiol Dis 2014 May;65:82-92.

26. Sardar Sinha M, Ansell-Schultz A, Civitelli L, Hildesjö C, Larsson M, Lannfelt L, et al.: Alzheimer's disease pathology propagation by exosomes containing toxic amyloid-beta oligomers. Acta Neuropathol 2018;136:41-56.

27. Sackmann V, Ansell A, Sackmann C, Lund H, Harris RA, Hallbeck M, et al.: Anti-inflammatory (M2) macrophage media reduce transmission of oligomeric amyloid beta in differentiated SH-SY5Y cells. Neurobiol Aging 2017;60:173-182.

28. Twelves D, Perkins KSM, Counsell C: Systematic review of incidence studies of Parkinson's disease. Mov Disord 2003;18:19-31.

29. Lewy F: Paralysis agitans. Julius Springer, 1912.

30. Fearnley J, Lees A: Ageing and Parkinson's disease: substantia nigra regional selectivity. Brain 1991;114:2283-2301.

31. Damier P, Hirsch EC, Agid Y, Graybiel AM: The substantia nigra of the human brain II. Patterns of loss of dopamine-containing neurons in Parkinson's disease. Brain 1999;122:1437-48.

32. Braak H, Del Tredici K, Rüb U, De Vos RAI, Jansen Steur ENH, Braak E: Staging of brain pathology related to sporadic Parkinson's disease. Neurobiol Aging 2003;24:197-211.

33. Kim SD, Allen NE, Canning CG, Fung VSC: Parkinson disease. Handb Clin Neurol 2018;159:173193.

34. Bengoa-Vergniory N, Roberts RF, Wade-Martins R, Alegre-Abarrategui J: Alpha-synuclein oligomers: a new hope. Acta Neuropathol 2017;134:819-838.

35. Sidransky E, Nalls MA, Aasly JO, Aharon-Peretz J, Annesi G, Barbosa ER, et al.: Multicenter Analysis of Glucocerebrosidase Mutations in Parkinson's Disease. N Engl J Med 2009;361:16511661.

36. Kumar KR, Ramirez A, Göbel A, Kresojević N, Svetel M, Lohmann K, et al.: Glucocerebrosidase mutations in a Serbian Parkinson's disease population. Eur J Neurol 2013;20:402-405.

37. Gatto EM, Da Prat G, Etcheverry JL, Drelichman G, Cesarini M: Parkinsonisms and glucocerebrosidase deficiency: A comprehensive review for molecular and cellular mechanism of glucocerebrosidase deficiency. Brain Sci 2019;9:1-15.

38. Ascherio A, Schwarzschild MA: The epidemiology of Parkinson's disease: risk factors and prevention. Lancet Neurol 2016;15:1257-1272.

39. Gray R, Ives N, Rick C, Patel S, Gray A, Jenkinson C, et al.: Long-term effectiveness of dopamine agonists and monoamine oxidase $\mathrm{B}$ inhibitors compared with levodopa as initial treatment for Parkinson's disease (PD MED): A large, open-label, pragmatic randomised trial. Lancet 2014;384:1196-1205.

40. LeWitt P, Fahn S: Levodopa therapy for Parkinson disease: A look backward and forward. Neurology 2019;86. DOI: 10.1212/WNL.0000000000002509

41. Burré J: The synaptic function of $\alpha$-synuclein. J Parkinsons Dis 2015;5:699-713.

42. Davidson WS, Jonas A, Clayton DF, George JM: Stabilization of $\alpha$-Synuclein secondary structure upon binding to synthetic membranes. J Biol Chem 1998;273:9443-9449.

43. Giasson BI, Murray IVJ, Trojanowski JQ, Lee VMY: A Hydrophobic Stretch of 12 Amino Acid Residues in the Middle of $\alpha$-Synuclein Is Essential for Filament Assembly. J Biol Chem 2001;276:2380-2386.

44. Oueslati A, Fournier M, Lashuel HA: Role of post-translational modifications in modulating the 
structure, function and toxicity of $\alpha$-synuclein. Implications for Parkinson's disease pathogenesis and therapies [Internet]. Elsevier B.V., 2010. DOI: 10.1016/S0079-6123(10)83007-9

45. Celej MS, Sarroukh R, Goormaghtigh E, Fidelio GD, Ruysschaert J-M, Raussens V: Toxic prefibrillar $\alpha$-synuclein amyloid oligomers adopt a distinctive antiparallel $\beta$-sheet structure. Biochem J 2012;443:719-726.

46. Uversky VN, Lee HJ, Li J, Fink AL, Lee SJ: Stabilization of Partially Folded Conformation during a-Synuclein Oligomerization in Both Purified and Cytosolic Preparations. J Biol Chem 2001;276:43495-43498.

47. Uversky VN, Li J, Fink AL: Metal-triggered structural transformations, aggregation, and fibrillation of human $\alpha$-synuclein: A possible molecular link between parkinson's disease and heavy metal exposure. J Biol Chem 2001;276:44284-44296.

48. Vladimir NU, Ghiam Y, Pierre OS, John G, Charles BG, Anthony LF: Methionine oxidation inhibits fibrillation of human alpha-synuclein in vitro [Internet]. . Febs Lett 2002;517:239-244.

49. Klucken J, Helling S, Schlachetzki JCM, Winkler J, Schäffer TE, Marcus K, et al.: Oxidative stressinduced posttranslational modifications of alpha-synuclein: Specific modification of alphasynuclein by 4-hydroxy-2-nonenal increases dopaminergic toxicity. Mol Cell Neurosci 2013;54:7183.

50. Rochet JC, Conway KA, Lansbury PT: Inhibition of fibrillization and accumulation of prefibrillar oligomers in mixtures of human and mouse $\alpha$-synuclein. Biochemistry 2000;39:10619-10626.

51. Domert J, Sackmann C, Severinsson E, Agholme L, Ingelsson M, Hallbeck M: Aggregated AlphaSynuclein Transfer Efficiently between Cultured Human Neuron- Like Cells and Localize to Lysosomes. PLoS One 2016;11:1-16.

52. Reyes JF, Sackmann C, Hoffmann A, Svenningsson P, Winkler J, Ingelsson M, et al.: Binding of $\alpha-$ synuclein oligomers to $\mathrm{Cx} 32$ facilitates protein uptake and transfer in neurons and oligodendrocytes. Acta Neuropathol 2019; DOI: 10.1007/s00401-019-02007-x

53. Sackmann V, Sinha Sardar M, Sackmann C, Civitelli L, Bergström J, Ansell-Schultz A, et al.: Inhibition of nSMase 2 reduces the transfer of oligomeric $\alpha$-synuclein irrespective of hypoxia. Front Mol Neurosci 2019; DOI: 10.3389/fnmol.2019.00200

54. Danzer KM, Kranich LR, Ruf WP, Cagsal-Getkin O, Winslow AR, Zhu L, et al.: Exosomal cell-tocell transmission of alpha synuclein oligomers. Mol Neurodegener 2012;7:42.

55. Alvarez-Erviti L, Seow Y, Schapira AH, Gardiner C, Sargent IL, Wood MJA, et al.: Lysosomal dysfunction increases exosome-mediated alpha-synuclein release and transmission. Neurobiol Dis 2011;42:360-367.

56. Delenclos M, Trendafilova T, Mahesh D, Baine AM, Moussaud S, Yan IK, et al.: Investigation of endocytic pathways for the internalization of exosome-associated oligomeric alpha-synuclein. Front Neurosci 2017;11:1-10.

57. Franco R, Fernández-Suárez D: Alternatively activated microglia and macrophages in the central nervous system. Prog Neurobiol 2015;131:65-86.

58. Maezawa I, Zimin PI, Wulff H, Jin LW: Amyloid- $\beta$ protein oligomer at low nanomolar concentrations activates microglia and induces microglial neurotoxicity. J Biol Chem 2011;286:3693-3706.

59. Walker DG, Link J, Lue L-F, Dalsing-Hernandez JE, Boyes BE: Gene expression changes by amyloid $\beta$ peptide-stimulated human postmortem brain microglia identify activation of multiple inflammatory processes. J Leukoc Biol 2006;79:596-610.

60. Meyer-Luehmann M, Spires-Jones TL, Prada C, Garcia-Alloza M, De Calignon A, Rozkalne A, et al.: Rapid appearance and local toxicity of amyloid- $\beta$ plaques in a mouse model of Alzheimer's disease. Nature 2008;451:720-724.

61. Acarin L, González B, Castellano B: Neuronal, astroglial and microglial cytokine expression after an excitotoxic lesion in the immature rat brain. Eur J Neurosci 2000;12:3505-20.

62. Heneka MT, O'Banion MK, Terwel D, Kummer MP: Neuroinflammatory processes in Alzheimer's disease. J Neural Transm 2010;117:919-47. 
63. Colton CA, Mott RT, Sharpe H, Xu Q, Van Nostrand WE, Vitek MP: Expression profiles for macrophage alternative activation genes in $\mathrm{AD}$ and in mouse models of $\mathrm{AD}$. J Neuroinflammation 2006;3:1-12.

64. Jimenez S, Baglietto-Vargas D, Caballero C, Moreno-Gonzalez I, Torres M, Sanchez-Varo R, et al.: Inflammatory response in the hippocampus of PS1M146L/APP751SL mouse model of Alzheimer's disease: age-dependent switch in the microglial phenotype from alternative to classic. J Neurosci 2008 Nov 5;28:11650-61.

65. Mawuenyega KG, Sigurdson W, Ovod V, Munsell L, Kasten T, Morris JC, et al.: Decreased clearance of CNS $\beta$-amyloid in Alzheimer's disease. Science (80- ) 2010;330:1774.

66. Koenigsknecht-Talboo J, Landreth GE: Microglial phagocytosis induced by fibrillar $\beta$-amyloid and IgGs are differentially regulated by proinflammatory cytokines. J Neurosci 2005;25:8240-8249.

67. Michelucci A, Heurtaux T, Grandbarbe L, Morga E, Heuschling P: Characterization of the microglial phenotype under specific pro-inflammatory and anti-inflammatory conditions: Effects of oligomeric and fibrillar amyloid- $\beta$. J Neuroimmunol 2009;210:3-12.

68. Kiyota T, Okuyama S, Swan RJ, Jacobsen MT, Gendelman HE, Ikezu T: CNS expression of antiinflammatory cytokine interleukin-4 attenuates Alzheimer's disease-like pathogenesis in APP+PS1 bigenic mice. FASEB J 2010;24:3093-102.

69. Richard KL, Filali M, Préfontaine P, Rivest S: Toll-like receptor 2 acts as a natural innate immune receptor to clear amyloid beta 1-42 and delay the cognitive decline in a mouse model of Alzheimer's disease. J Neurosci 2008;28:5784-93.

70. Vom Berg J, Prokop S, Miller KR, Obst J, Kälin RE, Lopategui-Cabezas I, et al.: Inhibition of IL12/IL-23 signaling reduces Alzheimer's disease-like pathology and cognitive decline. Nat Med 2012 Dec;18:1812-9.

71. Chakrabarty P, Tianbai L, Herring A, Ceballos-Diaz C, Das P, Golde TE: Hippocampal expression of murine IL-4 results in exacerbation of amyloid deposition. Mol Neurodegener 2012;7:1-12.

72. El Khoury J, Toft M, Hickman SE, Means TK, Terada K, Geula C, et al.: Ccr2 deficiency impairs microglial accumulation and accelerates progression of Alzheimer-like disease. Nat Med 2007;13:432-8.

73. Tang Y, Le W: Differential Roles of M1 and M2 Microglia in Neurodegenerative Diseases. Mol Neurobiol 2016;53:1181-1194.

74. Ouchi Y, Yoshikawa E, Sekine Y, Futatsubashi M, Kanno T, Ogusu T, et al.: Microglial activation and dopamine terminal loss in early Parkinson's disease. Ann Neurol 2005;57:168-175.

75. Zhang W, Wang T, Pei Z, Miller DS, Wu X, Block ML, et al.: Aggregated $\alpha$-synuclein activates microglia: A process leading to disease progression in Parkinson's disease. FASEB J 2005;19:533542.

76. Lee E-J, Woo M-S, Moon P-G, Baek M-C, Choi I-Y, Kim W-K, et al.: $\alpha$-Synuclein Activates Microglia by Inducing the Expressions of Matrix Metalloproteinases and the Subsequent Activation of Protease-Activated Receptor-1. J Immunol 2010;185:615-623.

77. Gao HM, Kotzbauer PT, Uryu K, Leight S, Trojanowski JQ, Lee VMY: Neuroinflammation and oxidation/nitration of $\alpha$-synuclein linked to dopaminergic neurodegeneration. $\mathrm{J}$ Neurosci 2008;28:7687-7698.

78. Tang Y, Li T, Li J, Yang J, Liu H, Zhang XJ, et al.: Jmjd3 is essential for the epigenetic modulation of microglia phenotypes in the immune pathogenesis of Parkinson's disease. Cell Death Differ 2014;21:369-380.

79. Wolf P: The Nature and Significance of Platelet Products in Human Plasma. Br J Haematol 1967; DOI: $10.1111 / \mathrm{j} .1365-2141.1967 . t b 08741 . x$

80. Yáñez-Mó M, Siljander PRM, Andreu Z, Zavec AB, Borràs FE, Buzas EI, et al.: Biological properties of extracellular vesicles and their physiological functions. J Extracell Vesicles 2015;4:160.

81. Vella LJ, Hill AF, Cheng L: Focus on extracellular vesicles: Exosomes and their role in protein trafficking and biomarker potential in Alzheimer's and Parkinson's disease. Int J Mol Sci 2016;17. 
DOI: 10.3390/ijms17020173

82. Baixauli F, López-Otín C, Mittelbrunn M: Exosomes and autophagy: Coordinated mechanisms for the maintenance of cellular fitness. Front Immunol 2014;5:1-6.

83. Howitt J, Hill AF: Exosomes in the pathology of neurodegenerative diseases. J Biol Chem 2016;291:26589-26597.

84. Vingtdeux V, Hamdane M, Loyens A, Gelé P, Drobeck H, Bégard S, et al.: Alkalizing drugs induce accumulation of amyloid precursor protein by-products in luminal vesicles of multivesicular bodies. J Biol Chem 2007;282:18197-18205.

85. Sharples RA, Vella LJ, Nisbet RM, Naylor R, Perez K, Barnham KJ, et al.: Inhibition of $\gamma$-secretase causes increased secretion of amyloid precursor protein $\mathrm{C}$-terminal fragments in association with exosomes. FASEB J 2008;22:1469-1478.

86. Dinkins MB, Enasko J, Hernandez C, Wang G, Kong J, Helwa I, et al.: Neutral Sphingomyelinase2 Deficiency Ameliorates Alzheimer's Disease Pathology and Improves Cognition in the 5XFAD Mouse. J Neurosci 2016;36:8653-67.

87. Zheng T, Pu J, Chen Y, Mao Y, Guo Z, Pan H, et al.: Plasma exosomes spread and cluster around $\beta$-amyloid plaques in an animal model of Alzheimer's disease. Front Aging Neurosci 2017;9:1-12.

88. Yuyama K, Sun H, Mitsutake S, Igarashi Y: Sphingolipid-modulated exosome secretion promotes clearance of amyloid- $\beta$ by microglia. J Biol Chem 2012;287:10977-10989.

89. Yuyama K, Sun H, Usuki S, Sakai S, Hanamatsu H, Mioka T, et al.: A potential function for neuronal exosomes: Sequestering intracerebral amyloid- $\beta$ peptide. FEBS Lett 2015;589:84-88.

90. Xia Y, Zhang G, Han C, Ma K, Guo X, Wan F, et al.: Microglia as modulators of exosomal alphasynuclein transmission. Cell Death Dis 2019;10. DOI: 10.1038/s41419-019-1404-9

91. Gustafsson G, Lööv C, Persson E, Lázaro DF, Takeda S, Bergström J, et al.: Secretion and Uptake of $\alpha$-Synuclein Via Extracellular Vesicles in Cultured Cells. Cell Mol Neurobiol 2018;38:15391550 .

92. Saman S, Kim WH, Raya M, Visnick Y, Miro S, Saman S, et al.: Exosome-associated tau is secreted in tauopathy models and is selectively phosphorylated in cerebrospinal fluid in early Alzheimer disease. J Biol Chem 2012;287:3842-3849.

93. Chai X, Dage JL, Citron M: Constitutive secretion of tau protein by an unconventional mechanism. Neurobiol Dis 2012;48:356-366.

94. Simón D, García-García E, Gómez-Ramos A, Falcón-Pérez JM, Daz-Hernández M, Hernández F, et al.: Tau overexpression results in its secretion via membrane vesicles. Neurodegener Dis 2012;10:73-75.

95. Asai H, Ikezu S, Tsunoda S, Medalla M, Luebke J, Haydar T, et al.: Depletion of microglia and inhibition of exosome synthesis halt tau propagation. Nat Neurosci 2015;18:1584-1593.

96. Stoorvogel W, Strous GJ, Geuze HJ, Oorschot V, Schwartzt AL: Late endosomes derive from early endosomes by maturation. Cell 1991;65:417-427.

97. Hanson PI, Cashikar A: Multivesicular Body Morphogenesis. Annu Rev Cell Dev Biol 2012;28:337-362.

98. van Niel G, Charrin S, Simoes S, Romao M, Rochin L, Saftig P, et al.: The Tetraspanin CD63 Regulates ESCRT-Independent and -Dependent Endosomal Sorting during Melanogenesis. Dev Cell 2011;21:708-721.

99. Trajkovic K, Hsu C, Chiantia S, Rajendran L, Wenzel D, Wieland F, et al.: Ceramide triggers budding of exosome vesicles into multivesicular endosomes. Science 2008;319:1244-1247.

100. Ghossoub R, Lembo F, Rubio A, Gaillard CB, Bouchet J, Vitale N, et al.: Syntenin-ALIX exosome biogenesis and budding into multivesicular bodies are controlled by ARF6 and PLD2. Nat Commun 2014;5. DOI: $10.1038 /$ ncomms4477

101. Bobrie A, Colombo M, Krumeich S, Raposo G, Théry C: Diverse subpopulations of vesicles secreted by different intracellular mechanisms are present in exosome preparations obtained by differential ultracentrifugation. J Extracell Vesicles 2012;1. DOI: 10.3402/jev.v1i0.18397

102. Koliha N, Wiencek Y, Heider U, Jüngst C, Kladt N, Krauthäuser S, et al.: A novel multiplex bead- 
based platform highlights the diversity of extracellular vesicles. J Extracell Vesicles 2016;5. DOI: 10.3402/jev.v5.29975

103. Olsen ASB, Færgeman NJ: Sphingolipids: Membrane microdomains in brain development, function and neurological diseases. Open Biol 2017;7. DOI: 10.1098/rsob.170069

104. Karlsson K-A: Sphingolipid long chain bases. Lipids 1970 Nov;5:878-891.

105. Merrill AH: Sphingolipid and glycosphingolipid metabolic pathways in the era of sphingolipidomics. Chem Rev 2011;111:6387-6422.

106. Sandhoff R: Very long chain sphingolipids: Tissue expression, function and synthesis. FEBS Lett 2010;584:1907-1913.

107. Pruett ST, Bushnev A, Liotta DC, Hagedorn K, Adiga M, Haynes CA, et al.: Biodiversity of sphingoid bases ("sphingosines") and related amino alcohols. J Lipid Res 2008;49:1621-1639.

108. Sonnino S, Chigorno V: Ganglioside molecular species containing C18- and C20-sphingosine in mammalian nervous tissues and neuronal cell cultures. Biochim Biophys Acta - Rev Biomembr 2000;1469:63-77.

109. Gault CR, Obeid LM, Hannun YA: An Overview of Sphingolipid Metabolism: From Synthesis to Breakdown [Internet]. 2010. DOI: 10.1007/978-1-4419-6741-1_1

110. Filippov V, Song MA, Zhang K, Vinters H V., Tung S, Kirsch WM, et al.: Increased ceramide in brains with alzheimer's and other neurodegenerative diseases. J Alzheimer's Dis 2012;29:537-547.

111. Han X, Holtzman DM, McKeel DW, Kelley J, Morris JC: Substantial sulfatide deficiency and ceramide elevation in very early Alzheimer's disease: Potential role in disease pathogenesis. J Neurochem 2002;82:809-818.

112. Haughey NJ, Bandaru VVR, Bae M, Mattson MP: Roles for dysfunctional sphingolipid metabolism in Alzheimer's disease neuropathogenesis. Biochim Biophys Acta - Mol Cell Biol Lipids 2010;1801:878-886.

113. He X, Huang Y, Li B, Gong CX, Schuchman EH: Deregulation of sphingolipid metabolism in Alzheimer's disease. Neurobiol Aging 2010;31:398-408.

114. Dinkins MB, Dasgupta S, Wang G, Shu G, He Q, Kong JN, et al.: The 5XFAD Mouse Model of Alzheimer's Disease Exhibits an Age-Dependent Increase in Anti-Ceramide IgG and Exogenous Administration of Ceramide Further Increases Anti-Ceramide Titers and Amyloid Plaque Burden. J Alzheimer's Dis 2015;46:55-61.

115. Mielke MM, Haughey NJ, Han D, An Y, Bandaru VVR, Lyketsos CG, et al.: The Association between Plasma Ceramides and Sphingomyelins and Risk of Alzheimer's Disease Differs by Sex and APOE in the Baltimore Longitudinal Study of Aging. J Alzheimer's Dis 2017;60:819-828.

116. Savica R, Murray ME, Persson XM, Kantarci K, Parisi JE, Dickson DW, et al.: Plasma sphingolipid changes with autopsy-confirmed Lewy body or Alzheimer's pathology. Alzheimer's Dement Diagnosis, Assess Dis Monit 2016;3:43-50.

117. Mielke MM, Maetzler W, Haughey NJ, Bandaru VVR, Savica R, Berg D, et al.: Plasma Ceramide and Glucosylceramide Metabolism Is Altered in Sporadic Parkinson 's Disease and Associated with Cognitive Impairment : A Pilot Study. PLoS One 2013;8:1-6.

118. Mielke MM, Bandaru VVR, Haughey NJ, Xia J, Fried LP, Yasar S, et al.: Serum ceramides increase the risk of Alzheimer disease: The Women's Health and Aging Study II. Neurology 2012;79:633641.

119. Gegg ME, Burke D, Heales SJR, Cooper JM, Hardy J, Wood NW, et al.: Glucocerebrosidase deficiency in substantia nigra of parkinson disease brains. Ann Neurol 2012;72:455-463.

120. Murphy KE, Gysbers AM, Abbott SK, Tayebi N, Kim WS, Sidransky E, et al.: Reduced glucocerebrosidase is associated with increased $\alpha$-synuclein in sporadic Parkinson's disease. Brain 2014;137:834-848.

121. Mazzulli JR, Xu YH, Sun Y, Knight AL, McLean PJ, Caldwell GA, et al.: Gaucher disease glucocerebrosidase and $\alpha$-synuclein form a bidirectional pathogenic loop in synucleinopathies. Cell 2011;146:37-52.

122. Abbott SK, Li H, Muñoz SS, Knoch B, Batterham M, Murphy KE, et al.: Altered ceramide acyl 
chain length and ceramide synthase gene expression in Parkinson's disease. Mov Disord 2014;29:518-526.

123. Fabelo N, Martin V: Severe Alterations in Lipid Composition of Frontal Cortex Lipid Rafts from Parkinson's Disease and Incidental Parkinson's Disease. Mol Med 2011;17:1.

124. Gegg ME, Sweet L, Wang BH, Shihabuddin LS, Sardi SP, Schapira AHV: No evidence for substrate accumulation in Parkinson brains with GBA mutations. Mov Disord 2015;30:1085-1089.

125. Cheng D, Jenner AM, Shui G, Cheong WF, Mitchell TW, Nealon JR, et al.: Lipid pathway alterations in parkinson's disease primary visual cortex. PLoS One 2011;6. DOI: 10.1371/journal.pone.0017299

126. Ferrazza R, Cogo S, Melrose H, Bubacco L, Greggio E, Guella G, et al.: LRRK2 deficiency impacts ceramide metabolism in brain. Biochem Biophys Res Commun 2016;478:6-11.

127. Alcalay RN, Mallett V, Vanderperre B, Tavassoly O, Dauvilliers Y, Wu RYJ, et al.: SMPD1 mutations, activity, and alpha-synuclein accumulation in Parkinson's disease. Mov Disord 2019;110.

128. Bienias K, Fiedorowicz, Anna F, Sadowska A, Prokopiuk S, Car H: Regulation of sphingomyelin metabolism. Pharmacol Reports 2016;68:570-581.

129. Skotland T, Sandvig K, Llorente A: Progress in Lipid Research Lipids in exosomes : Current knowledge and the way forward. Prog Lipid Res 2017;66:30-41.

130. Chew W-S, Ong W-Y, Ng Y-Y, Sze SK, Chua JJ-E, Tan LH-R, et al.: Enriched Expression of Neutral Sphingomyelinase 2 in the Striatum is Essential for Regulation of Lipid Raft Content and Motor Coordination. Mol Neurobiol 2017;55:5741-5756.

131. Karakashian AA, Giltiay N V, Smith GM, Nikolova-karakashian MN: Expression of neutral sphingomyelinase-2 (NSMase-2) in primary rat hepatocytes modulates IL- $\beta$-induced JNK activation. FASEB J 2004;2:1-22.

132. Rutkute K, Karakashian AA, Giltiay N V., Dobierzewska A, Nikolova-Karakashian MN: Aging in rat causes hepatic hyperresposiveness to interleukin-1 $\beta$ which is mediated by neutral sphingomyelinase-2. Hepatology 2007;46:1166-1176.

133. Levy M, Castillo SS, Goldkorn T: nSMase2 activation and trafficking are modulated by oxidative stress to induce apoptosis. Biochem Biophys Res Commin 2006;344:900-905.

134. Rutkute K, Asmis RH, Nikolova-Karakashian MN: Regulation of neutral sphingomyelinase-2 by GSH: a new insight to the role of oxidative stress in aging-associated inflammation. J Lipid Res 2007;48:2443-52.

135. Castillo SS, Levy M, Thaikoottathil J V., Goldkorn T: Reactive nitrogen and oxygen species activate different sphingomyelinases to induce apoptosis in airway epithelial cells. Exp Cell Res 2007;313:2680-2686.

136. Yang DI, Yeh CH, Chen S, Xu J, Hsu CY: Neutral sphingomyelinase activation in endothelial and glial cell death induced by amyloid beta-peptide. Neurobiol Dis 2004;17:99-107.

137. Lee JT, Xu J, Lee JM, Ku G, Han X, Yang DI, et al.: Amyloid- $\beta$ peptide induces oligodendrocyte death by activating the neutral sphingomyelinase-ceramide pathway. J Cell Biol 2004;164:123-131.

138. Dinkins MB, Dasgupta S, Wang G, Zhu G, Bieberich E: Exosome Reduction In Vivo Is Associated with Lower Amyloid Plaque Load in the 5XFAD Mouse Model of Alzheimer 's Disease. Neurobiol Aging 2014;35:1792-1800.

139. Falker C, Hartmann A, Guett I, Dohler F, Altmeppen H, Betzel C, et al.: Exosomal cellular prion protein drives fibrillization of amyloid beta and counteracts amyloid beta-mediated neurotoxicity. $\mathrm{J}$ Neurochem 2016;137:88-100.

140. Guo BB, Bellingham SA, Hill AF: The neutral sphingomyelinase pathway regulates packaging of the prion protein into exosomes. J Biol Chem 2015;290:3455-3467.

141. Kubo SI, Nemani VM, Chalkley RJ, Anthony MD, Hattori N, Mizuno Y, et al.: A combinatorial code for the interaction of $\alpha$-synuclein with membranes. J Biol Chem 2005;280:31664-31672.

142. Kubo S, Hatano T, Hattori N: Lipid rafts involvement in the pathogenesis of Parkinson s disease. Front Biosci 2015;20:4308. 
143. Fortin DL, Troyer MD, Nakamura K, Kubo S, Anthony MD, Edwards RH: Lipid Rafts Mediate the Synaptic Localization of alpha-Synuclein. J Neurosci 2004;24:6715-6723.

144. Ohsumi Y: Historical landmarks of autophagy research. Cell Res 2014;24:9-23.

145. He C, Klionsky DJ: Regulation Mechanisms and Signaling Pathways of Autophagy. Annu Rev Genet 2009;43:67-93.

146. Nixon RA: Autophagy, amyloidogenesis and Alzheimer disease. J Cell Sci 2007;120:4081-4091.

147. Yang DS, Stavrides P, Mohan PS, Kaushik S, Kumar A, Ohno M, et al.: Reversal of autophagy dysfunction in the TgCRND8 mouse model of Alzheimer's disease ameliorates amyloid pathologies and memory deficits. Brain 2011;134:258-277.

148. Caccamo A, Majumder S, Richardson A, Strong R, Oddo S: Molecular interplay between mammalian target of rapamycin (mTOR), amyloid- $\beta$, and Tau: Effects on cognitive impairments. J Biol Chem 2010;285:13107-13120.

149. Haung Yu W, Cuervo AM, Kumar A, Peterhoff CM, Schmidt SD, Lee JH, et al.: Macroautophagy - A novel $\beta$-amyloid peptide-generating pathway activated in Alzheimer's disease. J Cell Biol 2005;171:87-98.

150. Zheng L, Terman A, Hallbeck M, Dehvari N, Cowburn RF, Benedikz E, et al.: Macroautophagygenerated increase of lysosomal amyloid $\beta$-protein mediates oxidant-induced apoptosis of cultured neuroblastoma cells. Autophagy 2011;7:1528-1545.

151. Webb JL, Ravikumar B, Atkins J, Skepper JN, Rubinsztein DC: $\alpha$-synuclein Is Degraded by Both Autophagy and the Proteasome. J Biol Chem 2003;278:25009-25013.

152. Tofaris GK, Kim HT, Hourez R, Jung J-W, Kim KP, Goldberg AL: Ubiquitin ligase Nedd4 promotes $\alpha$-synuclein degradation by the endosomal-lysosomal pathway. Proc Natl Acad Sci 2011;108:17004-17009.

153. Volpicelli-Daley LA, Gamble KL, Schultheiss CE, Riddle DM, West AB, Lee VM-Y: Formation of $\alpha$-synuclein Lewy neurite-like aggregates in axons impedes the transport of distinct endosomes. Mol Biol Cell 2014;25:4010-4023.

154. Winslow AR, Chen CW, Corrochano S, Acevedo-Arozena A, Gordon DE, Peden AA, et al.: alphaSynuclein impairs macroautophagy: Implications for Parkinson's disease. J Cell Biol 2010;190:1023-1037.

155. Minakaki G, Menges S, Kittel A, Emmanouilidou E, Schaeffner I, Barkovits K, et al.: Autophagy inhibition promotes SNCA/alpha-synuclein release and transfer via extracellular vesicles with a hybrid autophagosome-exosome-like phenotype. Autophagy 2018;14:98-119.

156. Lee JA, Beigneux A, Ahmad ST, Young SG, Gao FB: ESCRT-III Dysfunction Causes Autophagosome Accumulation and Neurodegeneration. Curr Biol 2007;17:1561-1567.

157. Rusten TE, Vaccari T, Lindmo K, Rodahl LMW, Nezis IP, Sem-Jacobsen C, et al.: ESCRTs and Fab1 Regulate Distinct Steps of Autophagy. Curr Biol 2007;17:1817-1825.

158. Fader CM, Sánchez D, Furlán M, Colombo MI: Induction of autophagy promotes fusion of multivesicular bodies with autophagic vacuoles in K562 cells. Traffic 2008;9:230-250.

159. Guo H, Chitiprolu M, Roncevic L, Javalet C, Hemming FJ, Trung MT, et al.: Atg5 Disassociates the V1V0-ATPase to Promote Exosome Production and Tumor Metastasis Independent of Canonical Macroautophagy. Dev Cell 2017;43:716-730.e7.

160. Murrow L, Debnath J: Atg12-Atg3 Coordinates Basal Autophagy, Endolysosomal Trafficking, and Exosome Release. Mol Cell Oncol 2018;5:37-41.

161. Shrivastava S, Devhare P, Sujijantarat N, Steele R, Kwon Y-C, Ray R, et al.: Knockdown of Autophagy Inhibits Infectious Hepatitis C Virus Release by the Exosomal Pathway. J Virol 2016;90:1387-1396.

162. Nilsson P, Sekiguchi M, Akagi T, Izumi S, Komori T, Hui K, et al.: Autophagy-related protein 7 deficiency in amyloid beta precursor protein transgenic mice decreases amyloid beta in the multivesicular bodies and induces amyloid beta accumulation in the golgi. Am J Pathol 2015;185:305-313.

163. Eratne D, Loi SM, Farrand S, Kelso W, Velakoulis D, Looi JCL: Alzheimer's disease: clinical 
update on epidemiology, pathophysiology and diagnosis. Australas Psychiatry 2018;26:347-357.

164. Dubois B, Feldman HH, Jacova C, Hampel H, Molinuevo JL, Blennow K, et al.: Advancing research diagnostic criteria for Alzheimer's disease: The IWG-2 criteria. Lancet Neurol 2014;13:614-629.

165. Marcusson J: Dementia - investigation specialist level. internetmedicin.se 2017;

166. Weller J, Budson A: Current understanding of Alzheimer's disease diagnosis and treatment. F1000Research 2018;7:1161.

167. Alvarez-Erviti L, Seow Y, Yin H, Betts C, Lakhal S, Wood MJ: Delivery of siRNA to the mouse brain by systemic injection of targeted exosomes. Nat Biotechnol 2011;29:341-46.

168. Grapp M, Wrede A, Schweizer M, Hüwel S, Galla HJ, Snaidero N, et al.: Choroid plexus transcytosis and exosome shuttling deliver folate into brain parenchyma. Nat Commun 2013;4. DOI: $10.1038 /$ ncomms 3123

169. Lakhal S, Wood MJA: Exosome nanotechnology: An emerging paradigm shift in drug delivery: Exploitation of exosome nanovesicles for systemic in vivo delivery of RNAi heralds new horizons for drug delivery across biological barriers. BioEssays 2011;33:737-741.

170. Eitan E, Hutchison ER, Marosi K, Comotto J, Mustapic M, Nigam SM, et al.: Extracellular vesicleassociated $\mathrm{A} \beta$ mediates trans-neuronal bioenergetic and $\mathrm{Ca} 2+$-handling deficits in Alzheimer's disease models. npj Aging Mech Dis 2016;2:16019.

171. Wang MJ, Yi S, Han J, Park SY, Jang J, Chun IK, et al.: Oligomeric forms of amyloid- $\beta$ protein in plasma as a potential blood-based biomarker for Alzheimer' s disease. Alzheimers Res Ther 2017;9:1-10.

172. An SSA, Lee B, Yu JS, Lim K, Kim GJ, Lee R, et al.: Dynamic changes of oligomeric amyloid $\beta$ levels in plasma induced by spiked synthetic A $\beta 42$. Alzheimers Res Ther 2017;9:1-10.

173. Agholme L, Lindström T, Kågedal K, Marcusson J, Hallbeck M: An in vitro model for neuroscience: differentiation of SH-SY5Y cells into cells with morphological and biochemical characteristics of mature neurons. J Alzheimers Dis 2010 Jan;20:1069-82.

174. Ran FA, Hsu PDP, Wright J, Agarwala V, Scott D a, Zhang F: Genome engineering using the CRISPR-Cas9 system. Nat Protoc 2013;8:2281-2308.

175. Komatsu M, Waguri S, Ueno T, Iwata J, Murata S, Tanida I, et al.: Impairment of starvation-induced and constitutive autophagy in Atg7-deficient mice. J Cell Biol 2005;169:425-434.

176. Tsien JZ, Chen DF, Gerber D, Tom C, Mercer EH, Anderson DJ, et al.: Subregion- and cell typerestricted gene knockout in mouse brain. Cell 1996;87:1317-1326.

177. Saito T, Matsuba Y, Mihira N, Takano J, Nilsson P, Itohara S, et al.: Single App knock-in mouse models of Alzheimer's disease. Nat Neurosci 2014;17:661-663.

178. Ansell-Schultz A, Reyes JF, Samuelsson M, Hallbeck M: Reduced retromer function results in the accumulation of amyloid-beta oligomers. Mol Cell Neurosci 2018;93:18-26.

179. Näsström T, Fagerqvist T, Barbu M, Karlsson M, Nikolajeff F, Kasrayan A, et al.: The lipid peroxidation products 4-oxo-2-nonenal and 4-hydroxy-2-nonenal promote the formation of $\alpha$ synuclein oligomers with distinct biochemical, morphological, and functional properties. Free Radic Biol Med 2011;50:428-437.

180. Sardar Sinha M, Villamil Giraldo AM, Öllinger K, Hallbeck M, Civitelli L: Lipid vesicles affect the aggregation of 4-hydroxy-2-nonenal-modified $\alpha$-synuclein oligomers. Biochim Biophys Acta - Mol Basis Dis 2018;1864:3060-3068.

181. Englund H, Sehlin D, Johansson AS, Nilsson LNG, Gellerfors P, Paulie S, et al.: Sensitive ELISA detection of amyloid- $\beta$ protofibrils in biological samples. J Neurochem 2007;103:334-345.

182. Horikoshi Y, Sakaguchi G, Becker AG, Gray AJ, Duff K, Aisen PS, et al.: Development of A $\beta$ terminal end-specific antibodies and sensitive ELISA for A $\beta$ variant. Biochem Biophys Res Commun 2004 Jul;319:733-737.

183. Griffin WS, Stanley LC, Ling C, White L, MacLeod V, Perrot LJ, et al.: Brain interleukin 1 and S100 immunoreactivity are elevated in Down syndrome and Alzheimer disease. [Internet]. . Proc Natl Acad Sci U S A 1989 Oct;86:7611-15.

184. Akiyama H, Barger S, Barnum S, Bradt B, Bauer J, Cole GM, et al.: Inflammation and Alzheimer's 
disease. Neurobiol Aging 2000;21:383-421.

185. Heneka MT, Kummer MP, Latz E: Innate immune activation in neurodegenerative disease. Nat Rev Immunol 2014 Jun 25;14:463-477.

186. Taylor JM, Minter MR, Newman AG, Zhang M, Adlard PA, Crack PJ: Type-1 interferon signaling mediates neuro-inflammatory events in models of Alzheimer's disease. Neurobiol Aging 2014 May;35:1012-23.

187. Li S, Wang L, Michael Berman M, Kong Y-Y, Dorf ME: Mapping a Dynamic Innate Immunity Protein Interaction Network Regulating Type I Interferon Production. Immunity 2011;35:426-40.

188. Haynes CM, Titus EA, Cooper AA: Degradation of misfolded proteins prevents ER-derived oxidative stress and cell death. Mol Cell 2004;15:767-76.

189. Colacurcio DJ, Nixon RA: Disorders of lysosomal acidification - The emerging role of v-ATPase in aging and neurodegenerative disease. Ageing Res Rev 2016;32:75-88.

190. Su JH, Deng G, Cotman CW: BAX Protein Expression Is Increased in Alzheimer's Brain: Correlations with DNA Damage, Bcl-2 Expression, and Brain Pathology. J Neuropathol Exp Neurol 1997;56:86-93.

191. Sun Y, Rong X, Lu W, Peng Y, Li J, Xu S, et al.: Translational Study of Alzheimer's Disease Biomarkers from brain tissues in AbetaPP/PS1 mice and serum of AD patients. J Alzheimer's Dis 2015;45:269-82.

192. Szodorai A, Kuan Y, Hunzelmann S, Engel U, Sakane A, Sasaki T, et al.: APP anterograde transport requires Rab3A GTPase activity for assembly of the transport vesicle. J Neurosci 2009;29:1453444.

193. Lang S, Erdmann F, Jung M, Wagner R, Cavalie A, Zimmermann R: Sec61 complexes form ubiquitous ER Ca2+ leak channels. Channels 2011;5:228-35.

194. Demuro A, Parker I, Stutzmann GE: Calcium signaling and amyloid toxicity in Alzheimer disease. J Biol Chem 2010;285:12463-8.

195. Kitamura Y, Shimohama S, Ota T, Matsuoka Y, Nomura Y, Taniguchi T: Alteration of transcription factors NF-kappa-B and STAT1 in Alzheimer's disease brains. Neurosci Lett 1997;237:17-20.

196. Hsu W, Chiu T, Tai D, Ma Y, Lee E: A novel defense mechanism that is activated on amyloid-beta insult to mediate cell survival: role of SGK1-STAT1/STAT2 signaling. Cell Death Differ 2009;16:1515-29.

197. Wan J, Fu AKY, Ip FCF, Ng H-K, Hugon J, Page G, et al.: Tyk2/STAT3 Signaling Mediates betaAmyloid-Induced Neuronal Cell Death: Implications in Alzheimer's Disease. J Neurosci 2010;30:6873-81.

198. Jager WADH: Sphingomyelin in Lewy Inclusion Bodies in Parkinson's Disease. Arch Neurol 1969;21:615-19.

199. Robak LA, Jansen IE, Van Rooij J, Uitterlinden AG, Kraaij R, Jankovic J, et al.: Excessive burden of lysosomal storage disorder gene variants in Parkinson's disease. Brain 2017;140:3191-3203.

200. Hwang O: Role of Oxidative Stress in Parkinson's Disease. Exp Neurobiol 2013;22:11.

201. Scudamore O, Ciossek T, Bank B: Increased Oxidative Stress Exacerbates a -Synuclein Aggregation In Vivo 2018;77:443-453.

202. Law BA, Liao X, Moore KS, Southard A, Roddy P, Ji R, et al.: Lipotoxic very-long-chain ceramides cause mitochondrial dysfunction, oxidative stress, and cell death in cardiomyocytes. FASEB J 2018;32:1403-1416.

203. Zhou W, Woodson M, Sherman MB, Neelakanta G, Sultana H: Exosomes mediate Zika virus transmission through SMPD3 neutral Sphingomyelinase in cortical neurons. Emerg Microbes Infect 2019;8:307-326.

204. Menck K, Sönmezer C, Worst TS, Schulz M, Dihazi GH, Streit F, et al.: Neutral sphingomyelinases control extracellular vesicles budding from the plasma membrane. J Extracell Vesicles 2017;6. DOI: 10.1080/20013078.2017.1378056

205. Boland B, Kumar A, Lee S, Platt FM, Wegiel J, Yu WH, et al.: Autophagy Induction and Autophagosome Clearance in Neurons: Relationship to Autophagic Pathology in Alzheimer's 
Disease. J Neurosci 2008;28:6926-6937.

206. Boland B, Smith DA, Mooney D, Jung SS, Walsh DM, Platt FM: Macroautophagy is not directly involved in the metabolism of amyloid precursor protein. J Biol Chem 2010;285:37415-37426.

207. Jaeger PA, Pickford F, Sun CH, Lucin KM, Masliah E, Wyss-Coray T: Regulation of amyloid precursor protein processing by the beclin 1 complex. PLoS One 2010;5. DOI: 10.1371/journal.pone.0011102

208. Nilsson P, Loganathan K, Sekiguchi M, Matsuba Y, Hui K, Tsubuki S, et al.: Abeta Secretion and Plaque Formation Depend on Autophagy. Cell Rep 2013;5:61-69.

209. Xu J, Camfield R, Gorski SM: The interplay between exosomes and autophagy - partners in crime. J Cell Sci 2018;131:jcs215210.

210. Mo J-A, Lim J-H, Sul A-R, Lee M, Youn YC, Kim H-J: Cerebrospinal Fluid $\beta$-Amyloid1-42 Levels in the Differential Diagnosis of Alzheimer's Disease-Systematic Review and Meta-Analysis. PLoS One 2015;10:e0116802.

[24] Nath et al., Spreading of neurodegenerative pathology via neuron-to-neuron transmission of $\beta$ amyloid. p. 8770, J Neurosci (2012) was re-printed with credit to the original journal available at https://doi.org/10.1523/JNEUROSCI.0615-12.2012.

[173] Agholme et al., An In Vitro Model for Neuroscience: Differentiation of SH-SY5Y Cells into Cells with Morphological and Biochemical Characteristics of Mature Neurons, p. 1074, JAD (2010) was reprinted with permission from IOS Press. The publication is available at IOS Press through http://dx.doi.org/10.3233/JAD-2010-091363. 
"I only know one story.

But oftentimes small pieces seem to be stories themselves."

-The Name of the Wind

by Patrick Rothfuss 


\section{Papers}

The papers associated with this thesis have been removed for copyright reasons. For more details about these see:

http://urn.kb.se/resolve?urn=urn:nbn:se:liu:diva-160949 


\section{FACULTY OF MEDICINE AND HEALTH SCIENCES}

Linköping University Medical Dissertation No. 1703, 2019

Departement of Clinical and Experimental Medicine

Linköping University

SE-581 83 Linköping, Sweden

www.liu.se 